\title{
Recomendação para a Quantificação pelo Ultrassom da Doença Aterosclerótica das Artérias Carótidas e Vertebrais: Grupo de Trabalho do Departamento de Imagem Cardiovascular da Sociedade Brasileira de Cardiologia - DIC - SBC
}

\author{
Cláudia Maria Vilas Freire, Monica Luiza de Alcantara, Simone Nascimento dos Santos, Salomon Israel \\ do Amaral, Orlando Veloso, Carmen Lucia Lascasas Porto, Márcio Vinícius Lins Barros, Ana Cristina Lopes \\ Albricker, Ana Cláudia Gomes Pereira Petisco, Fanilda Souto Barros, José Aldo Ribeiro Teodoro, Armando Luiz \\ Cantisano, José Carlos Moreira, Arnaldo Rabischoffsky \\ Departamento de Imagem Cardiovascular da Sociedade Brasileira de Cardiologia (SBC/DIC)
}

Coordenadoras: Cláudia Maria Vilas Freire, Monica Luiza de Alcantara e Simone Nascimento dos Santos Coordenação DIC: Arnaldo Rabischoffsky e José Carlos Moreira

\section{Introdução}

A doença carotídea vem recebendo grande atenção por parte de diversas sociedades internacionais de radiologia, cirurgia vascular e cardiologia em razão do grande interesse no diagnóstico e tratamento da doença aterosclerótica.

O sistema carotídeo e vertebral extracraniano é facilmente avaliado pela ultrassonografia vascular tornando-a, assim, em várias instituições, o método de escolha para diagnóstico e decisão terapêutica. Diversas classificações com critérios variados para a quantificação das estenoses culminaram em algumas publicações sob a forma de consensos ou recomendações, a destacar o Consenso da Sociedade Norte-Americana de Radiologia datado de $2003^{1}$ e revisitado por AbuRahma em 2011², a recomendação do Reino Unido de $2009^{3}$ e, mais recentemente, a recomendação da Sociedade Espanhola de Neurologia de $2013^{4}$.

No Brasil, os médicos que realizam esse exame vêm utilizando esses consensos para quantificar as estenoses carotídeas. Ao longo dos últimos anos procurou-se validar as recomendações na prática diária. Algumas questões permanecem em aberto ou apresentam opiniões conflitantes, gerando dúvidas entre aqueles que realizam o método. Soma-se a isso a diferença cultural entre a comunidade médica brasileira e a de outros países. No nosso caso, há uma valorização da gradação das estenoses em intervalos percentuais menores para todos os graus de estenose, incluindo aqueles inferiores a 50\%. Não raro, exige-se a informação acerca da espessura mediointimal como marcador de risco para doença cardiovascular. Por fim, o crescente número de solicitações de estudo das artérias vertebrais torna a avaliação ainda mais complexa.

O objetivo do grupo de trabalho é estabelecer uma recomendação abrangente, que aborde os variados

\section{Palavras-chave}

Doenças das Artérias Carótidas; Aterosclerose; Estenose das Carótidas; Ultrassonografia de Intervenção. aspectos: anatômicos, técnicos e critérios diagnósticos para a quantificação da doença aterosclerótica das carótidas e vertebrais pela ultrassonografia vascular.

O grande desafio desta recomendação consistiu em selecionar e adequar parâmetros obtidos com a ultrassonografia aos dos demais métodos de imagem diagnóstica, gerando dessa forma resultados de fácil entendimento e correlacionáveis.

Para tal, optamos por uma abordagem multiparamétrica a partir de dados compilados da literatura mundial.

Isso nos possibilitou diminuir o intervalo de gradação das estenoses para decis, adaptando-o à realidade cultural brasileira.

\section{Equipamento e Recursos Diagnósticos}

Em razão da grande variedade de equipamentos disponíveis no mercado, bem como de seus mais variáveis recursos tecnológicos, faz-se necessário definir os itens básicos, imprescindíveis para realização de um exame completo (compreensível) das carótidas e artérias vertebrais, bem como os recursos tecnológicos que podem melhorar a acurácia diagnóstica e a representação final dos dados, mas que não são imprescindíveis para o diagnóstico correto.

Entende-se como exame completo aquele capaz de identificar e quantificar corretamente as estenoses das carótidas e artérias vertebrais dentro de níveis de sensibilidade, especificidade e acurária semelhantes à média encontrada na literatura mundial.

Quando todas as categorias de doença das carótidas são consideradas, a especificidade da ultrassonografia vascular (USV) é de $88 \%$, e a sensibilidade, de 99\%, para distinguir um ramo interno normal ou doente, quando comparada à arteriografia ${ }^{5}$. A acurácia para detectar uma redução de 50\% a $99 \%$ de diâmetro do ramo interno é de 93\%. A concordância com arteriografia para classificação de uma lesão maior que $50 \%$ de redução de diâmetro é excelente ${ }^{6}$. Experiência com USV em pacientes submetidos a endarterectomia demonstra que os resultados da arteriografia raramente alteram o plano de tratamento quando um USV tecnicamente adequado mostrou uma estenose de 80\%-99\% em pacientes assintomáticos,

DOI: $10.5935 / 2318-8219.20150018$ 
ou uma estenose de 50\%-99\% em pacientes com sintomas neurológicos hemisféricos ${ }^{7,8}$.

Para fins didáticos dividiremos este tópico nos seguintes itens (quadro 1):

Recursos indispensáveis (RI) para realização do USV de carótidas e vertebrais;

Recursos complementares (RC) que facilitam superar dificuldades encontradas no exame.

Recursos tecnológicos modernos e perspectivas futuras (RM).

\section{Transdutores:}

(RI): Exames de USV necessitam de equipamentos de ultrassom com transdutores lineares de alta resolução e frequência de 5 a $12 \mathrm{MHz}$.

Como a escolha da frequência do transdutor depende do balanço entre melhor resolução axial (obtida com altas frequências) e a taxa de atenuação do som (transdutores de alta frequência apresentam maior atenuação e, portanto, pior penetração), a escolha de frequência do transdutor dependerá da profundidade da artéria a ser examinada, devendo-se escolher a frequência mais alta capaz de atingir a profundidade desejada.

(RC): Transdutores adicionais facilitam a realização do exame em algumas situações adversas. Em pacientes com pescoços largos podemos utilizar transdutores de menor frequência.

Transdutores convexos e o recurso de imagem trapezoidal facilitam a visualização das estruturas quando há limitação do campo de visão, como bifurcação alta da carótida e para visualização da emergência das artérias vertebrais.

Transdutores microconvexos e setoriais, com menor área de contato, podem ser usados quando há limitação de espaço como pescoço curto ou pacientes pediátricos.

(RM): No último ano foram lançados para fins comerciais, mas ainda em processo de aprovação pela Anvisa no Brasil, transdutores lineares com imagem tridimensional.

A racionalidade para estudos tridimensionais da doença aterosclerótica de carótida advém de que a placa aterosclerótica é uma estrutura complexa e que se desenvolve de maneira assimétrica, tornando a avaliação completa de sua estrutura e, principalmente, do tipo de progressão da placa muito difícil de ser estudada pelo US bidimensional ${ }^{9}$. Dificuldade facilmente superada pelo estudo em 3D, já que múltiplos planos são avaliados em secções tomográficas.

Nos últimos anos, alguns trabalhos vêm sendo publicados na literatura sobre a medida do volume da placa pelo US tridimensional, sendo alguns desses sobre o impacto terapêutico na taxa de crescimento da placa ou mesmo sobre a carga aterosclerótica na avaliação do risco cardiovascular ${ }^{10}$.

\section{Recursos de imagem bidimensional e otimização}

Além dos ajustes básicos de ganho total, ganho setorial, mapa de cinza, croma, profundidade e outros, alguns ajustes merecem consideração especial para melhor adequação da imagem:
Número de foco e distância focal: recomenda-se utilização de um ou dois focos, que devem ser posicionados ao nível ou imediatamente abaixo da região de interesse.

Faixa dinâmica ("dinamic range") ou compressão: diz respeito à faixa variável de ecos processados e exibidos pelo sistema, do mais fraco ao mais intenso. Os ecos recebidos mais intensos são aquele "estrondo principal" e os da interface entre o transdutor e a pele, que serão sempre de intensidade similar. À medida que diminui a faixa dinâmica, os ecos mais fracos na faixa de espectro de cinza são perdidos (pode ser entendido como o limiar variável de representação dos sinais mais fracos).

Quando se necessita de avaliação das tênues variações da ecogenicidade do tecido mantemos a faixa dinâmica mais alta (em torno de $70 \mathrm{~dB}$ ) em detrimento do número de quadros por segundo, como se faz no exame de radiologia geral.

Nos exames cardiológicos e vasculares o que interessa é a interface sangue-intima ou sangue-endocárdio para avaliação de estruturas em movimento; portanto, usamos faixas dinâmicas mais baixas (em torno de $50 \mathrm{~dB}$ ).

Nos exames vasculares de carótidas usualmente os equipamentos já estão pré-ajustados (faixa dinâmica mais baixa), lembrando-se que essa deve ser aumentada para o estudo da morfologia da placa e nos estudos contrastados.

(RI) Imagem fundamental x (RC) imagem harmônica: quando uma onda sinusoidal é emitida pelo transdutor ela atravessa o tecido, sendo parte dessa onda refletida e parte refratada. Entretanto, devido às características do meio e à própria compressão do tecido causada pelo choque de onda do ultrassom, há mudança nas características do meio e distorção da onda que volta dos tecidos. Com a imagem harmônica o sinal que retorna do tecido inclui não só a frequência "fundamental" transmitida, mas também sinal de outras frequências, notadamente a "segunda harmônica", que é duas vezes a frequência fundamental. Uma vez que o sinal harmônico e o fundamental combinados são recebidos, o equipamento separa os dois componentes e processa o sinal harmônico isoladamente.

A produção de sinais harmônicos varia entre os tipos de tecidos e principalmente em razão da profundidade do objeto refletor. Como demonstrado na Figura 1, nos campos proximais não há distorção suficiente para produzir harmônica. À medida que a onda sonora se move para o campo médio a distorção das ondas começa a produzir harmônicas, tendo o seu efeito máximo no centro. A partir disso, o efeito da atenuação do sinal destrói as harmônicas à medida que elas são criadas. Nos campos distais a atenuação excede a geração de harmônicas, persistindo somente o sinal fundamental ${ }^{11}$

Como vantagens da utilização da imagem harmônica podemos citar: o sinal formado pelas harmônicas é mais estreito e apresenta menos artefactos de "side lobes" (lóbulos laterais), resultando em uma substancial melhora da resolução da imagem, principalmente quando se usam agentes de contraste ${ }^{12}$. 


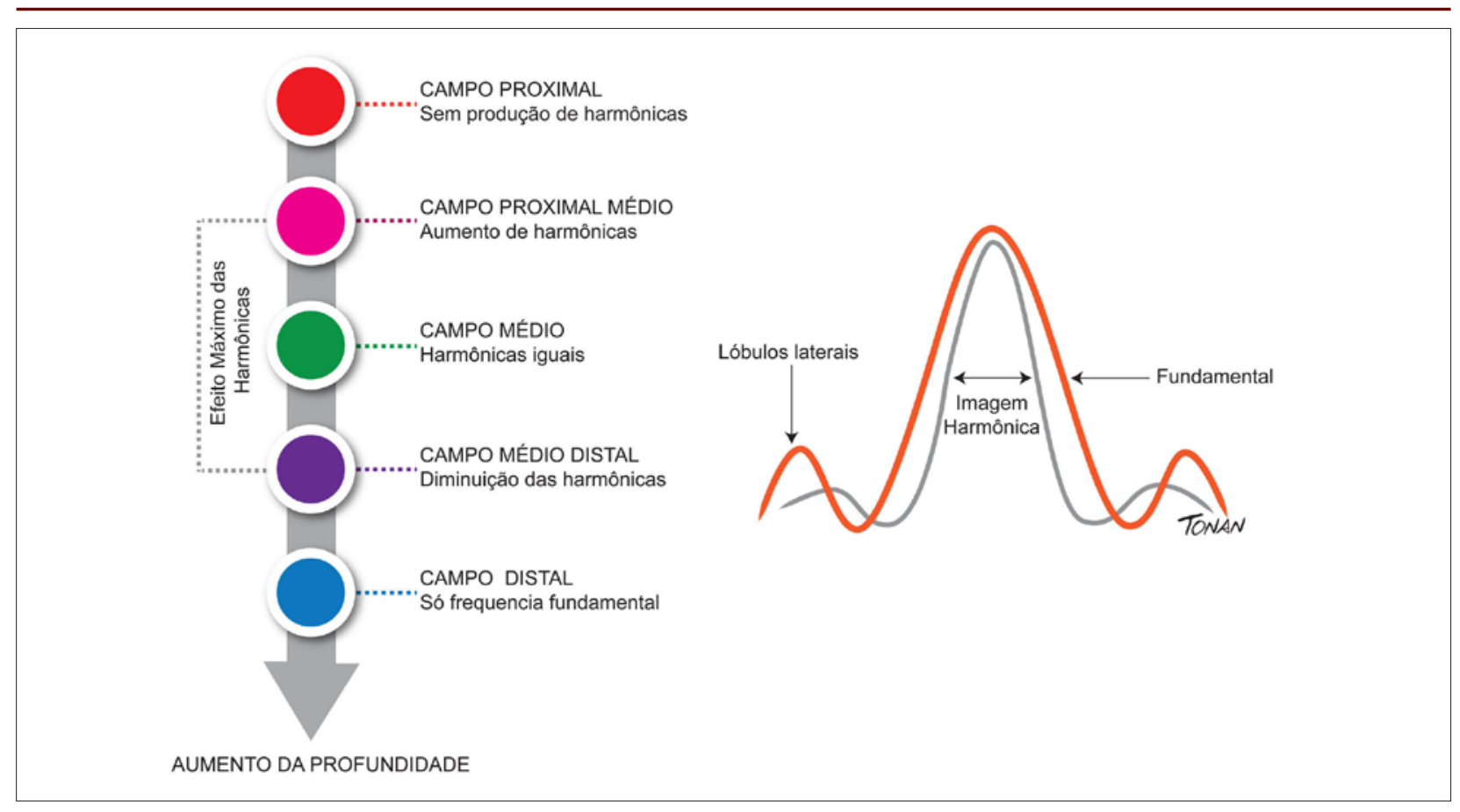

Figura 1 - Feixes harmônicos são mais estreitos que o convencional, assim como os lobos laterais são menores, resultando em ganho na resolução espacial.

Como no estudo de carótidas trabalhamos com estruturas normalmente superficiais, o uso de imagem harmônica pode ser dispensável; porém, torna-se fundamental para o estudo de estruturas mais profundas e para estudos com contraste de microbolhas.

É importante ressaltar que em muitos "presets" essa opção já está em uso e, conforme recomendação da American Society of Echocardiography, essa técnica deve ser desligada para a medida do complexo médiointimal (IMT), pois o uso de harmônica espessa o pixel.

(RC) Imagem composta ("compound image"): combina três ou mais imagens de diferentes ângulos de insonação em uma só imagem. Tradicionalmente, os transdutores emitem sinais de ultrassom em uma única "linha de visão", ou seja, perpendiculares ao transdutor e aguardam o eco de retorno. Com a imagem composta, o transdutor envia sinais em múltiplos planos e, ao recebê-los de volta, elimina os que não se repetem, diminuindo assim os artefatos.

Como vantagem da utilização da imagem composta tem-se um aumento da resolução da imagem por serem usadas múltiplas linhas de observação, eliminando-se artefatos, sombras e realçando as bordas das estruturas. Como desvantagens, essa técnica não é efetiva em imagens extremamente superficiais, não está presente nos transdutores setoriais e é menos efetiva à medida que as estruturas estejam localizadas em planos mais profundos. Lembramo-nos de que quanto mais planos são selecionados, maior a queda na taxa de quadros de imagem (Figura 2).

(RI) Imagem trapezoidal: recurso disponível na maioria dos equipamentos que aumenta o campo de visão por transformar os feixes lineares em trapezoidal, permitindo alcance de zonas menos acessíveis. Muito útil na avaliação da emergência da vertebral (Figura 3) e bifurcações carotídeas altas.

(RC) "Spackle Redution Imaging" (SRI, uScan, XRES, iClear, ApliPure etc): recurso que utiliza um algoritmo para identificar os sinais ultrassônicos mais intensos e os mais fracos. Avaliando a imagem pixel por pixel, eliminam-se as "manchas" dos sinais mais fracos que parecem extraviados (perdidos), enquanto os sinais mais fortes e constantes são reforçados, fornecendo uma imagem mais homogênea e limpa. Essa é uma tecnologia de pós-processamento e pode ser modificada após a imagem estar congelada. Facilita o reconhecimento das bordas para realização das medidas.

(RI) Densidade da linha: ajusta o número de linhas na varredura da imagem do ultrassom. Níveis mais altos fornecem melhor resolução da imagem, porém reduzem a taxa de quadros. Deve-se ajustá-la em níveis mais altos possíveis para taxas aceitáveis de velocidade de quadros.

\section{Orientação da imagem:}

A maioria dos guias para obtenção de imagens vasculares recomendam que nas imagens longitudinais as estruturas cefálicas sejam representadas à esquerda da tela, e nos cortes transversais, as estruturas laterais do lado direito, bem como as estruturas mediais do lado esquerdo sejam representadas à esquerda da tela do monitor ${ }^{13}$.

\section{(RI) Doppler espectral:}

A base para estratificação ultrassonogáfica da doença carotídea é a acurada mensuração das velocidades sanguíneas aliada à analise qualitativa da aparência da estenose, incluindo o lúmen residual quando bem visualizado ${ }^{3}$. O Doppler pulsado espectral é a forma 


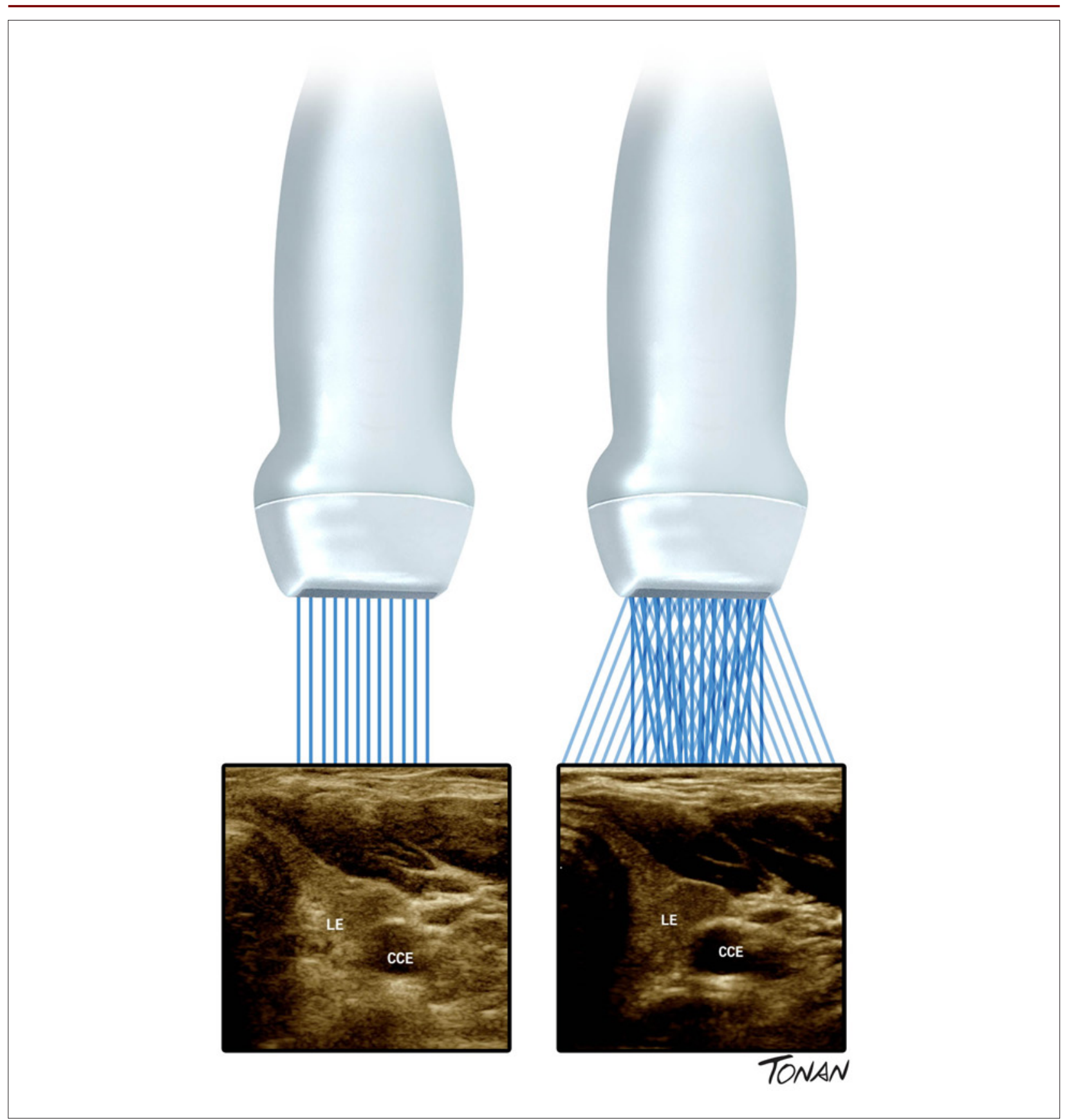

Figura 2 - A- Imagem fundamental; B-imagem composta.

disponível de quantificação de estenose através da medida de velocidade do fluxo em um determinado ponto do vaso. Para que seja feita da forma correta, é necessário estar ciente de alguns aspectos técnicos importantes:

Volume de amostra:

a) tamanho: para correta identificação do fluxo laminar no centro do vaso, sem contaminação das velocidades menores da periferia, com consequente borramento da janela espectral, o tamanho do volume de amostra não pode ser muito largo e nem muito pequeno, para que não se percam as maiores velocidades no local da estenose. Como o menor tamanho de amostra disponível nos equipamento de Doppler é de 1,0-1,5 mm, vasos de pequeno diâmetro invariavelmente demonstrarão borramento do espectro de velocidade de Doppler $^{14}$, o que deve ser considerado no estudo das artérias vertebrais.

b) posicionamento: o volume de amostra deve ser posicionado no centro do vaso. Posicionamento incorreto próximo à parede do vaso produzirá borramento do espectro devido à menor velocidade de movimento das células 


\section{Artigo Especial}

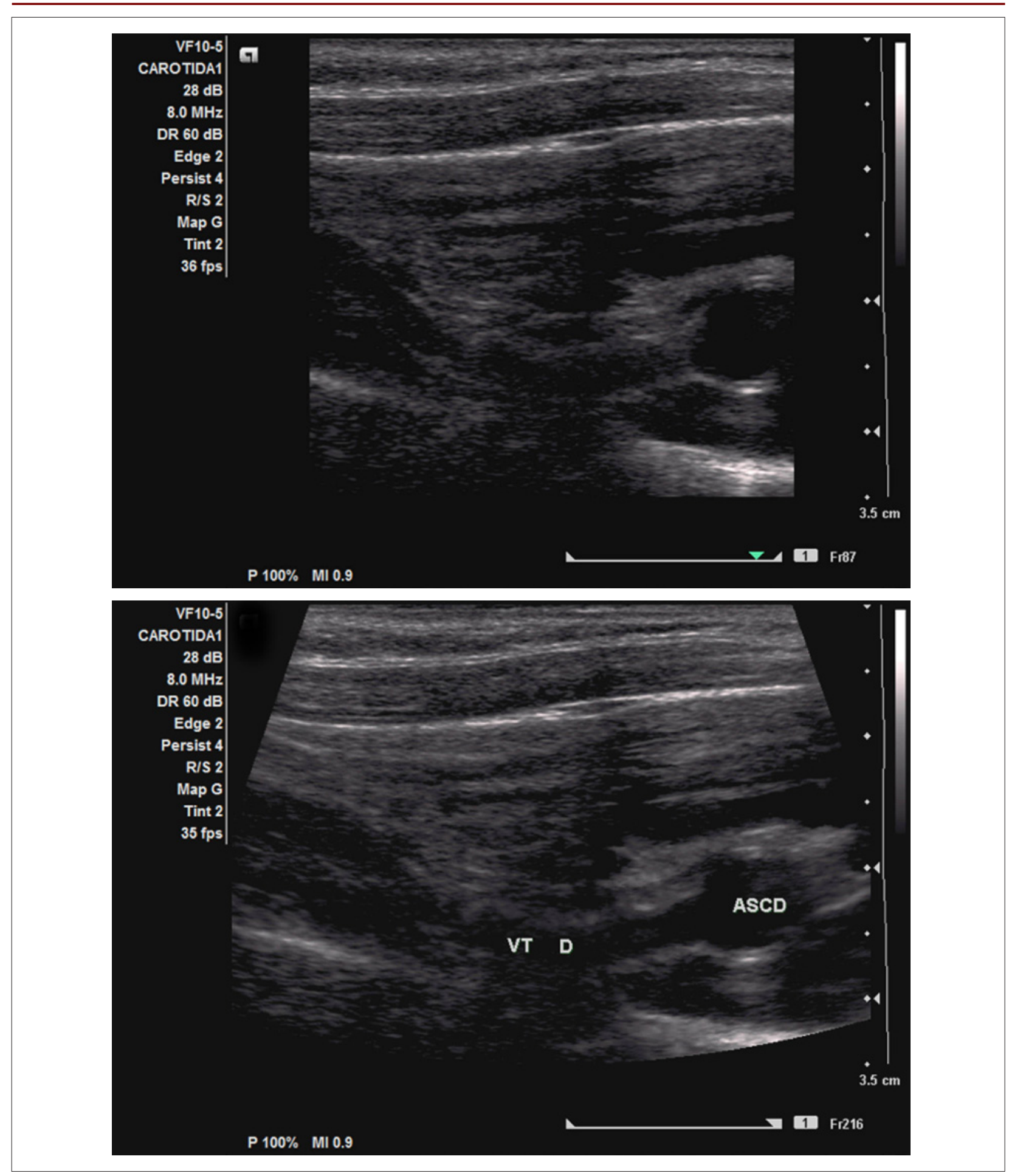

Figura 3 - A- Imagem retangular - difícil visualização da artéria subclávia e emergência da artéria vertebral. B-Imagem trapezoidal com ampla visibilização desses vasos.

vermelhas próximo à parede do vaso. As velocidades mais altas no centro do fluxo também podem ser perdidas ${ }^{11}$.

Também é importante considerar que, apesar de o color Doppler auxiliar na pesquisa do ponto de maior velocidade para o posicionamento do volume de amostra no ponto de maior estenose, uma meticulosa varredura com Doppler pulsátil deve sempre ser realizada em busca da detecção do local de maior velocidade (Figura 4). 
Todas as medidas de obtenção de velocidades de fluxo devem ser realizadas em cortes longitudinais do vaso e na maior extensão possível, com as paredes anterior e posterior bem visualizadas assegurando que a medida da velocidade seja realizada na linha central e o ângulo de Doppler possa prontamente ser estabelecido. Para obtenção das velocidades na carótida comum distal o volume de amostra deve ser posicionado cerca de $2 \mathrm{~cm}$ antes da bifurcação, no ponto em que as paredes do vaso ainda são paralelas e o diâmetro uniforme, antes que o vaso se dilate para a formação do bulbo ${ }^{14}$.

- Ganho do Doppler: uma significativa causa de erro na medida das velocidades é o ganho de Doppler exagerado ou o uso de pouco ganho. O ganho deve ser ajustado de modo que o pico da onda da curva de Doppler coincida com o ponto de maior brilho da curva (Figura 5).

Alterações na escala de cinza do Doppler, bem como ajuste incorreto de ganho e contraste do monitor podem provocar efeitos semelhantes ao ganho.

- Efeito da escala: diz respeito às faixas de velocidades que podem ser representadas no registro do Doppler espectral. Esse controle deve ser ajustado de modo que a velocidade máxima não seja amputada. Também é importante lembrar que o uso da escala muito alta, levando a um registro de ondas pequenas, pode levar a erros como má interpretação

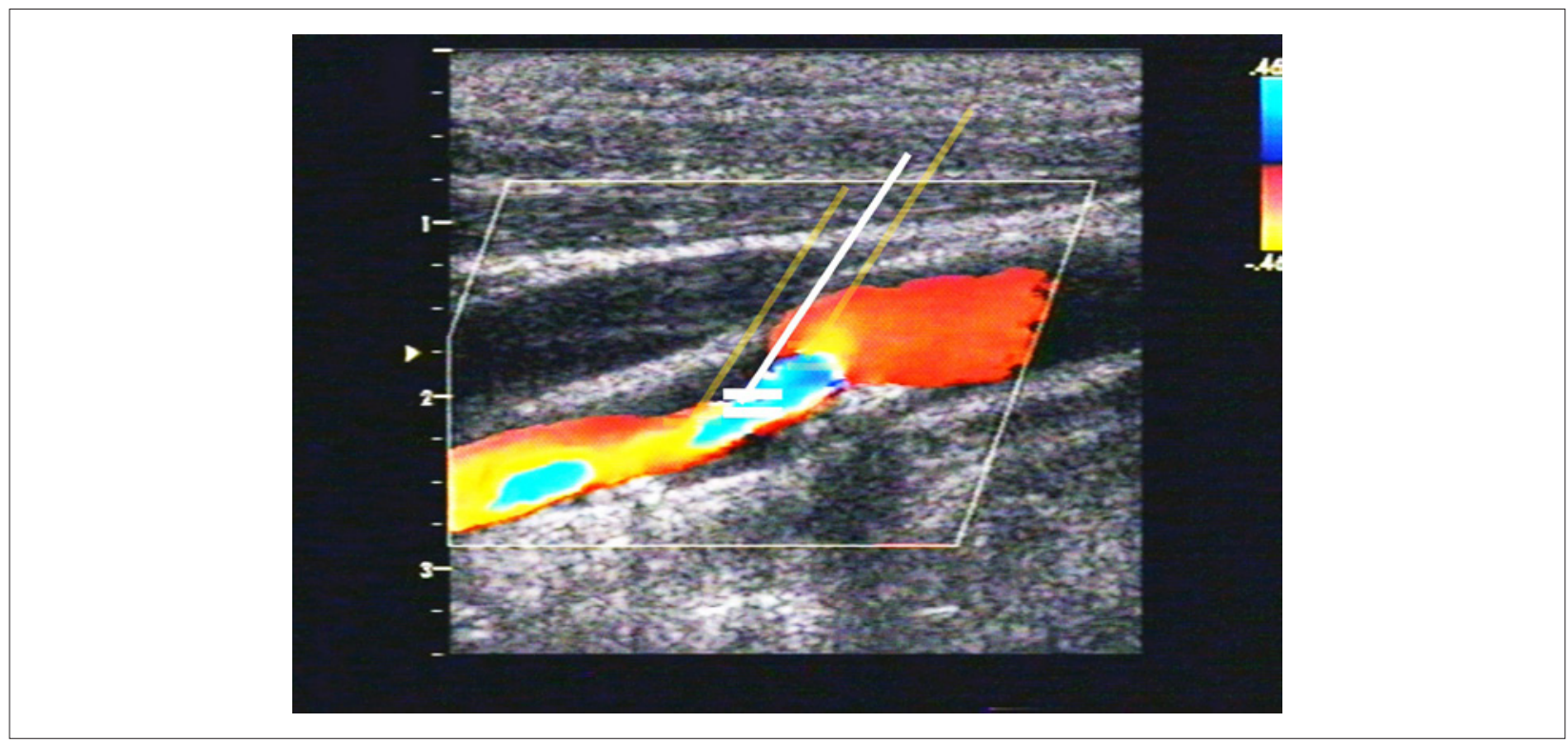

Figura 4 - Pontos de varredura que devem ser testados em busca da maior velocidade de fluxo.

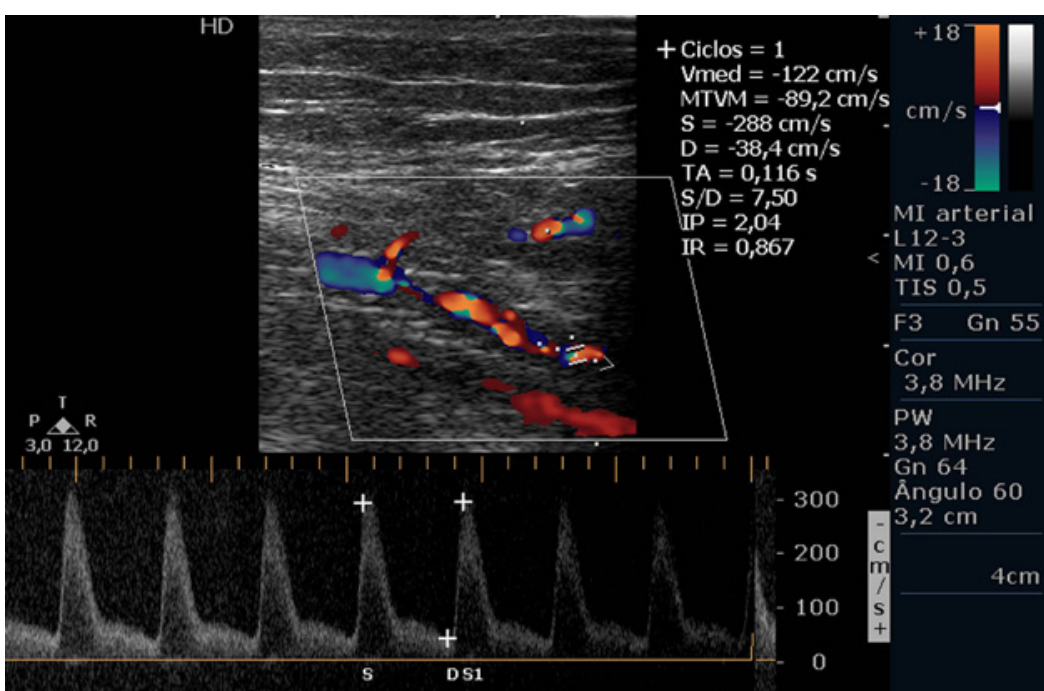

Figura 5 - Ilustração mostrando a importância do correto ajuste do ganho do Doppler de modo que o pico da onda coincida com o ponto de maior brilho (UK) 


\section{Artigo Especial}

do padrão de curva e na medida das velocidades de pico sistólico e da velocidade diastólica final (Figura 6).

- Filtro de parede:

As baixas frequências geradas pelo movimento das paredes dos vasos são facilmente detectadas pelos instrumentos de
Doppler e comumente interferem na demonstração clara do perfil do fluxo sanguíneo. O filtro é usado para eliminar os ruídos de baixa frequência (e para os exames de carótidas, e normalmente ajustado em 100 DB). O uso de filtro excessivo pode eliminar componentes da curva espectral levando a interpretação errônea do padrão da curva.
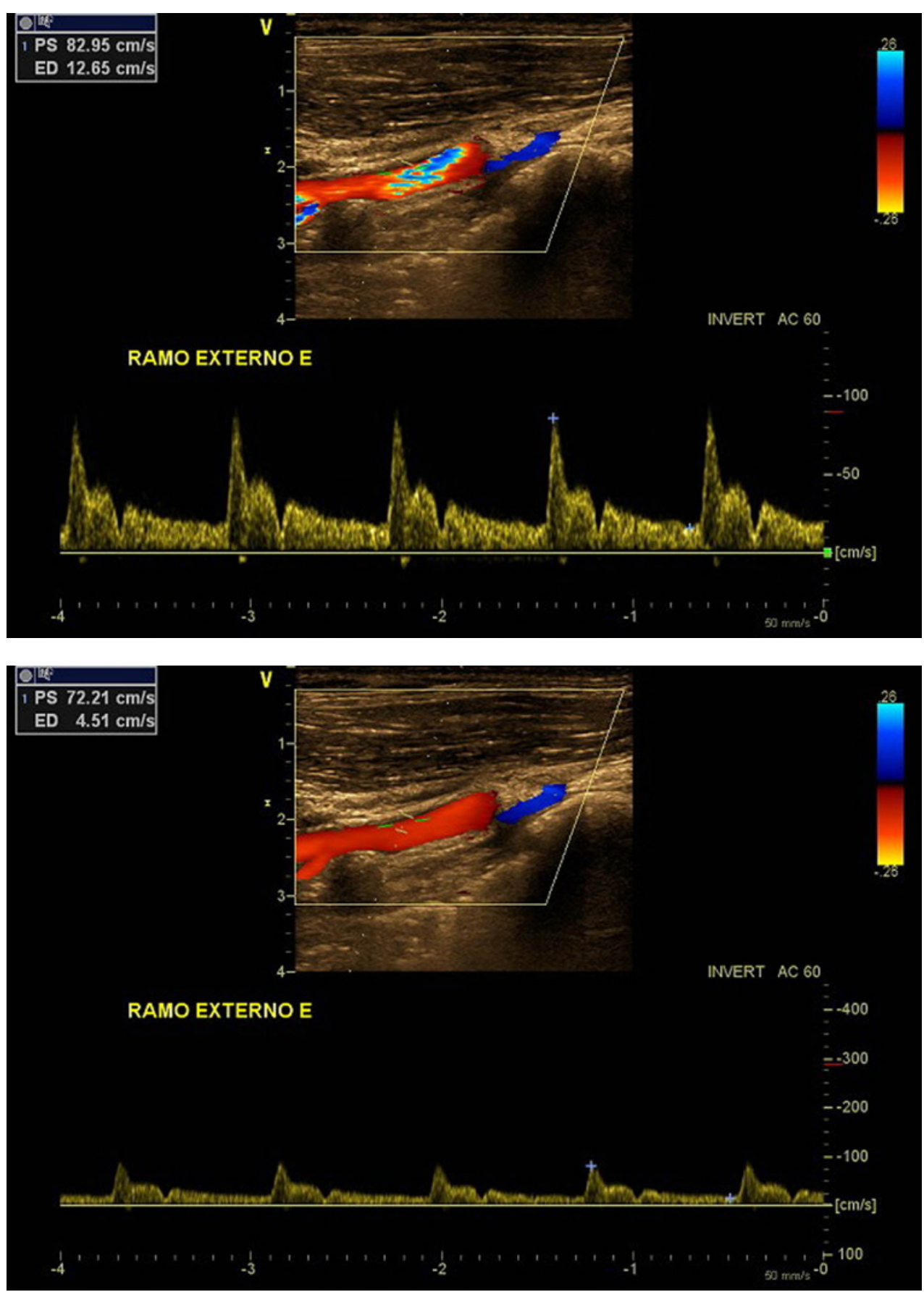

Figura 6 - A- Escala ocupando mais do que 50\% da área. Nota-se que com a menor escala (B), torna-se mais difíil a determinação precisa do pico de velocidade sistólica e da velocidade diastólica final. 
- Correção do ângulo:

O valor aferido das velocidades varia de acordo com a correção do ângulo de Doppler utilizada ${ }^{15}$. Em geral, menores ângulos tendem a dar velocidades mais baixas. Esse efeito em parte decorre da geometria do feixe de US, e em parte é devido à pior penetração dos pulsos de US em um vaso em ângulos rasos. Qualquer erro no ajuste da correção do ângulo de Doppler aumentará significativamente o erro quando grandes correções de ângulo forem usadas. Apesar de alguns advogarem que as medidas de velocidades sejam mais reprodutíveis se um ângulo fixo for usado, isso nem sempre é possível, seja pela angulação ("steering") do cursor de Doppler, seja por seu ajuste manual. O uso de ângulos entre 45 e 60 graus vai minimizar esse efeito e assegurar que qualquer erro na medida de velocidade devido ao alinhamento do ângulo de Doppler fique em menos de 10\%.

O grupo de trabalho não recomenda a utilização de ângulo fixo em 60 graus, devendo-se corrigir o ângulo de Doppler com eixo paralelo às paredes do vaso ou, em caso de jatos excêntricos, deve ser alinhado com o jato. Todos os esforços devem ser feitos para mantê-lo entre 45 e 60 graus. Nos casos de tortuosidades dos vasos o cursor deve ser alinhado à tangente da curvatura do vaso no ponto de medida (Figura 7).
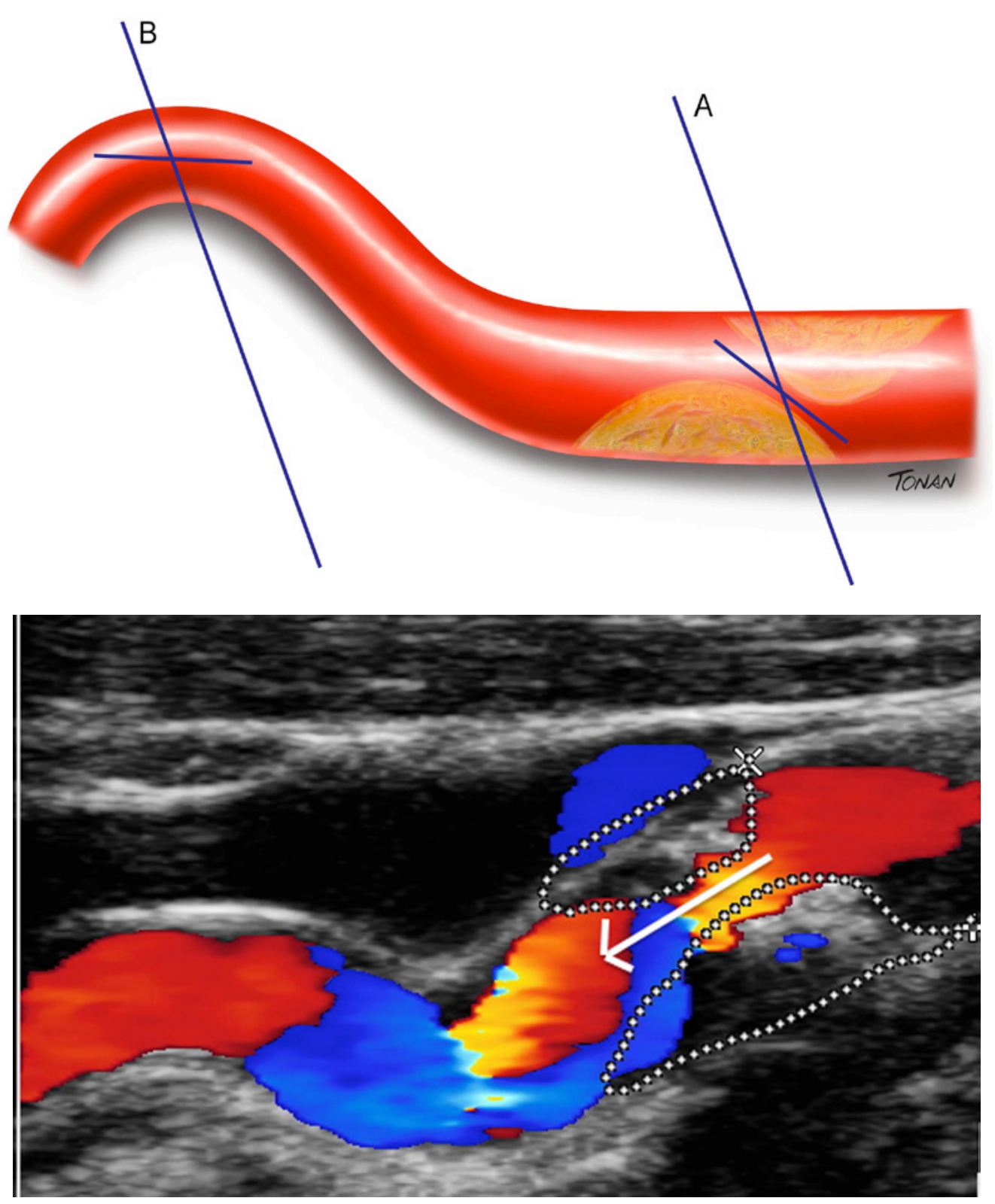

Figura 7 - A- Esquema ilustrando a colocação do cursor e o ângulo de insonação. B- Cursor e ângulo de insonação (seta). Paralelo ao vaso e em direção ao jato de fluxo no caso de estenose. 


\section{Artigo Especial}

\section{(RI) Doppler colorido:}

O estudo com Doppler colorido (DC) é parte fundamental e indispensável do exame. Apesar de não oferecer dados quantitativos, oferece dados qualitativos e ajuda a identificar as estenoses, bem como o melhor posicionamento do volume de amostra do Doppler para quantificação das velocidades.

O DC usa maiores volumes de amostra para detectarem as médias das diferenças de frequência de Doppler em uma área maior. O movimento das células vermelhas é codificado em cores de acordo com a velocidade e a direção do movimento e sobreposto à imagem bidimensional ${ }^{11}$.

A frequência de repetição de pulsos (PRF) determina o nível de saturação da cor e deve ser ajustada para demonstração de um fluxo laminar, ou seja, velocidades mais escuras na periferia do vaso e mais claras no centro do vaso, de modo que qualquer velocidade que ultrapasse o limite de Nyquist seja prontamente demonstrada pelo DC na forma de "aliasing" (Figura 8). É importante lembrar que o equipamento não é capaz de identificar os diferentes ângulos de Doppler para cada ponto de inclinação, de modo que regiões do vaso que estejam em ângulo mais próximo de zero grau serão demonstradas como tendo maiores velocidades. Apesar de ser uma informação "errônea", podemos tirar vantagem desse fato pelo pronto reconhecimento do local em que estaremos trabalhando com menor ângulo, que corresponde ao melhor local para posicionamento do cursor do Doppler espectral mesmo em um vaso sem estenoses.

As estenoses provocarão um jato de alta velocidade e uma súbita mudança no padrão da cor, ocorrendo o aparecimento de um mosaico de cores, identificado como "aliasing" no local do estreitamento luminal ${ }^{12}$. Na região pós-estenótica será demostrado o mosaico de cores, indicando a presença de fluxo turbulento. Quanto mais grave a estenose, maior a distância em que é detectada a turbulência do fluxo, característica essa que pode ajudar na quantificação das estenoses (principalmente em placas muito calcificadas, nas quais é impossível a quantificação local da estenose em razão da sombra acústica).

O DC também fornece informações adicionais nos casos de estenoses significativas como a persistência da cor, que é um sinal de cor contínuo, somente em direção anterógrada, em contraste com a alternância da cor na artéria normal. A persistência da cor corresponde à curva espectral monofásica das estenoses severas.

(RI) Doppler de amplitude, de potência ou de energia:

É uma técnica que representa a força total (amplitude) do sinal do Doppler de retorno. Como vantagens: sensibilidade para detecção de fluxos de baixa velocidade (de três a cinco vezes superior em relação ao DC); é menos ângulo-dependente; facilita o delineamento do lúmen residual ${ }^{16}$, sendo muito útil para análise da medidas dos critérios anatômicos, que serão discutidos posteriormente. Auxilia também na diferenciação entre oclusão e suboclusão, na detecção de vasos colaterais e na identificação da doença de pequenos vasos.

\section{(RC) "B-Flow":}

Uma técnica "não Doppler" de imagem do fluxo, que permite demonstração simultânea da imagem do fluxo e do tecido com uma melhor resolução espacial e uma melhor taxa de quadros, em relação às outras técnicas de Doppler, com consequente definição mais clara da interface lúmen-íntima, mesmo nas regiões estenóticas, com menos artefato de "sangramento" (blooming). Muito útil na detecção de pequenos "flaps" de dissecção e para avaliação de ulcerações nas placas ${ }^{16}$.

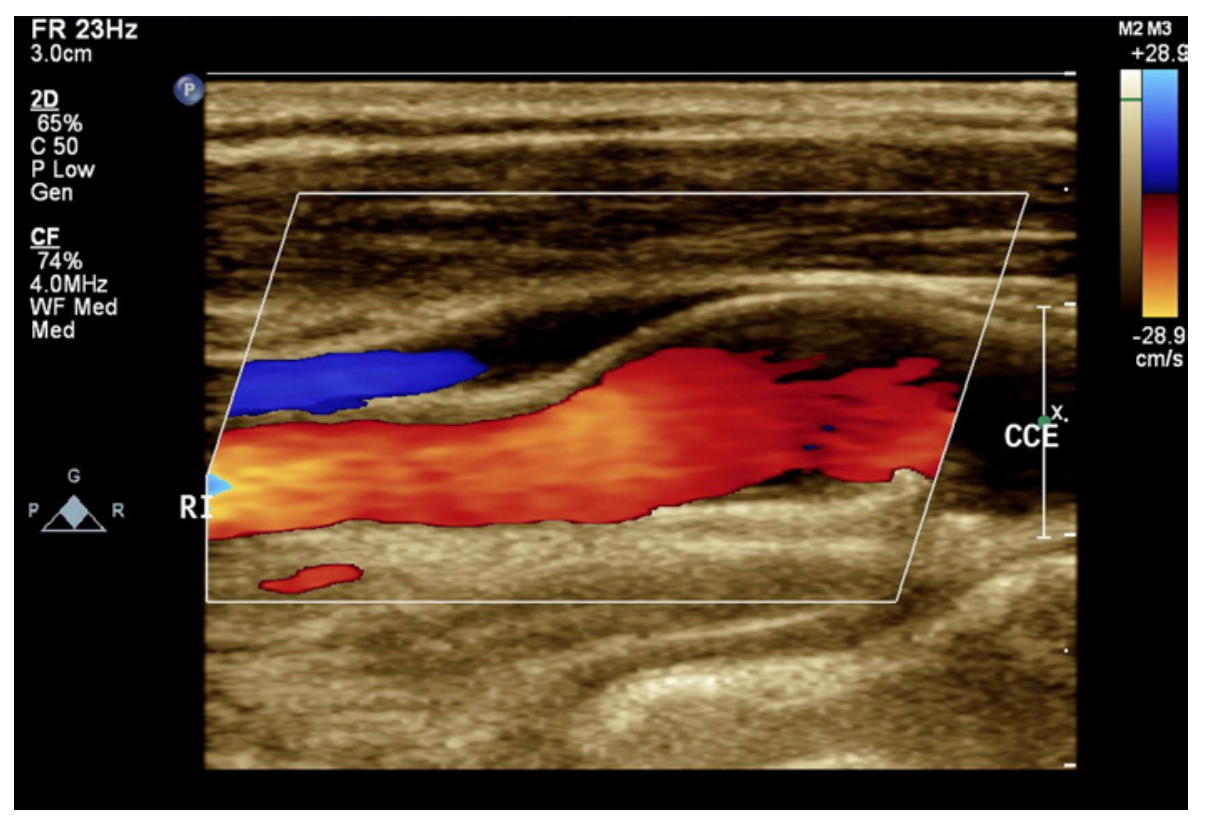

Figura 8 - "Aliasing" (seta) decorrente da melhor angulação do fluxo entre a região estudada e o transdutor, não indicando aumento focal da velocidade. 


\section{(RI) Software para cálculos e medidas vasculares:}

Softwares com pacotes vasculares são necessários em adição aos demais componentes dos equipamentos.

Cálculos de velocidade de pico sistólica, velocidade diastólica final, relação de velocidades dos fluxos, índices de resistência e pulsatilidade, tempo de aceleração do fluxo, integral da velocidade de fluxo e do volume de fluxo, bem como cálculos ao bidimensional (como medidas de distância, percentagem da luz residual em diâmetro e área) devem estar disponíveis em equipamentos de ultrassonografia vascular e foram considerados itens indispensáveis por esta comissão.

Pacote de medida automática da espessura médiointimal (EMI) foi considerado importante, mas não indispensável, tendo sido classificado como recurso complementar.

Pacotes para caracterização ultrassonográfica das placas por GSM e de colorização tecidual da placa (CATUS) foram considerados como perspectivas futuras.

Caliper: marca de posicionamento para as medidas de distância ou de velocidades, que é acionada ao selecionar as medidas do aparelho e deve ser posicionada corretamente, com o uso do "trackball". Alguns cuidados com o posicionamento do cursor foram considerados no consenso do Reino Unido, sedo referendado por esta comissão (Figura 9).

\section{(RM) Uso de contraste ultrassonográfico:}

Os contrastes ultrassonográficos ditos de terceira geração são compostos por microbolhas menores, com tamanho médio de 3 milimicras e pelo gás pefluobutano, tendo vantagem sobre os contrastes de primeira e segunda gerações, por serem mais estáveis, e permanecerem mais tempo na circulação, facilitando em muito o estudo da microcirculaçao ${ }^{17}$.

O CEUS ("contrast-enhanced ultrasound") já havia se mostrado de grande utilidade na avaliação dos vasos da macrocirculaçao, facilitando o diagnóstico nos casos de imagens subótimas, melhorando a capacidade diagnóstica em áreas obscurecidas por placas calcificadas, aumentando a capacidade de reconhecimento da interface lúmen-intima em todos os casos, assim como facilitando o registro das altas velocidades no local da estenose de carótidas.

Foi demonstrada também a grande utilidade na diferenciação entre suboclusão e oclusão do ramo interno da carótida, com sensibilidade de 100\%; especificidade de 90,5\% e acurácia de $97,4 \%$, quando comparada com a angiotomografia.

Seu uso no estudo da morfologia da placa vem crescendo, pois a neovascularização intraplaca, o que é considerado um marcador de vulnerabilidade, vem sendo empregada para identificar os pacientes com maior risco de eventos, mesmo sem estenose significativa ${ }^{18}$.

\section{Espessura Médiointimal das Artérias Carótidas}

\section{Introdução}

As doenças cardiovasculares (DCV) são a maior causa de morte nos países desenvolvidos e responsáveis por cerca de $30 \%$ da mortalidade total no mundo. Estima-se que cerca de 200 milhões de pessoas apresentem expressão clínica de doença arterial coronária (DAC), acidente vascular encefálico (AVE) ou outra doença vascular oclusiva ${ }^{19}$. A incidência de morte por DCV persiste em franca ascensão em populações de nações em desenvolvimento ${ }^{20}$. Entre esses países, até o ano 2040, o Brasil terá chegado ao maior índice de óbitos por DCV do mundo, superando países com maiores índices demográficos como a China e a Índia ${ }^{21}$.

O evento coronariano agudo é a primeira manifestação de DAC em cerca de metade dos indivíduos, sendo 50\% desses fatais. A alta mortalidade associada, à ausência de sintomas prévios, torna a identificação dos indivíduos em risco crucial para a prevenção efetiva das mortes por DCV.

Os escores de risco são utilizados na prática clínica numa tentativa de classificar os indivíduos em baixo, moderado e alto risco de evento cardiovascular. Um dos modelos mais utilizados nas últimas décadas é o Escore de Risco de Framingham (ERF), descrito por Wilson e cols. ${ }^{22}$, e que leva em consideração variáveis clínicas e laboratoriais de fácil acesso. Outros escores foram apresentados e utilizados em diferentes cenários e, mais recentemente, a Sociedade Brasileira de Cardiologia (SBC) recomendou, na última Diretriz de Prevenção da Aterosclerose, que fossem utilizados o Escore de Risco Global para avaliação do risco em dez anos, e o Escore de Risco pelo Tempo de vida para indivíduos $\geq 45$ anos com risco baixo ou intermediário em dez anos ${ }^{23}$.

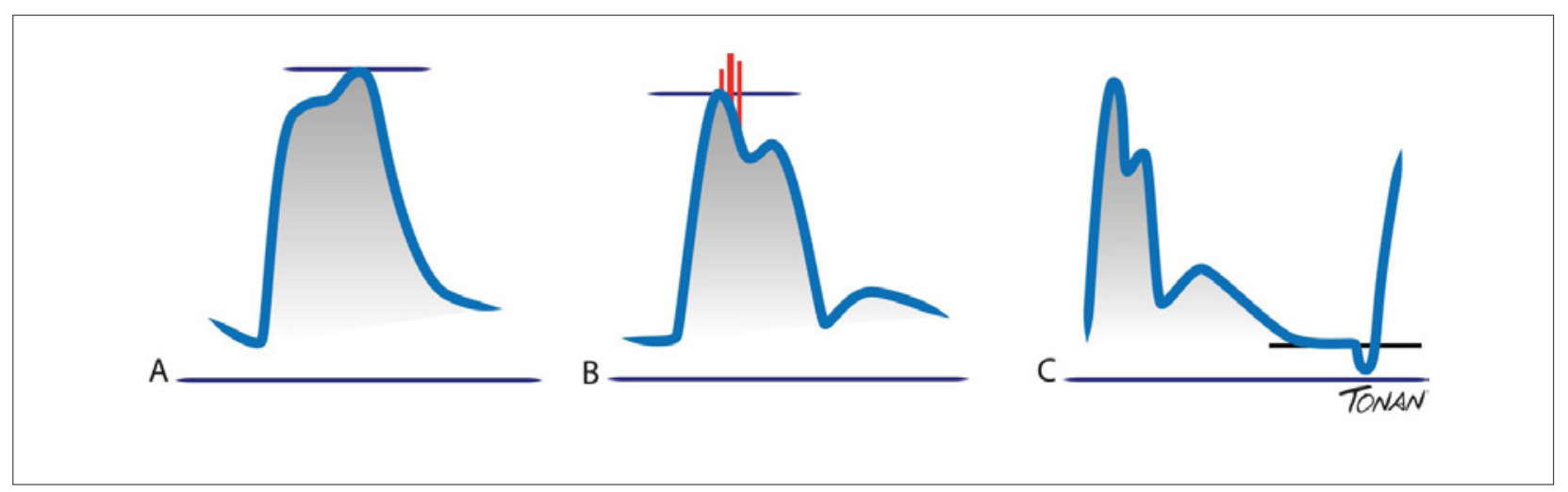

Figura 9 - Posicionamento correto do cursor de velocidade: A- Quando o pico sistólico é atrasado; B- Quando existem espículas devido a turbulência do fluxo; C- Quando a base da próxima aceleração sistólica está abaixo da velocidade diastólica. 


\section{Artigo Especial}

\section{Quadro1 - Resumo das recomendações de utilização dos recursos do equipamento}

\begin{tabular}{|c|c|c|c|c|}
\hline RECURSO & RECOMENDAÇÃO & PARAMETROS & VANTAGEM & SITUAÇÃO ESPECIAL \\
\hline Transdutor & $\mathrm{Rl}$ & $\begin{array}{c}\text { Multifrequencial } \\
\text { Linear de } 5-12 \mathrm{mgHz}\end{array}$ & Imagem de alta resolução & \\
\hline \multirow[t]{3}{*}{ Transdutores adicionais } & $\mathrm{RC}$ & Convexo de $2-5 \mathrm{mgHz}$ & $\begin{array}{l}\text { Maior penetração } \\
\text { Maior campo de visão }\end{array}$ & $\begin{array}{l}\text { Bifurcação alta } \\
\text { Pescoços largos }\end{array}$ \\
\hline & $\mathrm{RC}$ & Setorial 5-10 mgHZ & $\begin{array}{l}\text { Menor área de contato } \\
\text { ("footprint") }\end{array}$ & $\begin{array}{l}\text { Emergência das vertebrais } \\
\text { Carótida interna distal }\end{array}$ \\
\hline & $\mathrm{RC}$ & Microconvexo 3-8 mgHz & $\begin{array}{l}\text { Menor área de contato } \\
\text { ("footprint") } \\
\text { Maior campo de visão }\end{array}$ & $\begin{array}{c}\text { Bifurcação alta } \\
\text { Pescoços largos } \\
\text { Emergência das vertebrais } \\
\text { Carótida interna distal }\end{array}$ \\
\hline Imagem Trapezoidal & $\mathrm{RI}$ & & Maior campo de visão & $\begin{array}{l}\text { Bifurcação alta } \\
\text { Emergência das vertebrais } \\
\text { Carótida interna distal }\end{array}$ \\
\hline $\begin{array}{l}\text { Faixa Dinâmica "Dinamic } \\
\text { Range" }\end{array}$ & $\mathrm{RI}$ & Em torno de $50 \mathrm{~dB}$ & Mais contraste parede/lúmen & $\begin{array}{l}\text { Estudo da morfologia da placa } \\
\qquad \text { Em torno de } 70 \mathrm{~dB}\end{array}$ \\
\hline Imagem Harmonica & $\mathrm{RC}$ & & $\begin{array}{l}\text { Menos artefatos nos campos } \\
\text { médios }\end{array}$ & $\begin{array}{c}\text { Quando necessário avaliação } \\
\text { de vasos mais profundos. } \\
\text { Deve estar desligada para } \\
\text { medir a IMT }\end{array}$ \\
\hline Foco & $\mathrm{RI}$ & $\begin{array}{c}1 \text { a } 2 \text { focos ao nível e abaixo } \\
\text { do vaso }\end{array}$ & Melhora a resolução lateral & \\
\hline Imagem Composta "Sonuc CT" & $\mathrm{RC}$ & 2 a 5 & $\begin{array}{l}\text { Melhora Resolução } \\
\text { Diminui artefatos }\end{array}$ & \\
\hline $\begin{array}{l}\text { Spackle Redution Imaging } \\
\text { (SRI, uScan, XRES, IClear, } \\
\text { ApliPure) }\end{array}$ & RC & & $\begin{array}{l}\text { Diminui artefatos } \\
\text { Melhora Resolução }\end{array}$ & \\
\hline Densidade da Linha & $\mathrm{RI}$ & $\begin{array}{c}\text { Mais alto possível para taxa de } \\
\text { quadros aceitável }\end{array}$ & Melhora resolução lateral & \\
\hline $\begin{array}{l}\text { Volume de Amostra: } \\
\text { Tamanho }\end{array}$ & $\mathrm{RI}$ & 2/3 do diâmetro do vaso & Demonstração do fluxo laminar & \\
\hline $\begin{array}{l}\text { Volume de Amostra: } \\
\text { Posicionamento }\end{array}$ & & Local de Maior velocidade & & \\
\hline Correção de angulo & $\mathrm{RI}$ & $\begin{array}{l}45 \text { a } 60 \text { graus. } \\
\text { Paralelo a parede do vaso ou } \\
\text { ao fluxo }\end{array}$ & $\begin{array}{l}\text { Medida adequada das } \\
\text { velocidades }\end{array}$ & $\begin{array}{l}\text { Vasos tortuosos: Tangente da } \\
\text { curvatura do vaso }\end{array}$ \\
\hline Ganho do Doppler & $\mathrm{RI}$ & $\begin{array}{l}\text { Ponto de maior brilho, } \\
\text { coincidindo com a velocidade } \\
\text { de pico sistêmico }\end{array}$ & $\begin{array}{l}\text { Medida adequada das } \\
\text { velocidades }\end{array}$ & \\
\hline PW: Filtro de Parede & $\mathrm{RI}$ & $100-$ & $\begin{array}{l}\text { Mais alto: evita artefatos } \\
\text { Mais baico: envia perda de } \\
\text { informações do tipo de curva }\end{array}$ & \\
\hline Escala de velocidade & & $\begin{array}{l}\text { Ocupando mais que } 50 \% \text { da } \\
\text { área da tela }\end{array}$ & $\begin{array}{l}\text { Medida adequada das } \\
\text { velocidades }\end{array}$ & \\
\hline Doppler colorido & RI & $\begin{array}{c}\text { Ajustar RPF para } \\
\text { demonstração do fluxo } \\
\text { laminar: cores e mais escuras } \\
\text { na periferia }\end{array}$ & $\begin{array}{l}\text { Pronto reconhecimento de } \\
\text { aumento focal de velocidade }\end{array}$ & \\
\hline Doppler de amplitude & $\mathrm{RI}$ & & $\begin{array}{l}\text { Mais sensível a baixo fluxo } \\
\text { Menos ângulo dependente }\end{array}$ & $\begin{array}{l}\text { Determinação da luz residual } \\
\text { na medida anatômica da } \\
\text { estenose }\end{array}$ \\
\hline B-Flow & $\mathrm{RC}$ & & $\begin{array}{c}\text { Sensivel } \\
\text { Não depende de ângulo } \\
\text { Não tem "blooming" }\end{array}$ & $\begin{array}{c}\text { Determinação da luz residual } \\
\text { na medida anatômica da } \\
\text { estenose }\end{array}$ \\
\hline
\end{tabular}


Os escores para a estratificação do risco cardiovascular utilizados no Brasil não foram desenvolvidos na população brasileira, e além disso possuem limitações, principalmente na avaliação de jovens e mulheres ${ }^{24,25}$, na estimativa do risco a longo prazo $^{26}$, em indivíduos com diferentes níveis sociais ${ }^{27}$, e em pacientes com risco intermediário. Especificamente, na estratificação do risco intermediário, é onde versam as maiores limitações. Embora não existam estudos na população brasileira, nos Estados Unidos, 50\% dos homens com idade entre 50 e 59 anos, e $80 \%$ dos homens com idade entre 60 e 69 anos são considerados de médio risco pelo ERF; e 92\% das mulheres com menos de 70 anos são consideradas como de baixo risco ${ }^{28}$. Outro dado que reflete as limitações dos escores de risco se refere ao fato de que a maioria dos eventos cardiovasculares ocorre nos grupos de baixo e médio risco ${ }^{29}$.

Em acordo com os dados acima, a V Diretriz Brasileira de Dislipidemias e Prevenção da Aterosclerose recomenda a utilização de fatores agravantes do risco cardiovascular, nos indivíduos de risco intermediário, onde a presença de pelo menos um fator agravante reclassica o indivíduo para alto risco ${ }^{23}$. A medida da espessura mediointimal (EMI) das artérias carótidas e a presença de placa carotídea (PC), ambas detectadas pela ultrassonografia (US) vascular, são consideradas fatores agravantes.

Desde a publicação das últimas diretrizes brasileiras (2007-2013) 23,30, dos documentos de consenso de Mannheim 2004-2006 31 , e do consenso da Sociedade Americana de Ecocardiografia ${ }^{32}$, os especialistas brasileiros na área da USV estão se mobilizando para difundir essa prática. Esse documento tem como finalidade orientar a melhor utilização da USV, para a medida da espessura mediointimal e para a detecção de placas carotídeas.

\section{Definição ultrassonográfica da espessura mediointimal e da placa carotídea}

A EMI é caracterizada através da ultrassonografia pela presença, ao modo bidimensional, de uma dupla linha com definição das interfaces luz-íntima e média-adventícia. A distância entre as duas interfaces acústicas é considerada a medida da EMI (Figura 10). A placa carotídea ateromatosa (Figura 11) pode ser definida como uma estrutura focal estendendo-se no mínimo 0,5 mm para a luz do vaso, e/ou medindo mais do que $50 \%$ do valor da medida da EMI adjacente, e/ou ainda uma medida de EMI maior que 1,5 $\mathrm{mm}^{31}$. A Figura 12 exemplifica esquematicamente a medida da EMI e das três formas de definição da placa carotídea.

\section{Espessura médiointimal e eventos cardiovasculares}

Há mais de duas décadas estuda-se a associação entre o aumento da EMI e as doenças cardiovasculares. Os principais estudos longitudinais que associaram a medida da EMI com eventos cardiovasculares estão resumidos no Quadro $2^{33-39}$.

Sabe-se que os fatores de risco cardiovasculares tradicionais estão associados ao aumento da EMI, principalmente quando se considera a medida da EMI média na artéria carótida comum e a máxima na artéria carótida interna ${ }^{38,40,41}$.

O Estudo ELSA-Brasil analisou a medida da EMI da carótida comum, $1 \mathrm{~cm}$ abaixo da bifurcação, em 10.405 servidores públicos. Levaram-se em consideração a raça reportada pelo participante, o sexo, a idade, a presença de fatores de risco clássicos para doença aterosclerótica, bem como o uso de medicações relacionadas ao risco cardiovascular. As maiores medidas da EMI foram encontradas no sexo maculino e nos negros, tanto em análise univariada como multivariada. E esses resultados permaneceram significantes mesmo quando se considerou apenas o grupo de baixo risco para $\mathrm{DCV}^{42}$. O Estudo ELSA-Brasil está atualmente em andamento e, no futuro, são aguardados resultados em relação a capacidade da EMI predizer eventos cardiovasculares na população brasileira.

Para que um biomarcador de risco, mesmo que sabidamente associado a DCV, seja incluído na prática clínica para classificar o risco de um indivíduo, ele deve ser capaz de discriminar e reclassificar esse risco de maneira adicional aos

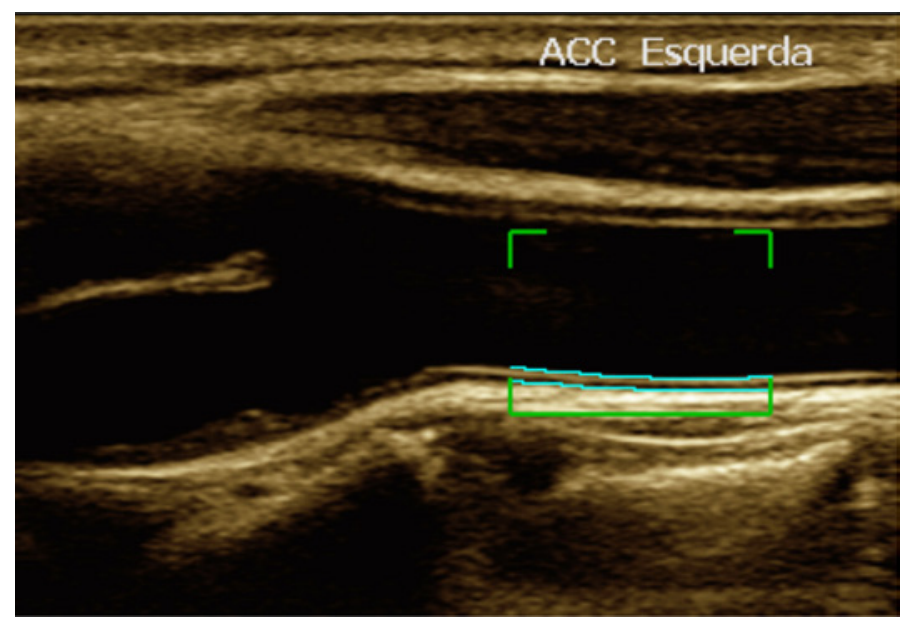

Figura 10 - Espessura médiointimal média da carótida comum. 


\section{Artigo Especial}

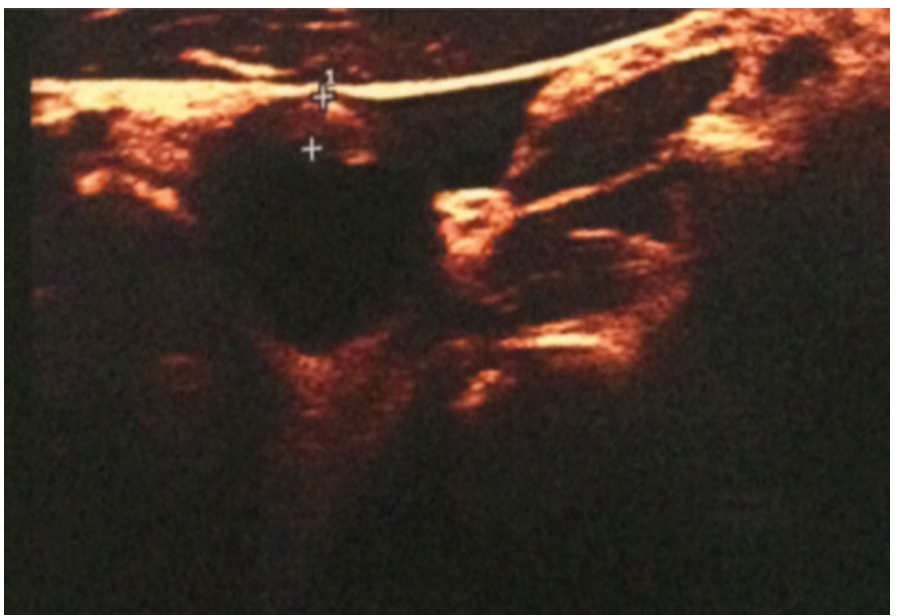

Figura 11 - Placa carotídea na parede anterior da bifurcação carotídea, medindo 2,5 mm.

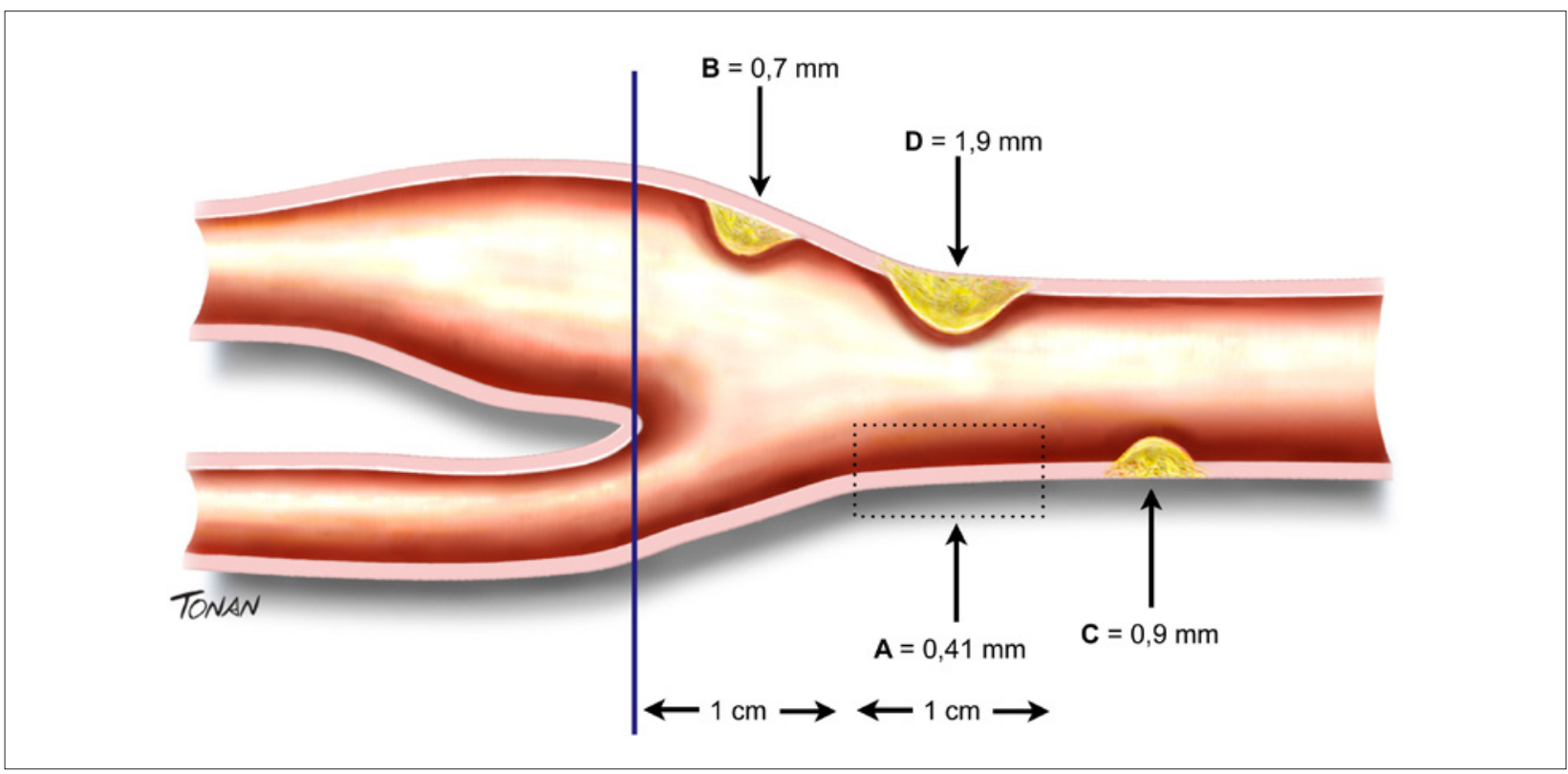

Figura 12 - Ilustração esquemática demonstrando exemplos de medida da EMI e de placas. Medida da EMI: (A). Medidas diferentes de três placas carotídeas; B. protusão $\geq 0,5 \mathrm{~mm}$ para a luz do vaso; $C$. medida $>50 \%$ do valor da medida da EMI adjacente; $D$. medida de $E M I>1,5 \mathrm{~mm}$.

fatores de risco tradicionais. Há opiniões oponentes sobre a utilização da medida da EMI na prática clínica. Nambi e cols. ${ }^{43}$ demonstraram em 13.145 participantes do estudo ARIC, seguidos por quinze anos, que o uso da medida da EMI, em conjunto com a presença de placa carotídea, teve impacto adicional aos fatores de risco tradicionais na predição do risco cardiovascular. Uma meta-análise recente, que incluiu estudos com populações e técnicas de medidas distintas, sem incluir a presença da placa carotídea, encontrou que a adição da EMI ao ERF foi associada a um modesto aumento na reclassificação, em indivíduos de risco intermediário, questionando a sua aplicabilidade clínica ${ }^{44}$. Assim, ao se analisar os estudos publicados e os seus resultados contraditórios, percebe-se que há diferentes metodologias empregadas na medida da EMI, como o local, a técnica, o equipamento e o tipo de medida considerada para a análise.

Talvez não só a variação na maneira de medir a EMI, mas também as variações relacionadas a idade, sexo, número de eventos, valores de corte para os grupos de risco e definições dos desfechos expliquem por que as evidências não são consistentes através dos estudos clínicos ${ }^{33,38,43,45,46}$. Diante dessa lacuna entre os estudos e a aplicabilidade clínica, as diretrizes mundiais nos colocam recomendações distintas. O consenso da Sociedade Americana de Ecocardiografia ${ }^{32}$ recomenda 
Quadro 2 - Principais estudos de associação da medida de espessura médiointimal com eventos cardiovasculares. (IAM = infarto agudo do miocárdio; $\mathrm{DCV}$ = doença cardiovascular; $\mathrm{AVE}$ = acidente vascular encefálico; $\mathrm{CRVM}$ = cirurgia de revascularização miocárdica; $M S$ = morte súbita)

\begin{tabular}{|c|c|c|c|c|}
\hline ESTUDOS & TAMANHO & SEGUIMENTO & DESFECHO & RAZÃO DE RISCO \\
\hline $\mathrm{KIHD}^{33}$ & 1257 & 1 mês a 2,5 anos & IAM & $\begin{array}{c}\text { Aumento } 0,1 \mathrm{~mm} \text { na EMI } 2.14 \\
(1.08-4.26)\end{array}$ \\
\hline $\mathrm{ARIC}^{34}$ & 12841 & 5 dias a 12 anos & IAM, morte por DCV & $\begin{array}{c}E M I \geq 1,0 \text { mm: F } 5.07 \text { (3.08- } \\
8.36) ; \text { M } 1.85 \text { (1.28-2.69) }\end{array}$ \\
\hline CAPS $^{35}$ & 5056 & 4,2 anos & IAM, AVE, morte & $\begin{array}{c}1,17 \text { (1.08-1.26) ACC; } 1.14 \\
(1.05-1.24) \text { bulbo; } 1.09 \text { (1.01- } \\
1.18) \mathrm{ACl}\end{array}$ \\
\hline Rotterdam Study ${ }^{36}$ & 6389 & $7-10$ anos & IAM & $1.95(1.19-3.19)$ \\
\hline $\mathrm{MESA}^{37}$ & 6814 & 7,6 anos & $\begin{array}{c}\text { IAM, CRVM, MS, morte por } \\
\text { DCV }\end{array}$ & $1.17(0.95-1.45)$ \\
\hline Framingham Offspring ${ }^{36}$ & 2965 & 7,2 anos & $\begin{array}{l}\text { IAM, angina, morte por DCV, } \\
\text { AVE, claudicação, IC }\end{array}$ & $\begin{array}{l}1.13(1.02-1.24) \text { média ACC; } \\
1.21(1.13-1.29) \text { máxima ACC; } \\
1.13(1.02-1,29) \text { máxima ACl; }\end{array}$ \\
\hline Tromso Study ${ }^{39}$ & 6229 & 6 anos & IAM & $\begin{array}{c}\text { Maior quartil } 1.73(0.98-3.06) \\
\mathrm{M} ; 2.86(1.07-7.65) \mathrm{F}\end{array}$ \\
\hline
\end{tabular}

a medida da EMI das carótidas para refinar a classificação de risco cardiovascular, em indivíduos assintomáticos, principalmente naqueles com risco intermediário. A última diretriz americana para avaliação do risco cardiovascular não recomenda a medida da EMI para avaliação do risco de primeiro evento cardiovascular ${ }^{47}$. Já nas últimas diretrizes brasileiras, o aumento da EMI acima de 1,0 mm é considerado um dos fatores agravantes que reclassificam os indivíduos em grupo de risco intermediário para alto risco ${ }^{23,48}$.

\section{Placa carotídea e eventos cardiovasculares}

A placa carotídea (PC) é uma manifestação da aterosclerose, e parece ser um preditor de risco cardiovascular mais forte do que a medida da EMI isoladamente. Uma recente metanálise que incluiu onze estudos populacionais, com mais de 54 mil pacientes demostrou que a PC, quando comparada a EMI, teve maior acurácia diagnóstica como preditor de IAM ${ }^{49}$. Após ajustes para os fatores de risco tradicionais, a presença de PC teve acurácia 35\% maior do que a EMI como preditor de eventos futuros.

De fato, no estudo de Touboul e cols. ${ }^{50}$, a presença de $\mathrm{PC}$ teve um valor adicional à medida da $\mathrm{EMI}$ isolada como preditora de risco de AVE. Essa coorte, com 510 pacientes com infarto cerebral diagnosticado pela ressonância magnética (RM), quando dividida em grupos de acordo com a presença ou ausência de PC, revelou que os pacientes com PC apresentaram um ERF em dez anos que gradualmente aumentou de $10 \%$ para $20 \%$, de acordo com os valores de EMI. A inclusão das duas variáveis (presença de placa e EMI) forneceu uma avaliação complementar ao ERF, do que quando comparada a essas variáveis isoladamente.

O Quadro 3 resume as principais publicações que estudaram a placa carotídea como indicador prognóstico de eventos cardiovasculares $33,36,38,39,43,51-55$. Esses estudos sugerem que a placa carotídea tem poder preditivo para a incidência de DCV.
As placas tendem a se formar na região da bifurcação carotídea e na porção proximal do ramo interno. Os estudos que incluiram a medida da EMI nessas regiões demostraram um potencial maior na predição de eventos cardiovasculares do que os estudos onde a metodologia utilizada foi a medida da EMI na parede posterior da carótida comum distal (EMI-CC), e daqueles que excluiram a placa da medida, se presente nessa região.

Polak e cols. ${ }^{38}$, em estudo com 2.965 membros do Framingham Offspring Study, com seguimento médio de 7,2 anos, demonstraram que a PC, definida como $\mathrm{EMI} \geq 1,5 \mathrm{~mm}$, teve associação independente com eventos cardiovasculares, aumentou significativamente a estatística C de 0.748 para 0.762 (aumento de $0.014 ; 95 \% \mathrm{Cl}$, 0.003-0.025; $p=0.02$ ), com índice de reclassificação de risco geral de 7,3\%. Em análises de subgrupos, o índice de reclassificação de risco foi de 9,2\% para mulheres e 9,1\% para indivíduos com idade $<60$ anos, confirmando a importância da utilização de variáveis de aterosclerose subclínica nesses grupos.

Em estudo ainda mais recente de Polak e cols. ${ }^{55}$, agora em 6,814 participantes da coorte Multi-Ethnic Study of Atherosclerosis (MESA), diferentes parâmetros métricos de PC foram preditores independentes de eventos cardiovasculares, aumentaram a estatística $\mathrm{C}$ e a reclassificação de risco.

A maioria dos estudos que avaliaram se a medida da EMI como marcador de imagem aos modelos de risco acrescentaria a predição do risco cardiovascular não utilizou a informação sobre ausência ou presença de PC. Apesar de os resultados de recentes meta-análises ${ }^{4,46,56}$ demonstrarem que o papel da EMI foi de pouca expressão na reclassificação de risco CV, sugerindo pouca importância clínica, os dados sobre PC não foram incluídos. Isso resultou em alguma confusão relacionada ao valor da ultrassonografia para avaliação da aterosclerose subclínica. Estudos mais recentes, que incorporam nas análises a PC, confirmaram a importância da avaliação 
Quadro 3 - Principais estudos de associação da presença de placa carotídea com eventos cardiovasculares. (IAM = infarto agudo do miocárdio; DCV = doença cardiovascular; $C R V M=$ cirurgia de revascularização miocárdica, AVE = acidente vascular encefálico)

\begin{tabular}{|c|c|c|c|c|}
\hline ESTUDOS & AMOSTRA & SEGUIMENTO MÉDIO & DESFECHO & RAZÃO DE RISCO \\
\hline Tromso Study ${ }^{39}$ & 6226 & 6 anos & IAM & $\begin{array}{c}\text { Maior tercil da área da placa: } \\
1.56(1.04-2.36) \mathrm{M} ; 3.95 \text { (2.16- } \\
\text { 7.19) F }\end{array}$ \\
\hline $\mathrm{KIHD}^{33}$ & 1288 & 2,5 anos & IAM & $\begin{array}{c}\text { Presença de placa; } 1.83 \\
(0,96-3,51)\end{array}$ \\
\hline Rotterdam Study ${ }^{36}$ & 6389 & $7-10$ anos & IAM & $\begin{array}{c}\text { Presença de placa: } 1.83 \\
(1.27-2.62)\end{array}$ \\
\hline $\mathrm{ARIC}^{34}$ & 13145 & 15,1 anos & IAM, morte por DCV, CRVM & $\begin{array}{c}\text { RR variável. Modelo com EMI } \\
\text { e PC aumentou AUC de } 0.742 \\
\text { para } 0.755\end{array}$ \\
\hline $\mathrm{MDCS}^{51}$ & 5163 & 7 anos & IAM, morte por DCV & $\begin{array}{c}\text { Presença de placa: } 1.81 \\
(1.14-2.87)\end{array}$ \\
\hline Cornout e col. ${ }^{52}$ & 2561 & 2-10 anos & Morte por DCV, IAM, angina & $\begin{array}{c}\text { Presença de placa: } 2.81 \\
(1.84-4.29)\end{array}$ \\
\hline Three-City ${ }^{53}$ & 5895 & 5.4 anos & $\begin{array}{c}\text { IAM, angina, morte por DCV, } \\
\text { CRVM }\end{array}$ & $\begin{array}{c}\text { Presença de placa: } 1.5 \\
\qquad(1.0-2.2) \\
\text { Placas em pelo menos dois } \\
\text { locais: } 2.2(1.6-3.1)\end{array}$ \\
\hline $\mathrm{CHS}^{54}$ & 5020 & 11 anos & $\begin{array}{l}\text { AVE, IAM, morte por DCV, } \\
\text { morte por todas as causas }\end{array}$ & $\begin{array}{c}\text { Placa de alto risco: } 1.38 \text { (1.14- } \\
\text { 1.67). Para mortalidade: } 1.23 \\
(1.04-1.44)\end{array}$ \\
\hline Framingham Off-spring ${ }^{38}$ & 2965 & 7,2 anos & $\begin{array}{l}\text { IAM, angina, morte por DCV, } \\
\text { AVE, claudicação IC }\end{array}$ & $\begin{array}{c}\text { Presença de placa: } 1.91 \\
(1.49-2.47)\end{array}$ \\
\hline MESA $^{55}$ & 6562 & 7,8 anos & $\begin{array}{l}\text { IAM, angina, morte por DCV, } \\
\text { CRVM, AVE }\end{array}$ & $\begin{array}{l}\text { Placa > 0\%: } 1.67 \text { (1.33-2.10). } \\
\text { Placa 25\%: } 1.67 \text { (1.30-2.13) }\end{array}$ \\
\hline
\end{tabular}

ultrassonográfica na predição do risco cardiovascular ${ }^{53,55,57}$, além de outros estudos que já tinham encontrado forte relação da presença da placa carotídea com prevalência de eventos cardiovasculares (Quadro 3).

A I Diretriz Brasileira de Prevenção Cardiovascular ${ }^{48} \mathrm{e}$ a V Diretriz Brasileira de Dislipidemias e Prevenção da Aterosclerose ${ }^{23}$ recomendam a presença de aterosclerose carotídea subclínica, detectada por metodologia de imagem, como critério de identificação de pacientes em alto risco de eventos coronariano. Além disso, consenso da Sociedade Americana de Ecocardiografia ${ }^{32}$ recomendam a utilização da placa carotídea como fator agravante do risco em pacientes de risco intermediário.

\section{Recomendações}

Diante dos poucos estudos realizados na população brasileira, e da fácil disponibilidade e baixo custo da US de artérias carótidas em nosso meio, recomenda-se a realização da medida da EMI em grupos específicos. Nesses grupos de indivíduos, a medida da EMI seria considerada aumentada se acima do percentil 75 para faixa etária, sexo e raça, de acordo com uma das tabelas normativas, auxiliando na discussão do tratamento clínico e modificação de estilo de vida. Recomenda-se que na presença de placa carotídea, independente do grau de obstrução, não é necessária a descrição da medida da EMI, com exceção para os exames solicitados especificamente para essa finalidade. Nesses casos a PC, se presente no local da medida da EMI, deve ser incluída na medida.

\section{Quando medir a espessura mediointimal}

1. Risco cardiovascular intermediário: utilizar a medida da EMI como fator agravante para a reclassificação em alto risco, alinhado com as orientações da $\checkmark$ Diretriz Brasileira de Dislipidemias e Prevenção da Aterosclerose $^{23}$ e da I Diretriz Brasileira de Prevenção Cardiovascular ${ }^{48}$.

2. Pacientes conhecidamente em maior risco de evento cardiovascular e de difícil classificação clínica:

- Pacientes com hipercolesterolemia familiar ${ }^{58}$.

- Portadores de doenças autoimunes ou uso de imunossupresores, corticoides e antirretrovirais, ou outros medicamentos que induzem a elevação do colesterol ${ }^{48}$.

- História de DCV precoce em parentes de primeiro grau $^{32}$.

- Indivíduos < 60 anos, com anormalidade severa em um fator de risco ${ }^{32}$.

- Mulheres < 60 anos, com no mínimo dois fatores de risco $^{32}$. 


\section{Técnicas de medidas}

A medida da EMI das artérias carótidas pode ser feita de forma automática/semiautomática ou manual, utilizando-se imagem ultrassonográfica ao modo bidimensional. As medidas podem ser realizadas "off line" ou "online". Mais recentemente, alguns equipamentos de US fornecem uma outra maneira de se medir a EMI em tempo real por sinal de radiofrequência (Figura 13); porém não existem estudos com tabelas normativas utilizando-se essa medida.

A caracterização ultrassonográfica da EMI deve ser realizada com o vaso sanguíneo em corte longitudinal, as paredes bem alinhadas, de maneira que se forme um padrão de dupla linha com definição das interfaces luz-íntima e média-adventícia. A distância entre as duas interfaces acústicas é considerada a medida da $\mathrm{EMI}^{31}$.

O protocolo recomendado para a medida da EMI é semelhante ao descrito do estudo ELSA-Brasil ${ }^{42}$, segundo o qual se realiza a medida da EMI de maneira automática na parede posterior das carótidas comuns à direita e à esquerda: no mínimo $1 \mathrm{~cm}$ proximalmente ao divisor de fluxo - referido como bifurcação. Recomenda-se imagem fundamental ao modo bidimensional, sem utilização do zoom, preferencialmente com frequências do transdutor maior que $7 \mathrm{MHz}$, sendo essa imagem analisada no eixo longitudinal, onde o segmento arterial é mais perpendicular ao feixe de ultrassom, com ajuste adequado do ganho e profundidade entre 3,0 e 4,0 cm. As imagens carotídeas devem ser obtidas nos acessos anterior, posterior ou no esternocleidomastoideo, perfazendo-se a imagem mais retilínea possível e com o padrão de dupla linha bem definido para ser selecionada e realizada a medida. A melhor imagem encontrada deve ser utilizada para a realização das medidas de EMI na prática clínica, visando a melhor adequação do tempo de exame.

Após aquisição dos dados numéricos da EMI, os valores médios serão comparados com valores de referência já existentes, de acordo com as tabelas normativas dos estudos ELSA-Brasil ${ }^{42}$, CAPS ${ }^{35}$ ou MESA ${ }^{59}$. A decisão sobre qual tabela utilizar dependerá do gênero, idade e etnia do indivíduo.

Muito embora a medida manual ponto a ponto seja menos reprodutível, levando-se em consideração a variabilidade dos equipamentos ultrassonográficos utilizados em nosso país, foi consenso que, nos equipamentos em que a medida automática da EMI não está disponível, a medida manual ponto a ponto pode ser realizada, respeitando-se estritamente as recomendações técnicas. Especial atenção deve ser dada aos pontos de colocação do cursor nas interfaces íntima-lúmen e média-adventícia, onde o examinador deve ser bastante cauteloso em não superestimar os valores. Nesse caso devem ser realizadas no mínimo cinco medidas de cada lado para se obter um valor médio (EMI média) ${ }^{60}$

\section{Interpretação dos resultados}

Conforme o estudo ELSA-Brasil ${ }^{42}$, as seguintes medidas da EMI podem ser realizadas:

1. EMI média (média das medidas na CCD ou CCE): A maioria dos equipamentos fornece essa medida de forma automática ou semiautomática (neste último caso, o examinador pode fazer pequenos ajustes em cima da medida automática). Uma vez obtidos os dois valores médios da EMI de cada lado, deve-se compará-los com a tabela, para a obtenção do percentil equivalente. O maior percentil deve ser considerado o percentil no qual se encontra o indivíduo estudado.

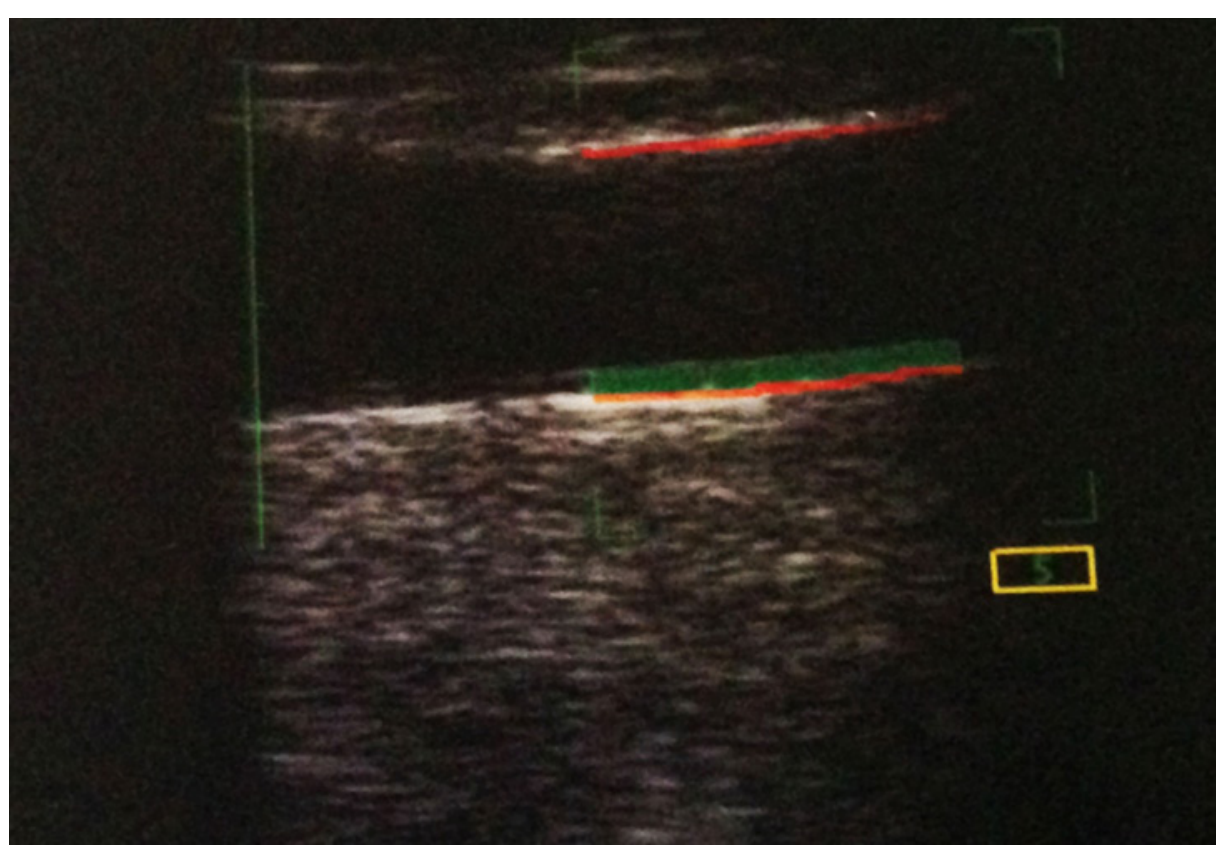

Figura 13 - Medida da EMI pela técnica de radiofrequência. 


\section{Artigo Especial}

2. EMI máxima (máxima medida na CCD ou CCE): Alguns equipamentos fornecem, além da EMI média descrita acima, o valor máximo da EMI, de cada lado. Numa tentativa de unificar as medidas e homogeneizar os laudos de diferentes laboratórios, recomenda-se a não utilização da EMI máxima, e apenas a EMI média.

3. EMI média ou máxima composta (média comum das medidas entre os lados direito e esquerdo): Embora exista essa possibilidade de medida, sendo também disponível a comparação com a tabela do estudo ELSA-Brasil ${ }^{42}$, recomenda-se a não utilização da medida composta. Como o intuito dessa recomendação é ajudar a identificar a aterosclerose subclínica da melhor forma possível, a maior medida encontrada entre as medidas seria a maior expressão em si da saúde vascular de determinado indivíduo.

Para a determinação do percentil da medida da EMI, devem-se consultar as seguintes tabelas de acordo com a faixa etária do indivíduo estudado:

1. Tabela ELSA-Brasil ${ }^{42}$ (Tabela 1): utilizada para indivíduos de ambos os sexos, na faixa etária entre 40 e 65 anos, de etnia branca, mulata ou negra.

2. Tabela CAPS $^{35}$ (Tabela 2): utilizada para indivíduos de ambos os sexos, na faixa etária entre 25 e 45 anos. Não existe classificação por etnia.

Tabela 1 - Tabela adaptada do Estudo ELSA-Brasi ${ }^{42}$

\begin{tabular}{|c|c|c|c|c|c|c|c|c|c|c|c|c|c|c|c|}
\hline \multirow[b]{2}{*}{ ETNAA } & \multicolumn{7}{|c|}{ EMI media CCE $(\mathrm{mm})$} & \multicolumn{8}{|c|}{ EMI media CCD $(\mathrm{mm})$} \\
\hline & PERCENTIL & $40 a$ & $45 \mathrm{a}$ & 50a & 55a & $60 \mathrm{a}$ & $65 a$ & ETNIA & PERCENTIL & 40a & $45 a$ & $50 a$ & $55 a$ & 60a & $65 a$ \\
\hline \multirow{4}{*}{$\begin{array}{l}\frac{8}{0} \\
\frac{2}{5} \\
\frac{1}{0}\end{array}$} & P25 & 0.47 & 0.49 & 0.52 & 0.54 & 0.57 & 0.60 & \multirow{4}{*}{$\frac{8}{\frac{8}{5}}$} & $P 25$ & 0.45 & 0.48 & 0.51 & 0.53 & 0.56 & 0.59 \\
\hline & P50 & 0.53 & 0.57 & 0.60 & 0.64 & 0.67 & 0.71 & & P50 & 0.51 & 0.54 & 0.58 & 0.61 & 0.65 & 0.69 \\
\hline & P75 & 0.60 & 0.65 & 0.69 & 0.73 & 0.77 & 0.81 & & P75 & 0.59 & 0.63 & 0.67 & 0.71 & 0.75 & 0.79 \\
\hline & P 90 & 0.70 & 0.75 & 0.80 & 0.85 & 0.90 & 0.95 & & P90 & 0.66 & 0.71 & 0.76 & 0.81 & 0.85 & 0.90 \\
\hline \multirow{4}{*}{$\frac{\circ}{\frac{8}{5}}$} & P25 & 0.48 & 0.50 & 0.53 & 0.56 & 0.58 & 0.61 & \multirow{4}{*}{$\frac{\mathrm{g}}{\mathrm{s}}$} & P25 & 0.44 & 0.47 & 0.50 & 0.53 & 0.56 & 0.60 \\
\hline & P50 & 0.53 & 0.57 & 0.61 & 0.65 & 0.69 & 0.73 & & P 50 & 0.50 & 0.54 & 0.58 & 0.62 & 0.66 & 0.69 \\
\hline & P 75 & 0.60 & 0.65 & 0.70 & 0.75 & 0.80 & 0.85 & & P 75 & 0.58 & 0.63 & 0.68 & 0.73 & 0.77 & 0.82 \\
\hline & P 90 & 0.69 & 0.75 & 0.80 & 0.86 & 0.92 & 0.97 & & P90 & 0.69 & 0.74 & 0.79 & 0.84 & 0.89 & 0.94 \\
\hline \multirow{4}{*}{$\begin{array}{l}\frac{8}{5} \\
\frac{\mathrm{m}}{2}\end{array}$} & P25 & 0.49 & 0.52 & 0.55 & 0.58 & 0.62 & 0.65 & \multirow{4}{*}{ 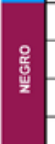 } & P25 & 0.46 & 0.50 & 0.53 & 0.57 & 0.60 & 0.64 \\
\hline & P50 & 0.56 & 0.59 & 0.63 & 0.67 & 0.71 & 0.75 & & P50 & 0.54 & 0.58 & 0.62 & 0.66 & 0.70 & 0.74 \\
\hline & P 75 & 0.64 & 0.68 & 0.72 & 0.77 & 0.81 & 0.86 & & P75 & 0.61 & 0.67 & 0.73 & 0.78 & 0.84 & 0.90 \\
\hline & P 90 & 0.71 & 0.78 & 0.84 & 0.91 & 0.97 & 1.03 & & P90 & 0.70 & 0.77 & 0.83 & 0.89 & 0.95 & 1.02 \\
\hline ETNA & PERCENTIL & $40 \mathrm{a}$ & $45 a$ & $50 a$ & $55 a$ & $60 \mathrm{a}$ & $65 a$ & ETNIA & PERCENTIL & $40 \mathrm{a}$ & 45a & $50 \mathrm{a}$ & $55 a$ & 60a & $65 a$ \\
\hline \multirow{4}{*}{$\begin{array}{l}\frac{8}{0} \\
\frac{\delta}{5} \\
\frac{\alpha}{\alpha}\end{array}$} & P25 & 0.44 & 0.47 & 0.50 & 0.53 & 0.56 & 0.59 & \multirow{4}{*}{$\frac{\mathrm{c}}{\mathrm{c}}$} & $P 25$ & 0.44 & 0.47 & 0.50 & 0.53 & 0.55 & 0.58 \\
\hline & P50 & 0.49 & 0.52 & 0.56 & 0.59 & 0.63 & 0.66 & & P50 & 0.48 & 0.52 & 0.56 & 0.59 & 0.63 & 0.66 \\
\hline & P 75 & 0.54 & 0.58 & 0.63 & 0.67 & 0.71 & 0.75 & & P75 & 0.53 & 0.58 & 0.62 & 0.66 & 0.70 & 0.75 \\
\hline & $P 90$ & 0.61 & 0.66 & 0.71 & 0.76 & 0.81 & 0.86 & & P 90 & 0.59 & 0.64 & 0.69 & 0.74 & 0.79 & 0.84 \\
\hline \multirow{4}{*}{$\begin{array}{l}\text { 号 } \\
\frac{3}{3}\end{array}$} & P 25 & 0.45 & 0.48 & 0.51 & 0.54 & 0.57 & 0.60 & \multirow{4}{*}{ 旁 } & P 25 & 0.44 & 0.47 & 0.50 & 0.53 & 0.56 & 0.59 \\
\hline & P50 & 0.50 & 0.53 & 0.57 & 0.60 & 0.64 & 0.67 & & P 50 & 0.49 & 0.52 & 0.56 & 0.60 & 0.64 & 0.68 \\
\hline & P75 & 0.56 & 0.60 & 0.64 & 0.68 & 0.72 & 0.77 & & P75 & 0.55 & 0.59 & 0.63 & 0.68 & 0.72 & 0.76 \\
\hline & P90 & 0.63 & 0.68 & 0.73 & 0.78 & 0.83 & 0.88 & & P 90 & 0.62 & 0.67 & 0.72 & 0.77 & 0.82 & 0.87 \\
\hline \multirow{4}{*}{$\begin{array}{l}\frac{\mathbb{E}}{\underline{\underline{W}}} \\
\frac{1}{2}\end{array}$} & P 25 & 0.46 & 0.49 & 0.52 & 0.55 & 0.58 & 0.61 & \multirow{4}{*}{$\begin{array}{l}\frac{8}{5} \\
\frac{1}{2}\end{array}$} & P 25 & 0.46 & 0.49 & 0.53 & 0.56 & 0.59 & 0.63 \\
\hline & P50 & 0.51 & 0.55 & 0.59 & 0.63 & 0.67 & 0.70 & & P50 & 0.51 & 0.55 & 0.59 & 0.63 & 0.67 & 0.71 \\
\hline & P 75 & 0.57 & 0.62 & 0.66 & 0.70 & 0.75 & 0.79 & & P75 & 0.58 & 0.62 & 0.67 & 0.71 & 0.76 & 0.80 \\
\hline & $\begin{array}{l}P 90 \\
0\end{array}$ & 0.64 & 0.70 & 0.76 & 0.82 & 0.88 & 0.94 & & P 90 & 0.64 & 0.71 & 0.77 & 0.83 & 0.90 & 0.96 \\
\hline
\end{tabular}

Tabela 2 - Tabela adaptada do Estudo CAPS ${ }^{35}$

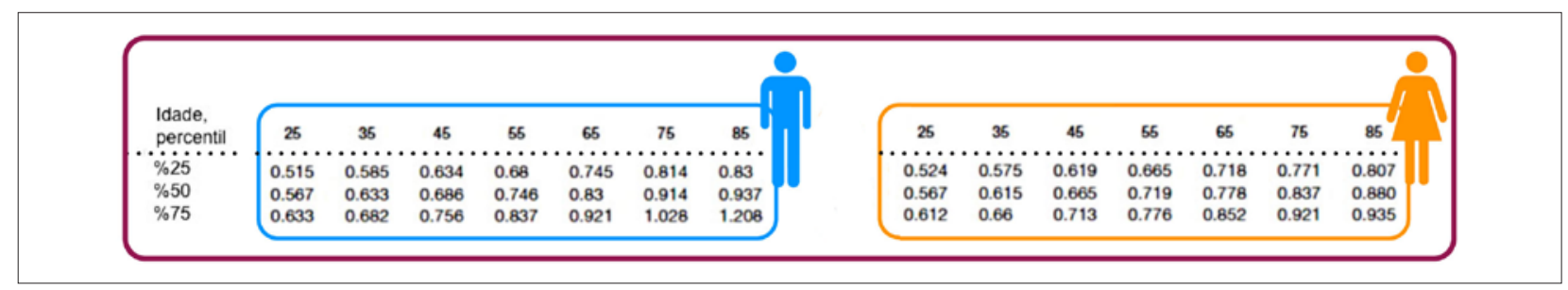


3. Tabela MESA ${ }^{59}$ (Tabela 3): utilizada para indivíduos de ambos os sexos, na faixa etária entre 65 e 84 anos, de etnia branca, negra, chinesa ou hispânica.

\section{Como descrever no laudo}

Recomenda-se a descrição da medida da EMI média de cada lado, em mm, no corpo do laudo. Além disso, deve-se acrescentar na conclusão se a medida encontra-se acima ou abaixo do percentil 75, e a tabela utilizada com sua referência bibliográfica.

\section{Perspectivas futuras}

A medida da EMI na população jovem poderá fornecer dados precoces de DCV. No entanto, ainda há lacunas no conhecimento atual. Novos estudos precisam responder questões relacionadas aos valores da EMI nas várias fases de desenvolvimento físico da criança e do adolescente; se o aumento da EMI traduz doença em outros sítios arteriais; qual o local da medida da EMI nas carótidas informa melhor o aumento do risco cardiovascular. Nos mais jovens, há uma tendência em se utilizar uma estimativa de risco cardiovascular que contemple um horizonte de 20-30 anos. No entanto, há limitações nos escores de risco. Por essa razão, a utilização de biomarcadores, como a EMI, melhora a predição de risco nesses $\operatorname{casos}^{61,62}$.
Com relação às novas tecnologias, a avaliação da carga aterosclerótica da PC através da ultrassonografia tridimensional (3D) parece ser uma opção na predição de risco cardiovascular. As imagens 3D da artéria carótida permitem a análise volumétrica além das características morfológicas da PC. Esses dados podem trazer informações mais precisas sobre a progressão ou regressão da doença aterosclerótica carotídea ${ }^{10,43}$.

\section{Avaliação Morfológica das Placas Carotídeas}

Atualmente, a decisão de intervir ou não em um paciente com estenose carotídea leva em consideração somente o grau de estenose. Muitos estudos, porém, demostraram que apesar da gravidade da estenose, alguns pacientes permanecem assintomáticos por anos, enquanto pacientes com graus moderados de estenose apresentam sintomas ${ }^{63,64}$. O grau de estenose somente parece não ser suficiente para determinar o risco de evento cerebrovascular ${ }^{65}$. Marcadores adicionais são necessários para identificar subgrupos com maior risco de eventos, que também se beneficiariam do tratamento cirúrgico ou endovascular.

A morfologia da placa tem um papel importante na ocorrência de eventos cerebrovasculares e pode também ser um importante preditor de eventos ${ }^{10,66}$. Surge então o

Tabela 3 - Tabela adaptada do Estudo MESA ${ }^{59}$

\begin{tabular}{|c|c|c|c|c|c|c|c|c|c|c|c|c|c|c|c|c|}
\hline \multirow{3}{*}{$\begin{array}{l}\text { Idade, } \\
\text { percentil }\end{array}$} & \multicolumn{12}{|c|}{ EMI media CCD } & \multirow{2}{*}{\multicolumn{4}{|c|}{ Mulher negra }} \\
\hline & \multicolumn{4}{|c|}{ Homem branco } & \multicolumn{4}{|c|}{ Mulher branca } & \multicolumn{4}{|c|}{ Homem negro } & & & & \\
\hline & $45-54$ & $55-64$ & $65-74$ & $75-84$ & $45-54$ & $55-64$ & $65-74$ & $75-84$ & $45-54$ & $55-64$ & $65-74$ & $75-84$ & $45-54$ & $55-64$ & $65-74$ & $75-84$ \\
\hline$\% 25$ & 0.52 & 0.57 & 0.65 & 0.72 & 0.51 & 0.55 & 0.65 & 0.72 & 0.58 & 0.61 & 0.71 & 0.74 & 0.55 & 0.60 & 0.65 & 0.71 \\
\hline$\% 50$ & 0.62 & 0.68 & 0.77 & 0.83 & 0.58 & 0.65 & 0.75 & 0.83 & 0.67 & 0.74 & 0.85 & 0.85 & 0.64 & 0.71 & 0.76 & 0.83 \\
\hline$\% 75$ & 0.71 & 0.81 & 0.92 & 0.97 & 0.67 & 0.76 & 0.87 & 0.93 & 0.80 & 0.92 & 0.99 & 1.02 & 0.74 & 0.81 & 0.92 & 0.96 \\
\hline \multirow{2}{*}{$\begin{array}{l}\text { Idade, } \\
\text { percentil }\end{array}$} & \multicolumn{4}{|c|}{ Homem chinês } & \multicolumn{4}{|c|}{ Mulher chinesa } & \multicolumn{4}{|c|}{ Homem hispânico } & \multicolumn{4}{|c|}{ Mulher hispânica } \\
\hline & $45-54$ & $55-64$ & $65-74$ & $75-84$ & $45-54$ & $55-64$ & $65-74$ & $75-84$ & $45-54$ & $55-64$ & $65-74$ & $75-84$ & $45-54$ & $55-64$ & $65-74$ & $76-84$ \\
\hline$\% 25$ & 0.54 & 0.56 & 0.62 & 0.66 & 0.55 & 0.54 & 0.59 & 0.67 & 0.53 & 0.60 & 0.65 & 0.71 & 0.51 & 0.57 & 0.65 & 0.63 \\
\hline$\% 50$ & 0.64 & 0.70 & 0.73 & 0.79 & 0.60 & 0.63 & 0.71 & 0.77 & 0.62 & 0.67 & 0.78 & 0.81 & 0.58 & 0.69 & 0.76 & 0.78 \\
\hline$\% 75$ & 0.73 & 0.83 & 0.92 & 0.98 & 0.70 & 0.77 & 0.84 & 0.96 & 0.73 & 0.82 & 0.90 & 0.92 & 0.67 & 0.77 & 0.87 & 0.92 \\
\hline
\end{tabular}

\begin{tabular}{|c|c|c|c|c|c|c|c|c|c|c|c|c|c|c|c|c|}
\hline \multirow{5}{*}{$\begin{array}{l}\text { Idade, } \\
\text { percentil } \\
\% 25 \\
\% 50 \\
\% 75\end{array}$} & \multicolumn{12}{|c|}{$\begin{array}{l}\text { EMI media CCE } \\
\text { Mulher branca }\end{array}$} & \multicolumn{4}{|c|}{ Mulher negra } \\
\hline & $45-54$ & $55-64$ & $65-74$ & $75-84$ & $45-54$ & $55-64$ & $65-74$ & $75-84$ & $45-54$ & $55-64$ & $65-74$ & $75-84$ & $45-54$ & $55-64$ & $65-74$ & $75-84$ \\
\hline & 0.54 & 0.57 & 0.67 & 0.71 & 0.50 & 0.55 & 0.63 & 0.70 & 0.56 & 0.63 & 0.69 & 0.72 & 0.54 & 0.59 & 0.63 & 0.68 \\
\hline & 0.63 & 0.69 & 0.81 & 0.85 & 0.58 & 0.64 & 0.73 & 0.80 & 0.69 & 0.75 & 0.82 & 0.85 & 0.63 & 0.67 & 0.76 & 0.78 \\
\hline & 0.78 & 0.82 & 0.95 & 1.00 & 0.67 & 0.75 & 0.85 & 0.94 & 0.81 & 0.92 & 0.99 & 1.02 & 0.73 & 0.80 & 0.90 & 0.91 \\
\hline \multirow{2}{*}{$\begin{array}{l}\text { Idade, } \\
\text { percentil }\end{array}$} & \multicolumn{4}{|c|}{ Homem chinês } & \multicolumn{4}{|c|}{ Mulher chinesa } & \multicolumn{4}{|c|}{ Homem hispânico } & \multicolumn{4}{|c|}{ Mulher hispânica } \\
\hline & $45-54$ & $55-64$ & $65-74$ & $75-84$ & $45-54$ & $55-64$ & $65-74$ & $75-84$ & $45-54$ & $55-64$ & $65-74$ & $75-84$ & 45-54 & $55-64$ & $65-74$ & $75-84$ \\
\hline$\% 25$ & 0.55 & 0.57 & 0.62 & 0.69 & 0.49 & 0.52 & 0.58 & 0.64 & 0.55 & 0.61 & 0.68 & 0.72 & 0.51 & 0.58 & 0.62 & 0.68 \\
\hline$\% 50$ & 0.63 & 0.70 & 0.72 & 0.84 & 0.58 & 0.63 & 0.71 & 0.76 & 0.64 & 0.72 & 0.80 & 0.86 & 0.58 & 0.68 & 0.72 & 0.77 \\
\hline$\% 75$ & 0.73 & 0.84 & 0.86 & 0.97 & 0.67 & 0.72 & 0.87 & 0.94 & 0.75 & 0.85 & 0.98 & 0.97 & 0.68 & 0.79 & 0.86 & 0.91 \\
\hline
\end{tabular}


conceito de placa instável ou vulnerável. A pesquisa das características relacionadas ao maior risco de eventos passa a ser uma importante ferramenta do exame ultrassonográfico.

As placas ateromatosas são compostas por um núcleo rico em lipídeos e uma capa fibrótica, que as separam do lúmen vascular. Histologicamente são características das placas instáveis: presença de erosões endoteliais; cápsula fibrótica fina; presença de volumoso núcleo lipídico; presença de macrófagos ativados; poucas células musculares; e alta síntese de metaloproteinases. Em contraste, a placa estável apresenta: endotélio íntegro; constituição do núcleo lipídico por células espumosas; numerosas células musculares; cápsula fibrosa espessa ${ }^{67}$. O desafio se faz em reconhecer as características ultrassonográficas da placa para poder facilitar a identificação de uma placa instável.

Para descrição das placas recomendamos o relato sistemático de suas características, ressaltando-se aquelas associadas ao maior risco de eventos. Na prática diária, porém, segundo o entendimento entre os participantes deste painel, recomenda-se destacar no laudo somente quando houver sintomas ipisilaterais, não justificados pelo grau de estenose. Placas com ulcerações ou a presença de componentes móveis devem ser relatadas mesmo em assintomáticos.

Por consenso, as características que devemos descrever são: localização; extensão da placa; ecogenicidade; textura; superfície; presença de componentes móveis; presença de zona anecoica junto à cápsula fibrótica. Essas características devem ser descritas nas placas mais importantes, principalmente naquelas com mais de $50 \%$ de estenose, para que o laudo não fique muito longo e tedioso, perdendo assim a capacidade de transmitir a real importância dos achados mencionados.

\section{Características das placas}

\section{Localização da placa}

Quanto à localização, recomendamos subdividir as carótidas em: carótida comum proximal, média e distal, bifurcação, ramo externo e ramo interno proximal e médio. A porção distal do ramo interno é a porção intracraniana, que inclui as porções petrosa, sifão cavernoso e supraclinoide. Na carótida direta, também temos o tronco braquiocefálico, que deve ser sempre examinado pela USV. A divisão desse segmento segue a recomendação do estudo Mannheim ${ }^{31}$, para medida da espessura médio mediointimal (Figura 14).

Importante ressaltar que não recomendamos a utilização do termo bulbo, já que esse se refere à forma globosa de plantas ou de lâmpadas. Na carótida, o bulbo poderia estar localizado na bifurcação envolvendo ambos os ramos, ser exclusivo do ramo interno e, até em casos mais raros, ser exclusivo do ramo externo, fazendo desse um termo impreciso, que deve ser evitado (Figura 15).

\section{Extensão da placa}

A extensão da placa deve ser medida (Figura 16), pois pode se correlacionar com a possibilidade de eventos e tem implicação na escolha da abordagem do tratamento cirúrgico e endovascular ${ }^{68}$. Estudos recentes com a ultrassonografia tridimensional vêm mostrando a importância de se conhecer o volume total da placa, bem como sua cinética de crescimento longitudinal e radial $\left.\right|^{9,69}$.

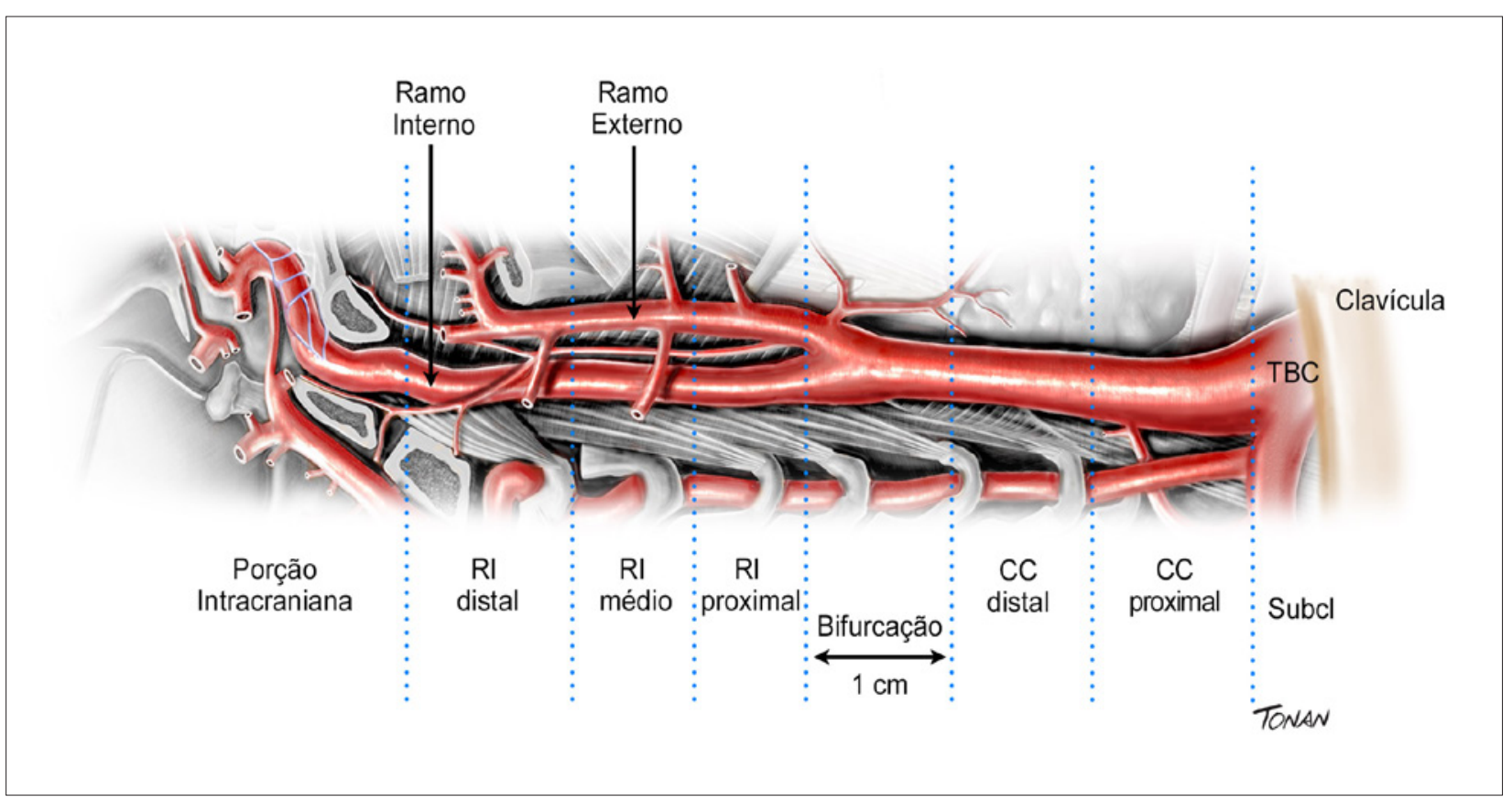

Figura 14 - Carótida direita e suas subdivisões anatômicas recomendadas pelo grupo (adaptada do estudo Mannheim ${ }^{31}$ ). 


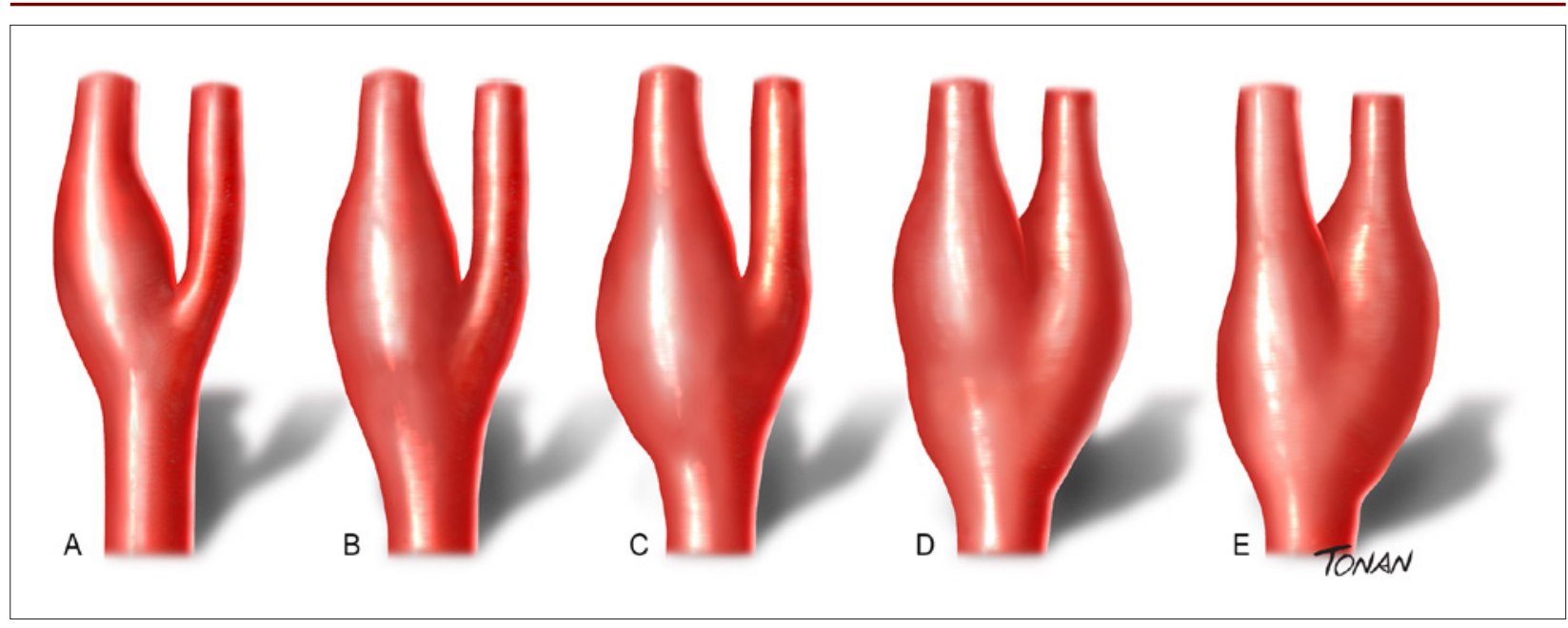

Figura 15 - Localizações possíveis do bulbo carotídeo: A- Porção proximal do ramo interno; B- Quase exclusivo do ramo interno; C- Envolvendo a bifurcação e o ramo interno; D-Envolvendo a bifurcação e ambos os ramos interno e externo; E- Envolvendo a bifurcação e o ramo externo.

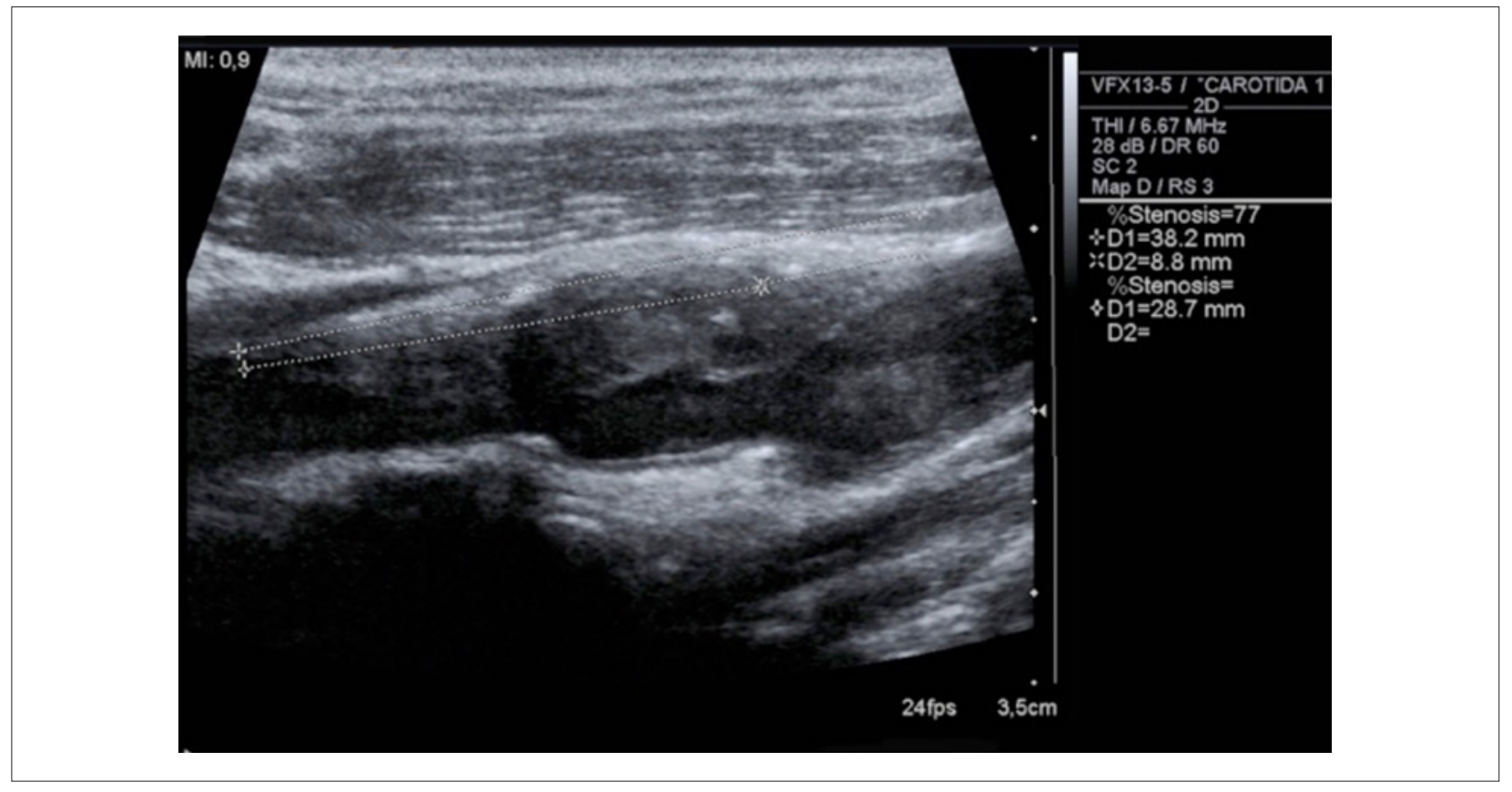

Figura 16 - Extensão total da placa medindo $38,3 \mathrm{~mm}$. Distância do início da placa até a bifurcação medindo 8,8 mm. Distância da bifurcação até o final da placa no ramo interno medindo $28,7 \mathrm{~mm}$.

\section{Ecogenicidade}

Define-se a ecogenicidade da placa comparando-a com a ecogenicidade de estruturas adjacentes a ela (sangue, músculo, adventícia do vaso e osso) no campo de imagem da carótida, classificando-as em três tipos ${ }^{70}$ :

a. Hipoecogênica ou ecolucente: mais escura, ou seja, ecogenicidade similar à do sangue e menos ecogênica do que o músculo esternocleidomastoideo. Nessas placas os componentes predominantes são gordura, sangue ou trombos de formação recente. b. Isoecogênica: ecogenicidade próxima à do músculo. Nessas placas o componente predominante é o tecido fibroso.

c. Hiperecogênica: mais branca que o músculo adjacente, com predomínio de tecido fibroso mais denso.

d. Calcificada: muito ecogênica, gerando sombra acústica, devido ao depósito de cálcio. Ecogenicidade comparável ao osso.

Quanto à textura da placa, Reilly e cols. ${ }^{71}$ as classificaram como homogêneas ou heterogêneas. 


\section{Artigo Especial}

- Homogêneas: uniforme com baixo nível de ecos e uniforme com alto nível de ecos.

- Heterogêneas: compostas por uma mistura de alto, médio e baixo nível de ecos.

Baseados no padrão de predomínio da ecogenicidade das placas, Gray-Weale e cols. propuseram uma classificação morfologica das placas ateromatosas, que foi depois modificada por Geroulakos e cols. (Quadro 4) em cinco tipos ${ }^{72}$ :

- Tipo 1: uniformemente ecolucente (homogênea), com ou sem capsula fibrótica definida.

- Tipo 2: predominantemente ecolucente, com áreas ecogênicas inferiores a 50\% do total da placa.

- Tipo 3: predominantemente ecogênicas, com área hiperecogênica superior a 50\% da área total da placa.

- Tipo 4: uniformemente ecogênica.
- Tipo 5: calcificada, com sombra acústica.

A metodologia de normalização da caracterização da placa assistida por computação faz a análise da textura da placa pela média da distribuição dos valores de cinza (GSM), atribuindo-se 0 para o sangue e 255 para a adventícia. Ela vem sendo usada para diminuir a variação interobservador das características atribuídas a cada placa, mas ainda não vem sendo utilizada como rotina na prática clínica ${ }^{73}$.

Quanto à superfície: a superficie luminal é classificada em três classes ${ }^{70}$ :

- Regular: irregularidades inferiores a 0,4 mm de profundidade.

- Irregular: de 0,4 a 2 mm de profundidade.

- Ulceração: depressão superior a 2,0 mm de profundidade, sendo outros critérios adicionais importantes. Os critérios

Quadro 4 - Classificação morfológica das placas segundo a classificação de Gray-Weale, modificada por Geroulakos, com respectivas incidência e eventos e exemplos de placa ao ultrassom

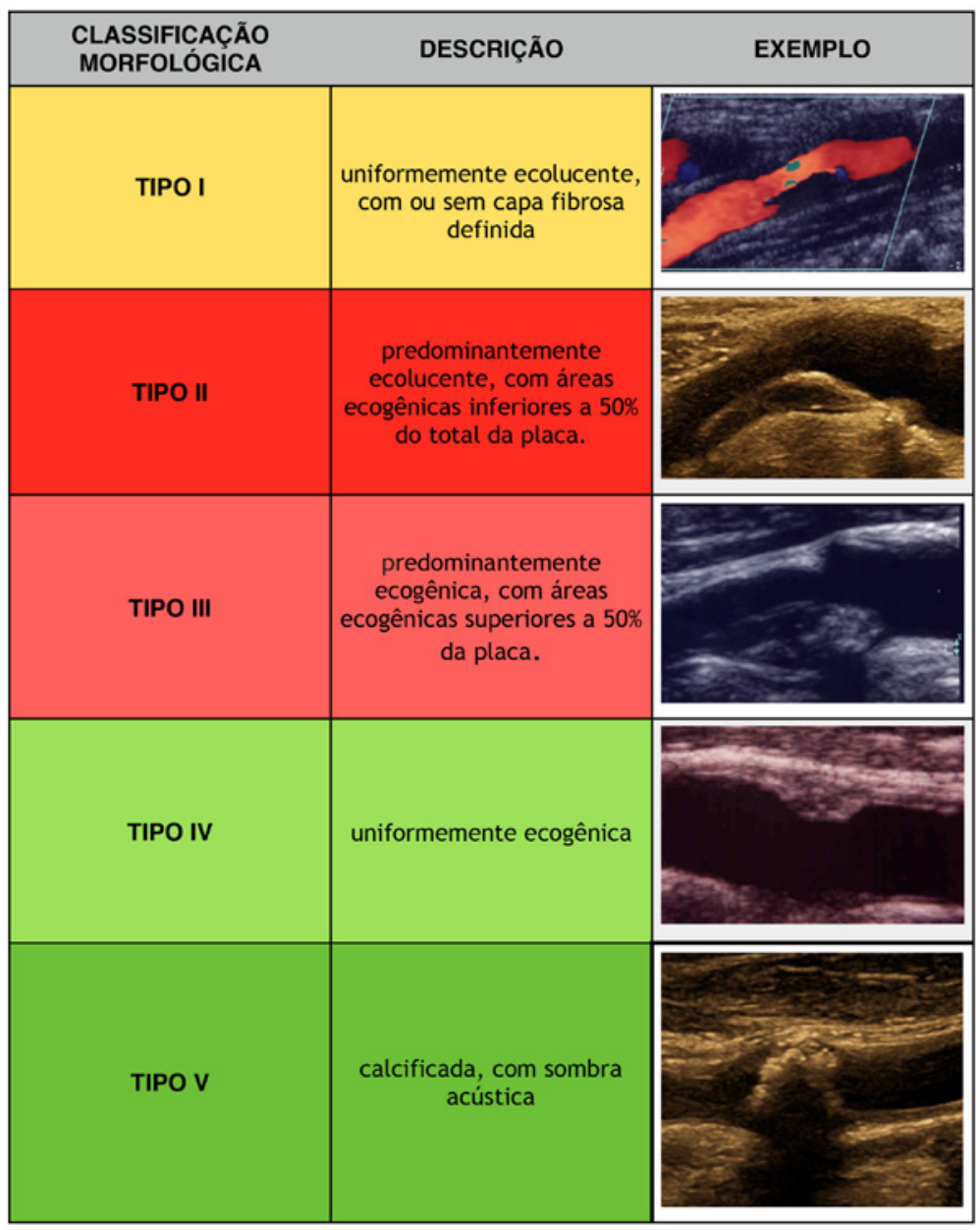

Escala de risco de eventos neurológicos associado ao tipo de placa (do menor para o maior risco). 
clássicos para diagnóstico das ulcerações foram definidos por De Bray e cols. ${ }^{70}$ como: cavidade com concavidade de $2 \mathrm{~mm}$ de extensão e $2 \mathrm{~mm}$ de profundidade; base com parede bem definida pelo modo B; área com fluxo reverso ao color Doppler no interior da cavidade. Esses critérios ditos clássicos são bastante específicos, mas muito pouco sensíveis no diagnóstico de ulceração ao USV. Mais recentemente Muraki e cols. ${ }^{74}$ publicaram novos critérios para o diagnóstico ultrassonográfico das ulcerações. Segundo esses autores, não é necessário incluir o tamanho da cavidade ou a presença de fluxo no interior da depressão, sendo necessário se identificar uma concavidade na placa com ecos menos intensos na base ("o interior da escavação") do que na superfície dos segmentos adjacentes da mesma placa, reportando uma sensibilidade de $85,7 \%$ e uma especificidade de $81,3 \%$ (Quadro 5).
Ainda neste tópico é importante diferenciar as úlceras ou escavações verdadeiras, das placas sequenciais ("tandem plaques") [Figura 17]. Nestas últimas, além de a cavidade ter um colo bem largo, não teriam os critérios de diferentes ecogenicidades descritos por Muraki e cols. ${ }^{74}$, sendo importante a varredura em corte transverso para melhor diagnóstico diferencial.

O primeiro estudo que mostrou o valor da caracterização ultrassonográfica das placas da bifurcação carotídea foi realizado por Johnson e cols. ${ }^{75}$ no início dos anos 1980. Nesse estudo, realizado em pacientes assintomáticos, demostrou-se que as placas hipoecogênicas, em comparação com as placas ecogênicas e calcificadas, aumentaram o risco de AVE em pacientes que foram seguidos durante três anos. Esse efeito foi mais notório nos pacientes portadores de

Quadro 5 - Tabela de classificação de superfície e características da placa aterosclerótica (Referência: *ACSRS).

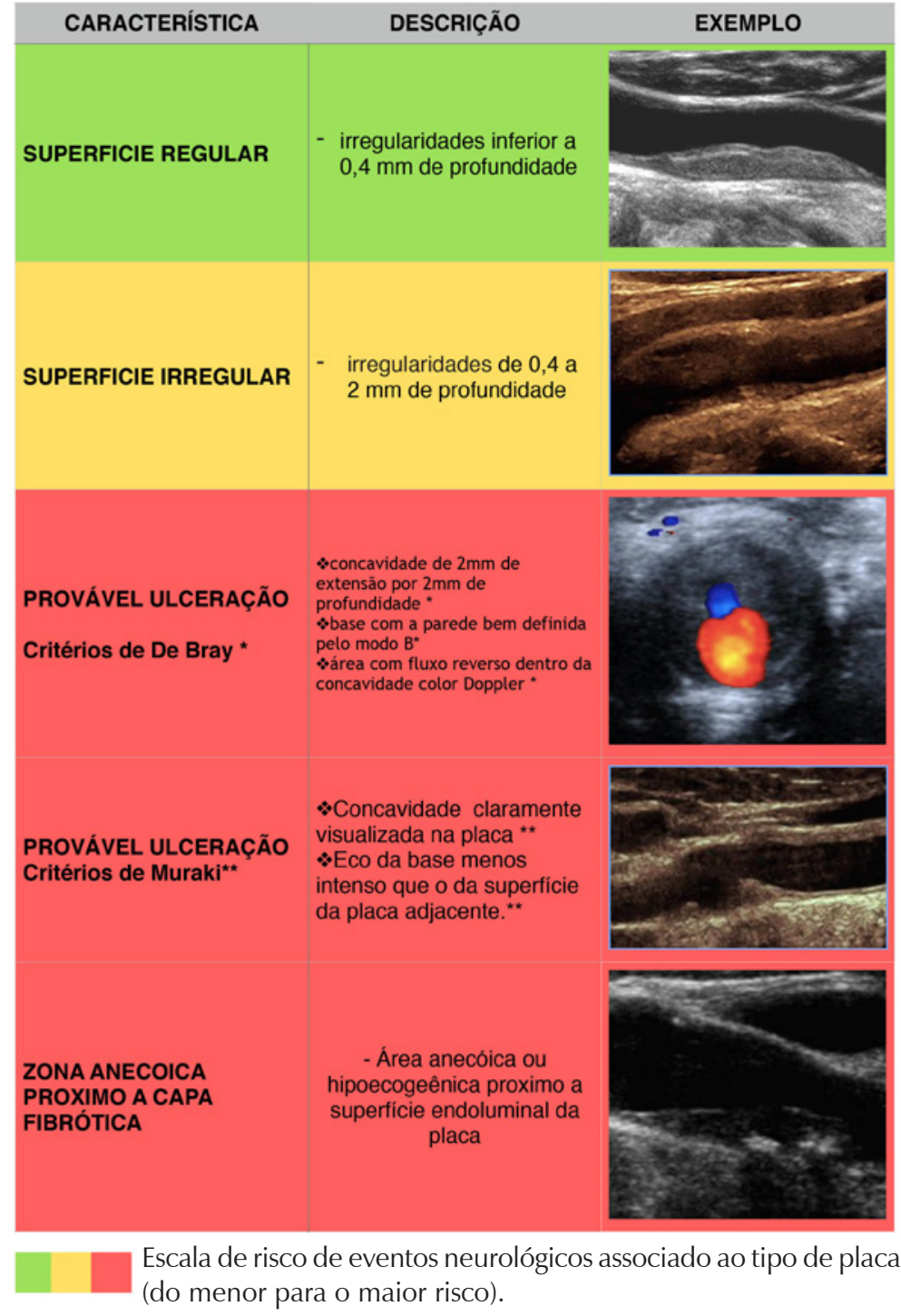




\section{Artigo Especial}

estenoses superiores a 70\%, sendo relatada ocorrência de evento cerebral em 19\% desse subgrupo, em comparação com o subgrupo com placas calcificadas, no qual nenhum paciente apresentou evento cerebrovascular.

Seguiram-se a esse vários estudos que mostraram que placas hipoecogênicas e heterogêneas, ou seja, as placas do tipo I e II da classificação de GW, principalmente quando associadas à estenose superior a 50\%, estavam associadas a um maior risco de eventos cerebrovasculares ${ }^{75-77}$. Já Mathiesen e cols. ${ }^{78}$ demostraram que placas dos tipos I e Il estão associadas a um maior risco de evento, independente do grau de estenose. Mais recentemente sugiram trabalhos associando as características da superfície da placa e do grau de estenose, propondo um escore de ocorrência do risco de eventos ${ }^{79}$.

A presença de área hipoecoica próxima ao lúmen também foi associada a maior risco de eventos neurológicos (taxa de evento de 16\%, comparada a 1,5\% de eventos no grupo sem essa característica). Essa característica da placa foi observada em $92 \%$ dos eventos neurológicos que ocorreram durante o folow-up ${ }^{80}$.

\section{Uso de contraste de microbolhas}

A utilização do contraste com microbolhas para a avaliação das placas carotídeas baseia-se na premissa de que a placa vulnerável apresenta uma fina cápsula fibrótica, que cobre um grande núcleo lipídico necrótico em um processo inflamatório ativo. A presença de neovascularização é a chave para a identificação da placa sob risco, já que os neovasos servem como porta de entrada para células inflamatórias, lipídios e células vermelhas, aumentando o espaço entre as junções e contribuído assim para o crescimento da placa. Além disso, os neovasos levam a um maior risco de ruptura, levando a hemorragia intraplaca e a um rápido crescimento dessa ${ }^{18}$.

Os agentes de contraste são compostos de microbolhas (aproximadamente 1-8 nanomicras), normalmente cheias por um gás perfluorinado, que tem baixa solubilidade, estabilizada com um fosfolipídeo e estabilizado por uma capa de proteína ou fosfolipídeo para aumentar o tempo de circulação ${ }^{24}$.

Alguns equipamentos de ultrassom, usando modulação de amplitude do sinal ou harmônica de pulso invertido, são capazes que recuperar sinais não lineares em um regime de baixa potência acústica, que são exclusivos das microbolhas, sendo assim capazes de suprimir a imagem do tecido e permitir a identificação específica das microbolhas ${ }^{23}$.

O contraste de microbolhas realça a parede vascular, permitindo uma melhor avaliação da superfície das placas. Pelo fato de poder detectar individualmente a passagem das bolhas pelos capilares, essa técnica permite a visualização direta da neovascularizaçao intraplaca, já que as microbolhas são estritamente marcadores intravasculares ${ }^{26}$. O Quadro 6 exemplifica a avaliação da vulnerabilidade das placas ateromatosas.

\section{QUANTIFICAÇÃO DAS ESTENOSES CAROTÍDEAS PELA ULTRASSONOGRAFIA VASCULAR}

\section{Introdução}

Historicamente a arteriografia convencional tem sido considerada o padrão de referência para a quantificação das estenoses das artérias carótidas ${ }^{81}$. Os estudos NASCET (North American Symptomatic Carotid Endarterctomy Trial), ECST (European Carotid Surgery Trial) e ACAS (Asymptomatic Carotid Atherosclerosis Study) utilizaram a arteriografia para estabelecer a severidade da doença e os pontos de corte específicos para indicação da intervenção cirúrgica em pacientes sintomáticos e assintomáticos ${ }^{82-84}$. Esses estudos randomizados mostraram que houve benefício em pacientes sintomáticos com estenoses entre $70 \%$ e $99 \%$, e em alguns com estenoses entre $50 \%$ e $69 \%$, assim como em pacientes assintomáticos com estenose $\geq 60 \%$.
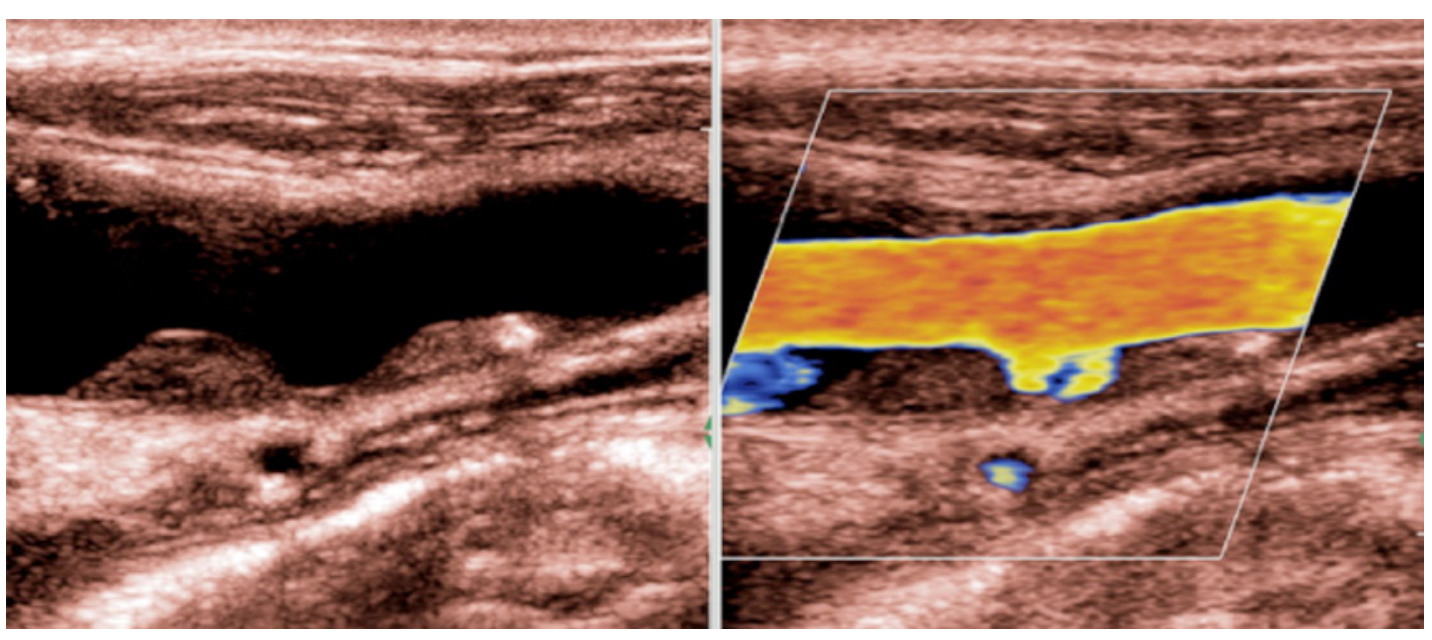

Figura 17 - A- Placas sequenciais ilustradas em modo B; B- Placas sequenciais ilustradas em modo B e color Doppler. 
Quadro 6 - Uso de contraste de microbolhas para avaliação da vulnerabilidade das placas ateromatosas.

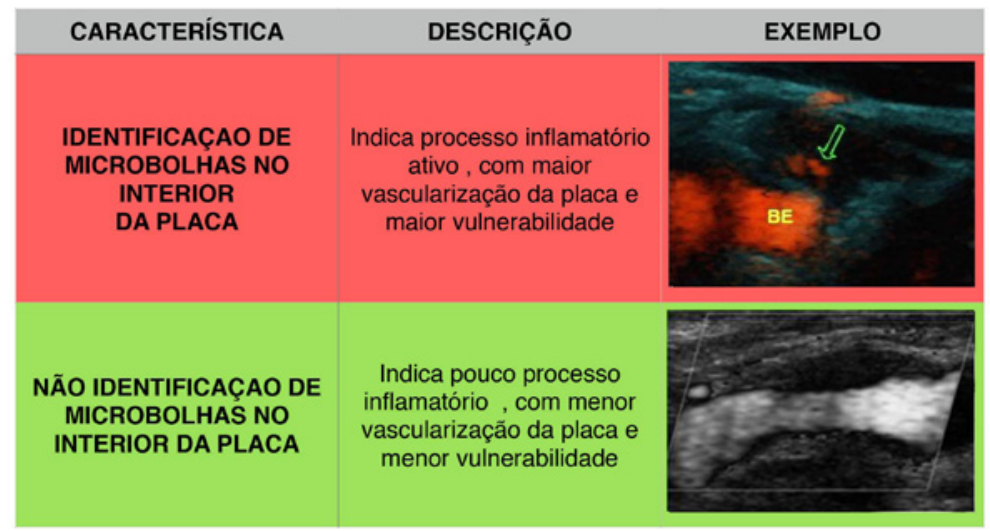

Escala de risco de eventos neurológicos associado ao tipo de placa (do menor para o maior risco).

A endarterectomia carotídea (EAC) se justifica quando o resultado operatório imediato e de longo prazo é melhor que a terapia conservadora, tendo a revascularização carotídea o objetivo de prevenir o acidente vascular encefálico (AVE), interferindo na história natural da doença de forma segura e efetiva. Como as indicações da EAC em pacientes assintomáticos não são tão robustas, alguns autores reservam a intervenção para pacientes selecionados com estenoses $\geq 80 \%{ }^{85}$. Mais recentemente a abordagem endovascular com utilização dos stents carotídeos vem se tornando uma alternativa, em especial nos pacientes com alto risco para a endarterectomia ${ }^{86}$.

Uma vez que a arteriografia tem caráter invasivo, faz uso de contraste iodado e não está isenta de riscos para o paciente, tornou-se necessário o desenvolvimento de métodos não invasivos que pudessem tanto identificar como quantificar as estenoses carotídeas ${ }^{87}$. Atualmente vários exames podem ser realizados para a avaliação da doença das artérias carótidas, como a arteriografia convencional, a angiografia por ressonância nuclear magnética (ARNM), a angiotomografia (CTA) e a USV8s.

Nas últimas três décadas, a USV tornou-se o método mais utilizado para a avaliação das artérias carótidas extracranianas $^{2,89}$. Isso se justifica por tratar-se de um método não invasivo, que não utiliza radiação ou contraste, fornece informações anatômicas e hemodinâmicas, tem boa reprodutibilidade, portabilidade e custo inferior aos demais exames diagnósticos. Tanto que a Sociedade Americana de Cirurgia Vascular preconiza a USV como primeira escolha para avaliação da doença arterial carotídea sintomática ou assintomática e muitas vezes a decisão cirúrgica é baseada apenas em seus resultados ${ }^{90,91}$.

Em geral, a avaliação da estenose carotídea pela USV envolve medidas da velocidade do fluxo e suas relações a partir do Doppler espectral, associadas à avaliação da imagem bidimensional e ao color Doppler. Várias instituições publicaram seus critérios de avaliação das estenoses por análises das velocidades do fluxo, com algumas diferenças em sua interpretação ${ }^{92-94}$.

Em 2002, em San Francisco, nos Estados Unidos, aconteceu uma reunião de especialistas com o intuito de oferecer recomendações para a realização dos exames de USV das artérias carótidas, assim como a interpretação dos resultados no diagnóstico da estenose da artéria carótida interna $(\mathrm{ACl})$. O texto gerado por essa reunião foi publicado no ano de 2003, tornando-se referência até os dias atuais ${ }^{1}$.

Em 2009, no Reino Unido, foi publicado um documento também com recomendações para a uniformização da prática da USV e normatizações quanto aos critérios a serem utilizados no diagnóstico das estenoses da $\mathrm{ACl}$, utilizando alguns critérios do consenso americano e acrescentando outros como o índice de St. Mary's que divide em decis o grau de estenose ${ }^{3}$. Porém, até o momento, não existe uma recomendação universalmente aceita que englobe um conjunto de critérios, assim como não há consenso sobre o peso relativo de cada um deles ${ }^{95}$. Recentemente um estudo avaliou dez instituições americanas e mostrou que, entre elas, havia a utilização de diferentes critérios Doppler ultrassonográficos para graduação das estenoses carotídeas gerando diferenças significativas no número de intervenções, subsequentemente impactando em custo no sistema de saúde ${ }^{96}$.

Como a USV é capaz de fornecer informações sobre a morfologia da placa, avaliar a estenose por métodos anatômicos e quantificar o grau de obstrução por diversos parâmetros Doppler velocimétricos, esse documento concorda com outros autores e aprova a abordagem multiparamétrica para a quantificação das estenoses da $\mathrm{ACl}^{97}$.

\section{Considerações técnicas para avaliação ao Doppler}

A avaliação da velocidade do sangue pelo método Doppler deve ser realizado em conjunto com a avaliação da placa ao bidimensional. Deve-se aferir, ao Doppler 


\section{Artigo Especial}

pulsado, o traçado espectral nas carótidas comuns, internas e externas bilateralmente e em qualquer ponto em que haja suspeita de estenose sugerida pelas imagens em Modo B e/ou Doppler colorido. A visualização da placa é imprescindível para o diagnóstico da estenose uma vez que condições hemodinâmicas diversas podem cursar com velocidades elevadas ou reduzidas independentemente da presença de estenoses.

\section{O ângulo de insonação}

Um problema frequentemente relatado diz respeito à estimativa da velocidade para a qual é utilizada a equação Doppler. Nela, quando calculamos a velocidade, o $\cos ^{\theta}$ (referente ao ângulo de insonação) encontra-se no denominador, gerando maiores velocidades quanto maior for o ângulo utilizado. Quando se corrige o ângulo, o examinador deve levar em consideração a possibilidade do erro, pois a condição ideal é aquela onde o feixe de ultrassom é paralelo ao fluxo do sangue, ou seja, ângulo zero que corresponderá à velocidade absoluta. Sabe-se que o cursor deve estar paralelo à parede do vaso, pois supomos que o fluxo também o seja e a amostra volume deve ser menor do que o lúmen e posicionada no seu centro e em direção ao fluxo. Assim acontece com as artérias carótidas, cujo posicionamento anatômico exige que, para a linha de insonação Doppler estar orientada com a parede do vaso, esse ângulo deva ser próximo a $60^{\circ}$. Ângulos maiores que $60^{\circ}$ cursam com erros maiores ${ }^{98}$.

Quando há uma estenose significativa, dependendo da conformidade da placa, o distúrbio de fluxo faz que esse nem sempre se mantenha paralelo à parede do vaso, portanto alguns autores preconizam que se deva alinhar o cursor na direção do jato ${ }^{95}$ (Figura 18). Porém, na literatura, há opiniões diferentes, estando os autores divididos entre os que acreditam ser ideal utilizar um ângulo fixo em $60^{\circ}$ e aqueles que optam por usar ângulos $\leq 60$ o alinhados

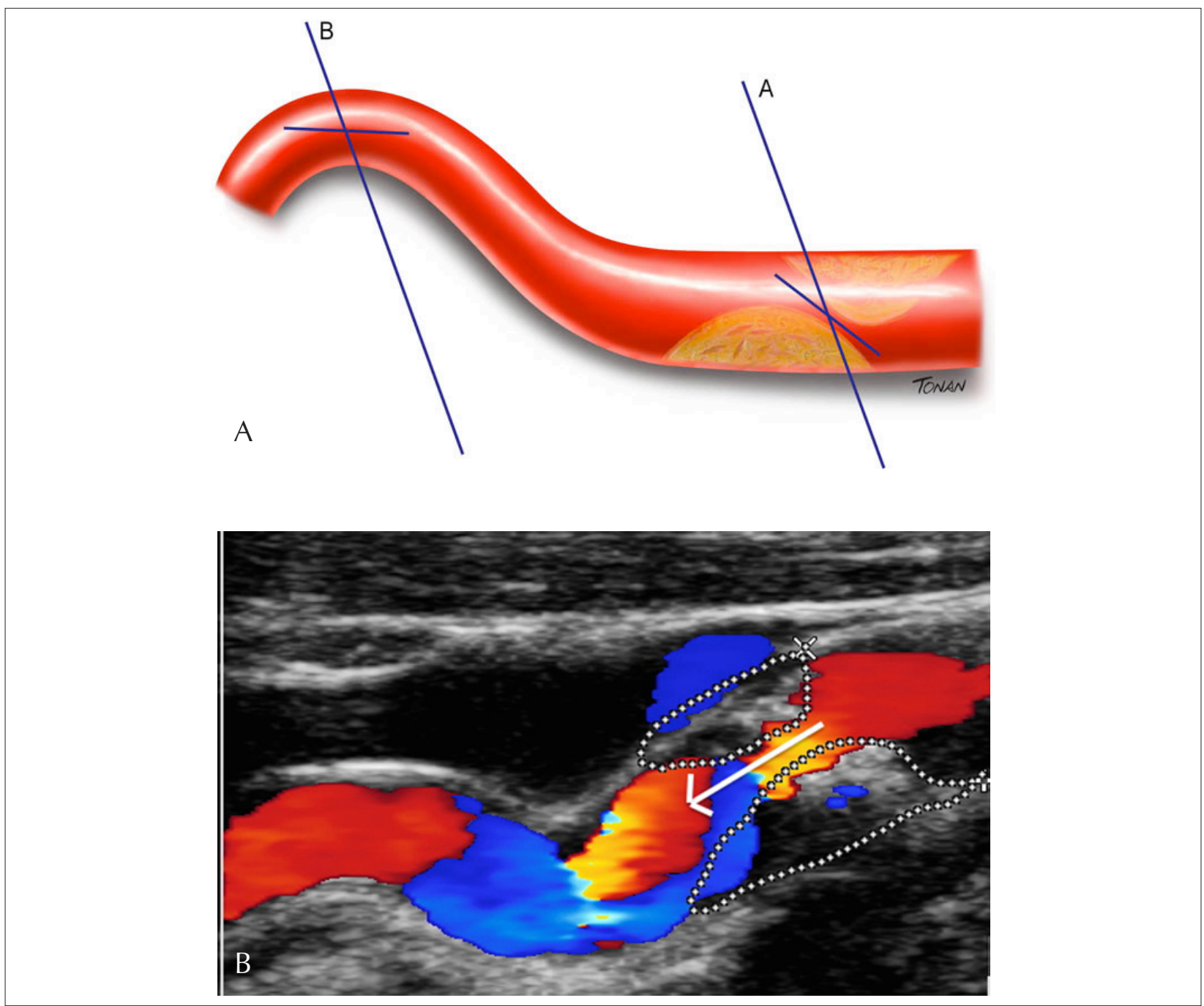

Figura 18 - 1a: Esquema ilustrando a colocação do cursor e o ângulo de insonação A- Paralelo ao jato no caso de estenose; B- Paralelo ao vaso; 1 b: Cursor e ângulo de insonação na direção ao jato de fluxo no caso de estenose (seta). 
com o fluxo ${ }^{89}$. Tola e cols. ${ }^{99}$ avaliaram a velocidade do fluxo aferida com ângulos de $45^{\circ}$ e $60^{\circ}$ e, mesmo sendo diferentes, não houve diferença na acurácia diagnóstica para estenoses da ACl. O consenso americano de 2003 sugere que seja usado um ângulo $\leq 60^{\circ}$, mas mostra que há opiniões conflitantes a esse respeito e nas recomendações do Reino Unido sugere-se que seja utilizado um ângulo que varie entre $45^{\circ}$ e $60^{\circ}$, devendo ser alinhado no caso dos jatos excêntricos ${ }^{1,3}$. O presente documento concorda e considera adequado que o ângulo de insonação seja $\leq 60^{\circ} \mathrm{e}$, alinhado com o fluxo quando necessário.

\section{Local da medida das velocidades}

$\mathrm{Na}$ artéria carótida comum (ACC), a medida das velocidades deve ser realizada em seu segmento proximal, médio e distal. Para a avaliação da razão de velocidades na quantificação das estenoses da $\mathrm{ACl}$, a $\mathrm{ACC}$ deve ser avaliada a aproximadamente $2 \mathrm{~cm}$ da bifurcação, preferencialmente em um segmento retilíneo, sem placas ${ }^{3,89,99}$ (Figura 19).

A $\mathrm{ACl}$ deve ter suas velocidades avaliadas no segmento proximal e médio, lembrando que as lesões ateroscleróticas usualmente afetam os $2 \mathrm{~cm}$ proximais ${ }^{100}$

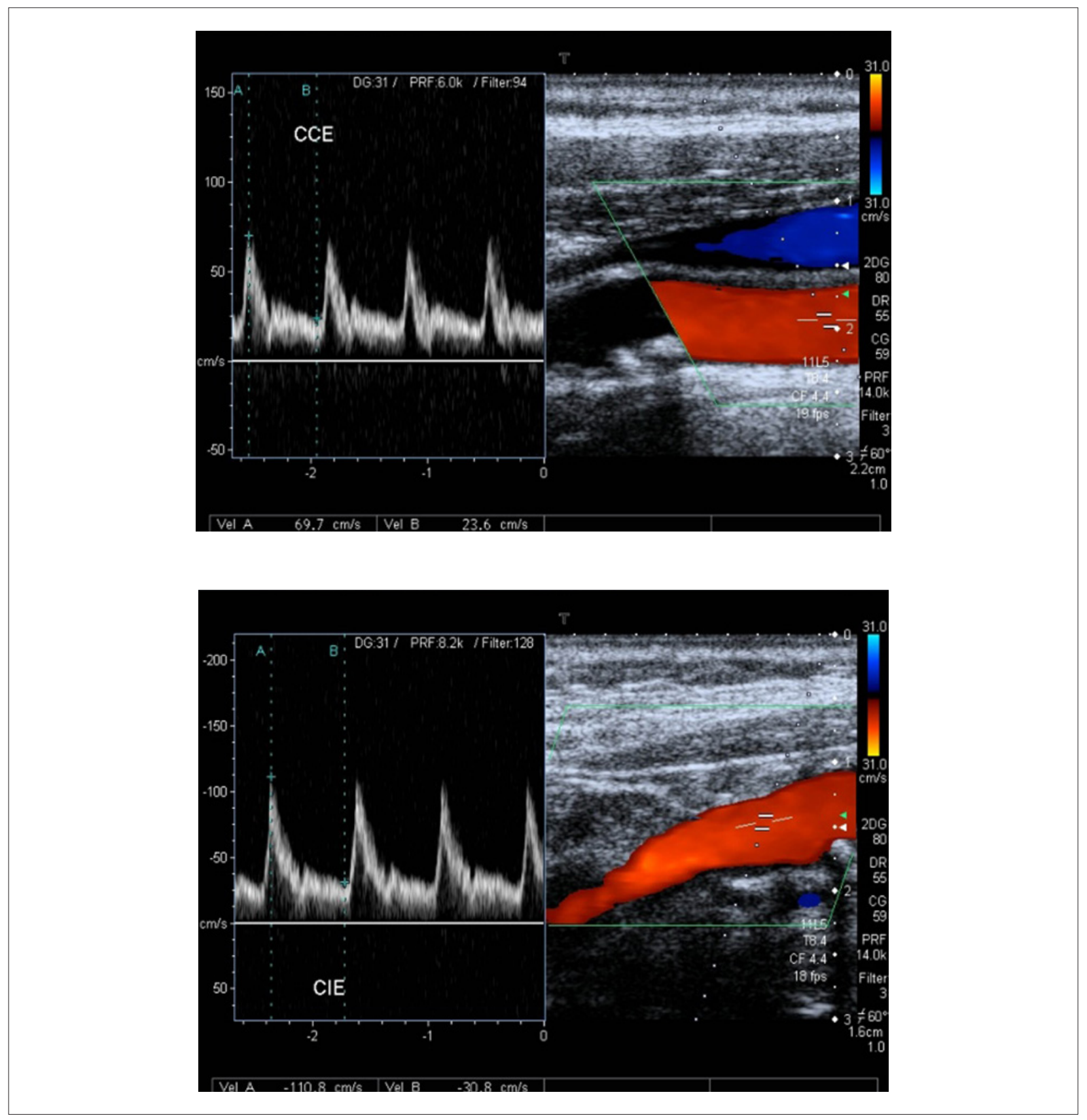

Figura 19 - A- fluxo na artéria carótida comum; B- fluxo na artéria carótida interna.

Medidas adicionais de velocidades devem sempre ser realizadas nos pontos onde haja suspeita de estenose ao Modo B e ao Doppler colorido. 


\section{Análise das medidas de velocidades}

\section{Padrão de onda normal nas carótidas}

A velocidade do fluxo arterial medida pelo Doppler é apresentada como ondas de velocidade de fluxo (espectro) em cada local examinado. As características dessas ondas dependem do tipo de fluxo no local, bem como de alterações produzidas na velocidade do sangue por condições proximais e distais ao local de medida. $\mathrm{Na} \mathrm{ACl}$ as ondas de velocidade de fluxo são normalmente de baixa resistência. Na artéria carótida externa (ACE) o padrão da onda de velocidade é de alta resistência, enquanto na ACC é do tipo intermediário entre as carótidas interna e externa ${ }^{101}$.

\section{Critérios de graduação da estenose carotídea - proposta do DIC}

Uma vez que a estenose foi identificada ao Modo B e/ou ao color Doppler, deve ser documentado o traçado espectral nesse ponto, sendo essa avaliação fundamental para a sua quantificação. Porém, as regiões pré-estenótica e pós-estenótica também devem ser avaliadas, pois podem fornecer informações adicionais. A avaliação das velocidades fornecidas pelo traçado espectral deve compreender: a velocidade do pico sistólico (VPS) e a velocidade diastólica final (VDF) nas ACC e ACl. A partir da velocidade sistólica e diastólica podemos obter as relações (razões): VPS ACl/ VPS ACC, VPS ACl/ VDF ACC e VDF $\mathrm{ACl} / \mathrm{VDF} \mathrm{ACC}$.

\section{Estenose da Artéria Carótida Interna}

Vários critérios para quantificação da estenose da $\mathrm{ACl}$ foram avaliados na literatura $92,93,94,106,115$, porém, ainda hoje, há divergências entre as instituições ${ }^{96}$. O consenso americano de 2003 e as recomendações do Reino Unido de 2009 foram uma tentativa de uniformizar os padrões de velocidade e categorização dos graus de estenose, sendo atualmente os mais utilizados na prática do dia a dia dos laboratórios de ultrassonografia ${ }^{1,3}$.

O presente documento traz uma sugestão de critérios para avaliação ao Doppler, baseados na literatura, que possam complementar os já vigentes e auxiliar o examinador no momento da quantificação da estenose carotídea. Como diferencial há a proposta de se subdividir as estenoses em decis de forma que o resultado ultrassonográfico possa fornecer informações ainda mais objetivas que ajudem na decisão terapêutica.

\section{a) Estenoses menores que 50\%:}

Inicialmente os critérios da universidade de Washington e de outras instituições subdividiam as obstruções menores que $50 \%$ pela avaliação ao Doppler espectral, porém, tanto o Consenso de 2003 como a normatização do Reino Unido de 2009 consideram essa avaliação imprecisa pelo Doppler ${ }^{1,3,89}$. Esse documento sugere que subdivisões para a categoria das estenoses menores que $50 \%$ sejam feitas pela análise ao Modo $\mathrm{B}$, utilizando preferencialmente o corte ultrassonográfico transverso que forneça a melhor imagem para o cálculo de redução do lúmen ${ }^{102}$ (Figura 20). b) Estenoses maiores que $50 \%$ :

É de fundamental importância a identificação das estenoses maiores que $50 \%$, em especial as maiores que $70 \%$ ou $80 \%$, uma vez que esses pacientes podem ser candidatos a intervenção cirúrgica ou endovascular. Dentre os critérios para avaliação das estenoses se destaca a VPS, que, na presença da placa, é considerado um parâmetro importante e objetivo. No entanto, a análise conjunta com outros parâmetros como a VDF e as razões de velocidades confere confiabilidade e facilita o diagnóstico (Figura 21). Além disso, com a utilização de diversos parâmetros é possível se estreitar a faixa diagnóstica. Assim, este documento sugere a subdivisão da classificação das estenoses da $\mathrm{ACl}$ em decis, conforme quadro 7.

Já foi demonstrada a correlação entre parâmetros de velocidade pela USV com a arteriografia. AbuRahma e cols. ${ }^{2}$ observaram que a melhor correlação entre as medidas realizadas pela USV e a arteriografia (teste de Pearson) ocorreu quando se usou a medida da VPS $(r=0,81)$, seguida pela medida da $\operatorname{VDF}(r=0,70)$, razão VPSACI / VPS ACC $(r=0,57)$ e razão VDF ACl / VDF ACC $(r=0,54)$. Em nosso meio, também foi observada uma correlação muito boa entre os valores da VPSACI, da razão VPSACI / VPS ACC e VDF ACI com os graus de estenose da $\mathrm{ACl}$ encontrados na arteriografia $(r=0,81$; $r=0,81 ; r=0,78 ;$ todos com $p<0,001)^{104}$. Braun e cols. ${ }^{105}$, por sua vez, encontraram uma melhor correlação da VPS ( $r=0,825)$ com a arteriografia, seguido da razão $\operatorname{VPS} A C l / \operatorname{VPS} A C C(r=0,766)$ e da $\operatorname{VDF}(r=0,762)$ e por fim da razão VDF ACl / VDF ACC ( $r=0,643)$.

Mesmo apresentando boa correlação com a arteriografia, a sensibilidade e a especificidade dos diferentes critérios variam conforme a instituição e o grau de estenose. $\mathrm{Na}$ identificação das estenoses maiores que 70\%, a USV exibe uma boa acurácia, porém estudos mostram que, para estenoses menores que 50\%, em especial as entre 50\%-69\% essa não apresenta o mesmo desempenho. Uma meta-análise publicada em 2006, com 41 estudos, comparou USV, CTA, ressonância nuclear magnética (RNM) e RNM contrastada com a arteriografia convencional no diagnóstico das estenoses carotídeas e mostrou que, para estenoses entre $70 \%-99 \%$, a sensibilidade e a especificidade da USV foi $89 \%$ e $84 \%$, respectivamente, enquanto para aquelas menores que $50 \%$, foi de $83 \%$ e $84 \%$; porém, para as estenoses entre 50\%-69\%, a USV apresentou uma sensibilidade de 36\%, apesar de uma especificidade de $91 \%^{88}$. Da mesma forma Sabeti e cols. ${ }^{106}$ mostraram que a USV concordou com a arteriografia em $96 \%(k=0,85)$ no diagnóstico da estenoses entre 70\%-99\%, mas apenas em $45 \%(k=0,26)$ nas estenoses menores que $70 \%$.

O consenso de 2003 e o Joint do Reino Unido preconizam a VPS $>230 \mathrm{~cm} / \mathrm{s}$ para a identificação das obstruções maiores que $70 \%$. AbuRahma e cols. ${ }^{2}$ validaram o consenso de 2003 em sua instituição e concluíram que os valores do consenso foram acurados para o diagnóstico das estenoses $\mathrm{ACl} \geq 70 \%$, porém sugerem que isoladamente a VPS $>230 \mathrm{~cm} / \mathrm{s}$ deveria ser usado para pacientes sintomáticos, enquanto, para os assintomáticos, a abordagem multiparamétrica (VPS > $230 \mathrm{~cm} / \mathrm{s}$; VDF > 

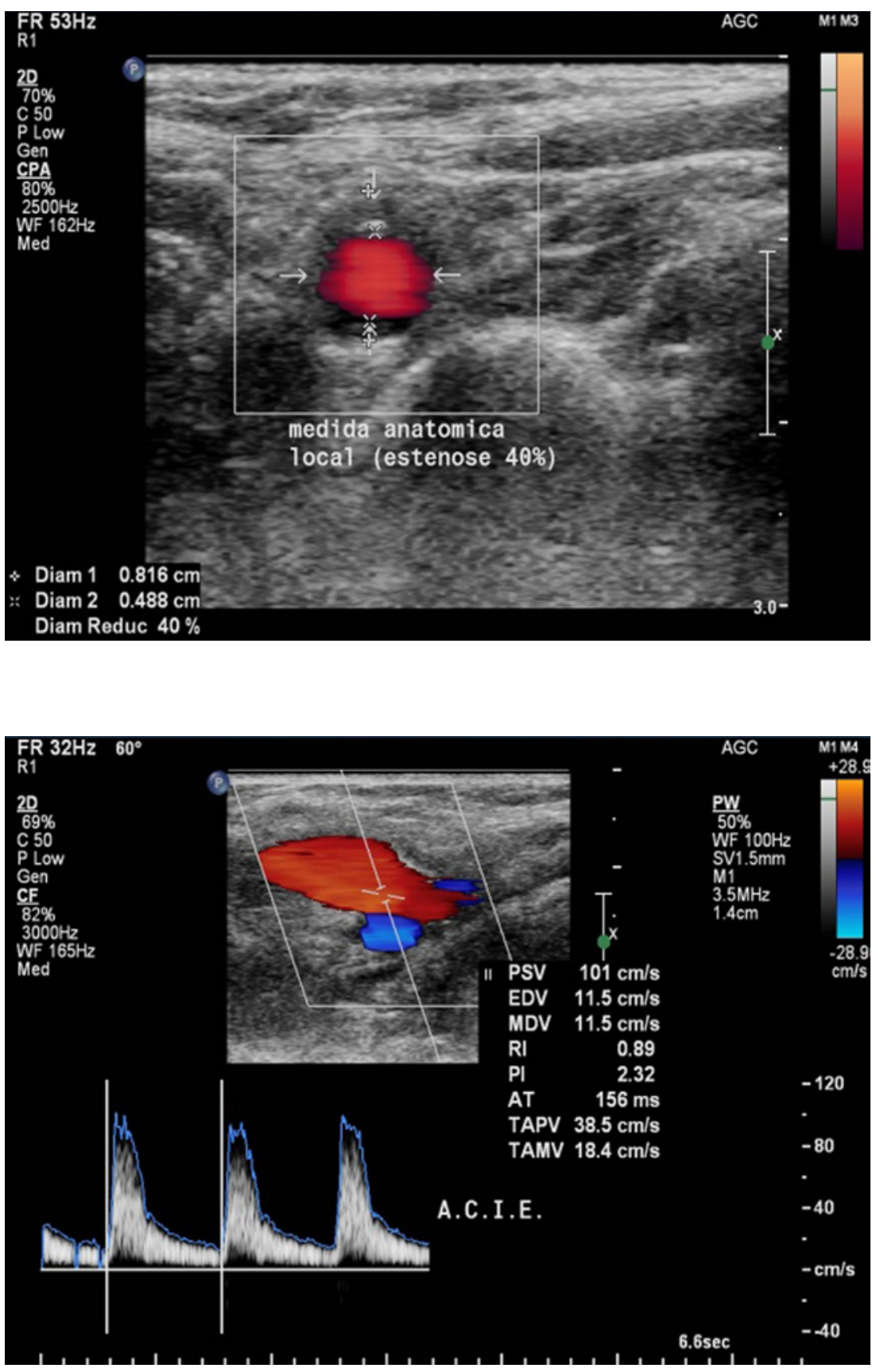

Figura 20 - Estenose < 50\% da artéria carótida interna (medida anatômica e avaliação do fluxo ao Doppler).

100 cm/s; razão VPS Cl/ VPS CC > 4) deve ser considerada, ou então uma VPS maior $(280 \mathrm{~cm} / \mathrm{s})$. Outros estudos também validaram o consenso de 2003 mostrando boa acurácia da VPS $>230 \mathrm{~cm} / \mathrm{s}$ para o diagnóstico das estenoses $\geq 70 \%{ }^{104,105}$.

Para o diagnóstico das estenoses entre 50\%-69\%, o consenso de 2003 e o Joint do Reino Unido preconizam a VPS entre $125-230 \mathrm{~cm} / \mathrm{s}$; no entanto, como vimos anteriormente, essa é uma categoria com critérios ainda não totalmente estabelecidos. Alguns autores encontraram um melhor desempenho da VPS maiores para o diagnóstico das estenoses $>50 \%$. AbuRahma e cols. ${ }^{2}$ mostraram uma melhor especificidade com a VPS $\geq 137 \mathrm{~cm} / \mathrm{s}$ do que com $125 \mathrm{~cm} / \mathrm{s}$ (91\% X 85\%), optando pela VPS de $140 \mathrm{~cm} / \mathrm{s}$ já utilizado em sua instituição. Valor semelhante foi encontrado em nosso meio por Petisco e cols. ${ }^{104}$, onde a VPS $\geq 141 \mathrm{~cm} / \mathrm{s}$ apresentou uma melhor especificidade que a VPS $\geq 125 \mathrm{~cm} / \mathrm{s}(90 \% X$ 83\%), porém com acurácia semelhante. 


\section{Artigo Especial}

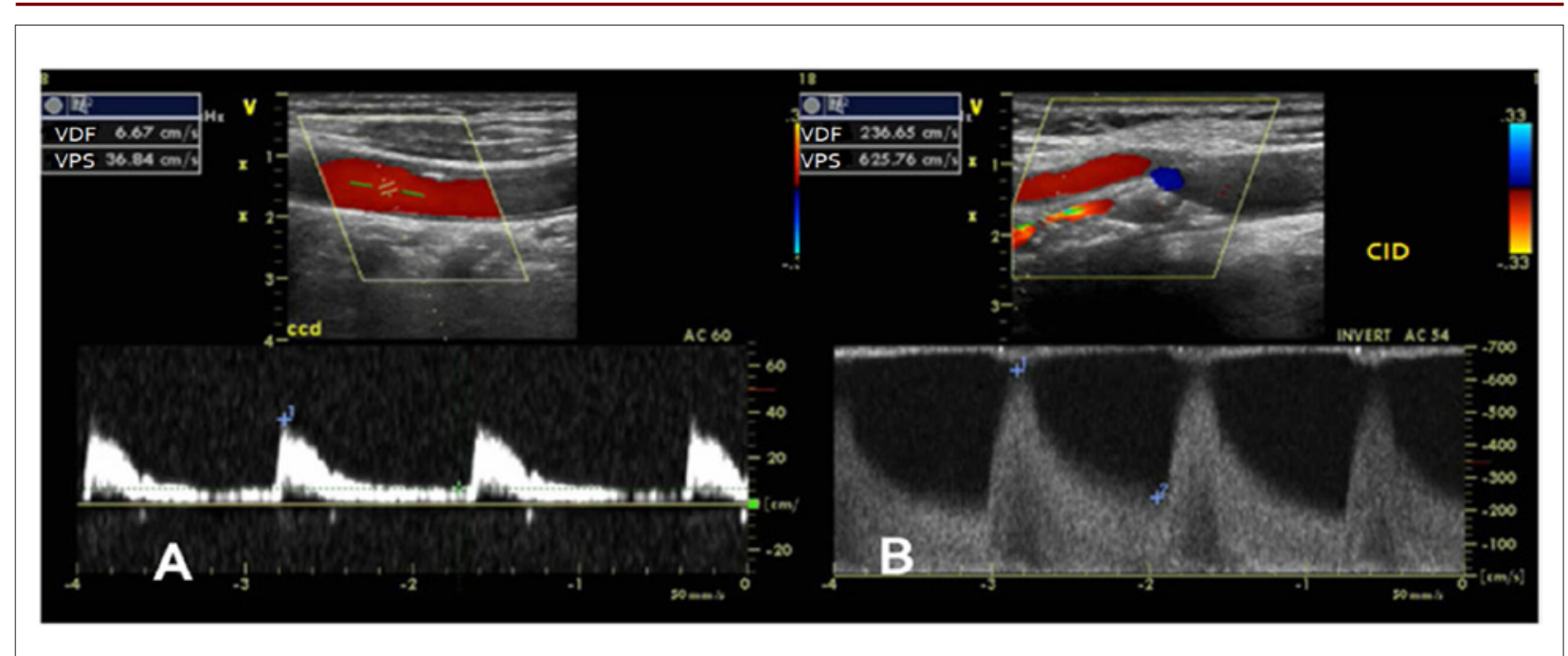

Figura 21 - Estenose > 90\% da artéria carótida interna. A- fluxo da artéria carótida comum; B- fluxo da artéria carótida interna.

Além da VPS, a associação da VDF pode ser útil no diagnóstico das obstruções maiores que $70 \%$ e $80 \%$. O consenso de 2003 sugere a VDF > $100 \mathrm{~cm} / \mathrm{s}$ como parâmetro adicional para a identificação das obstruções maiores que $70 \%$, assim como outros autores obtiveram boa especificidade utilizando esse parâmetro ${ }^{107,108}$. Para o diagnóstico das estenoses carotídeas maiores que $80 \%$, a VDF $>140 \mathrm{~cm} / \mathrm{s}$ é utilizada há anos pela Universidade de Washington e também se mostrou com especificidade maior que $90 \%$ em outros estudos ${ }^{104,109}$.

Além das velocidades absolutas as razões de velocidades são particularmente úteis, seja como adjuvantes na quantificação das estenoses, mas também em casos especiais, em que as velocidades podem estar alteradas por outras condições que podem subestimar ou superestimar o grau de estenose. As razões de velocidades utilizadas são: VPS ACl / VPS ACC, VPS ACl / VDF ACC e VDF ACl / VDF ACC. Dentre elas, a mais utilizada é a razão VPS ACI / VPS ACC que já foi avaliada por diversos estudos e é endossada tanto pelo Joint do Reino Unido, como pelo consenso americano de $2003^{3,118,119}$. A razão VPS ACl/ VDF ACC foi sugerida pelo Joint do Reino Unido (índice de St Mary's) com o intuito de subdividir as estenoses maiores que $50 \%$ em decis ${ }^{115}$. Esse é um parâmetro promissor, porém, até o momento, não foi muito estudado. Chua e cols. ${ }^{116}$ avaliaram as razões de velocidade e observaram 100\% de sensibilidade para a razão VPS ACI / VPS ACC e VPS ACI / VDF ACC para estenoses de 50\%, 60\% e 70\%, sendo os valores de corte para razão VPS ACI / VDF ACC, $\geq 3,5$, $\geq 10,3, \geq 10,3$, respectivamente, havendo sobreposição dos valores para $60 \%$ de $70 \%$. A razão VDF $\mathrm{ACl} / \mathrm{VDF}$ ACC também foi descrita por alguns autores, identificando estenoses maiores que $80 \%$ da $\mathrm{ACl}$ quando maior que $5,5^{106,116,117}$. Porém sua correlação com a arteriografia foi inferior à dos demais parâmetros (VPS, VDF e razão VPS $\mathrm{ACl}$ / VPS ACC) segundo os estudos de AbuRahma e cols. ${ }^{2}$ e Braun e cols. ${ }^{105}$, conforme já mostrado anteriormente.
A avaliação do fluxo pós-estenótico pode auxiliar na identificação da severidade da estenose, em situações como placas calcificadas. Quando há turbulência do fluxo pósestenótico, redução significativa da velocidade (VPS < 30 $\mathrm{cm} / \mathrm{s}$ ) e alargamento do tempo de aceleração suspeita-se que a estenose seja significativa ${ }^{95}$. Ressalta-se também a importância de comparar o fluxo pós-estenótico com o fluxo no vaso contralateral ${ }^{103}$.

c) Suboclusões e oclusões

O diagnóstico ultrassonográfico da suboclusão baseia-se na demonstração do estreitamento da luz do vaso ao color/ power Doppler, com fluxo filiforme (string sign ou trickle flow), porém pode estar associada a velocidades altas, baixas ou indetectáveis, o que eventualmente dificulta o diagnóstico. Segundo o consenso de 2003 para a diferenciação entre suboclusão e oclusão, recomenda-se não utilizar parâmetros de velocidade ao Doppler, mas sim a opinião do observador acerca das imagens. Como a suboclusão pode ser confundida com a oclusão, o Joint do Reino Unido e a AHA recomendam a complementação com outro método para definir: CTA, RNM, ou angiografia convencional ${ }^{118,119}$.

As oclusões carotídeas podem ser diagnosticadas pela ultrassonografia como a ausência de luz patente na escala de cinza e ausência de detecção de fluxo ao color/power Doppler e/ou Doppler espectral, assim como a presença de fluxo de alta resistência na ACC, e do fluxo "thud flow" - fluxo com velocidade muito reduzida e de altíssima resistência no ponto da oclusão ou pré-oclusão ${ }^{1,103}$ (Figuras 22 e 23).

$\mathrm{Na}$ presença de oclusão da $\mathrm{ACl}$ surgem mecanismos compensatórios, como o desenvolvimento de circulação colateral, com o intuito de prevenir a isquemia cerebral. A mais importante via de colateralização é pelo polígono de Willis.

Outra via colateral pode ser feita com fluxo anterógrado por ramos distais da ACE ipsilateral que se conectam com o ramo oftálmico da $\mathrm{ACl}$ ocluída, podendo então se detectar fluxo 

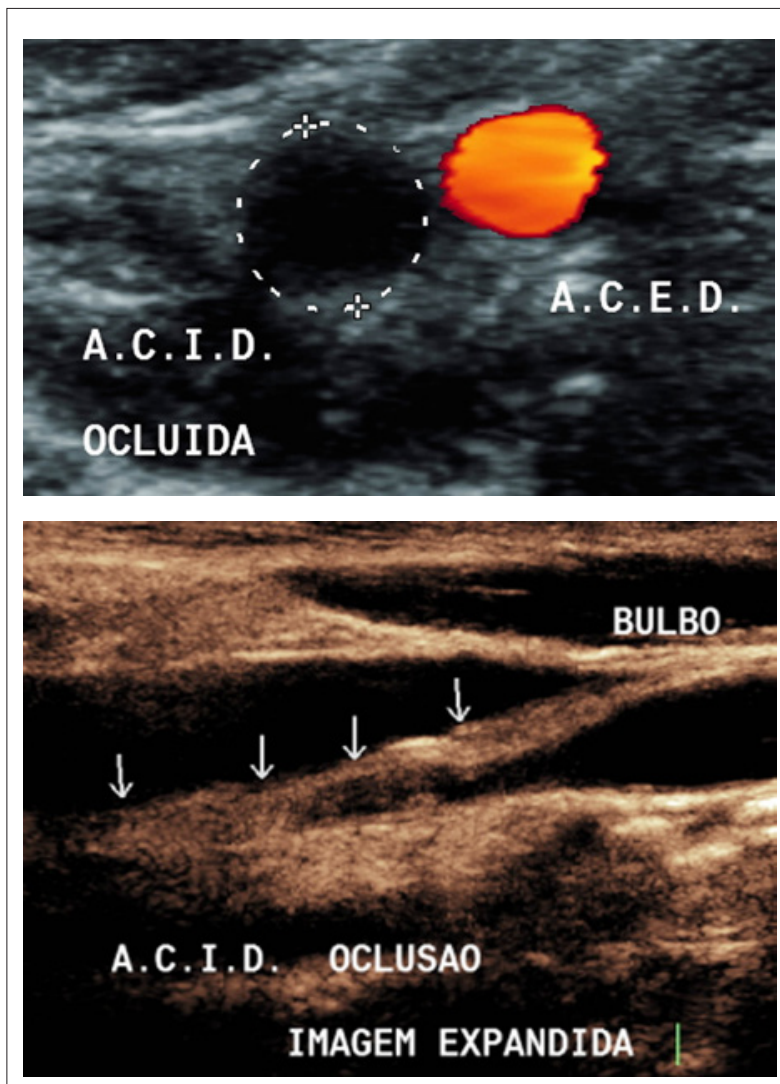

Figura 22 - Oclusão da artéria carótida interna.

retrógrado na artéria oftálmica ${ }^{120}$ (Figura 24). Porém, sabe-se que essa condição não está presente em todos os casos de oclusão da $\mathrm{ACl}$ em razão dos diferentes padrões da circulação retrobulbar ${ }^{121}$. Assim como se sabe que estenoses hemodinamicamente significativas (maiores que $70 \%$ e suboclusões) da $\mathrm{ACl}$ podem cursar com fluxo retrógrado da artéria oftálmica ${ }^{95}$.

Nos casos em que há oclusão da artéria carótida comum, a carótida interna pode encontrar-se pérvia, com fluxo anterógrado proveniente da artéria carótida externa (Figura 25).

- Estenose da artéria carótida comum e artéria carótida externa

A incidência isolada de estenose da ACC é baixa e pouco se sabe sobre a evolução dessa lesão. Suspeita-se que pacientes com estenose isolada da ACC apresentem mais sintomas hemisféricos, afasia e amaurose fugaz ${ }^{122,123}$.

Não há evidências de que as recomendações para a graduação da estenose da $\mathrm{ACl}$ devam ser aplicadas para classificar as lesões na ACC ou na ACE.

Alguns autores utilizam a VPS de $150 \mathrm{~cm} / \mathrm{s}$ para classificar a estenose como $>50 \%{ }^{122}$. Para esse mesmo grau de estenose, outros autores demonstraram que a VPS $>182 \mathrm{~cm} / \mathrm{s}$ apresentou uma sensibilidade de $64 \%$ e uma especificidade de $88 \%$ quando comparado com a angiotomografia ${ }^{124}$.
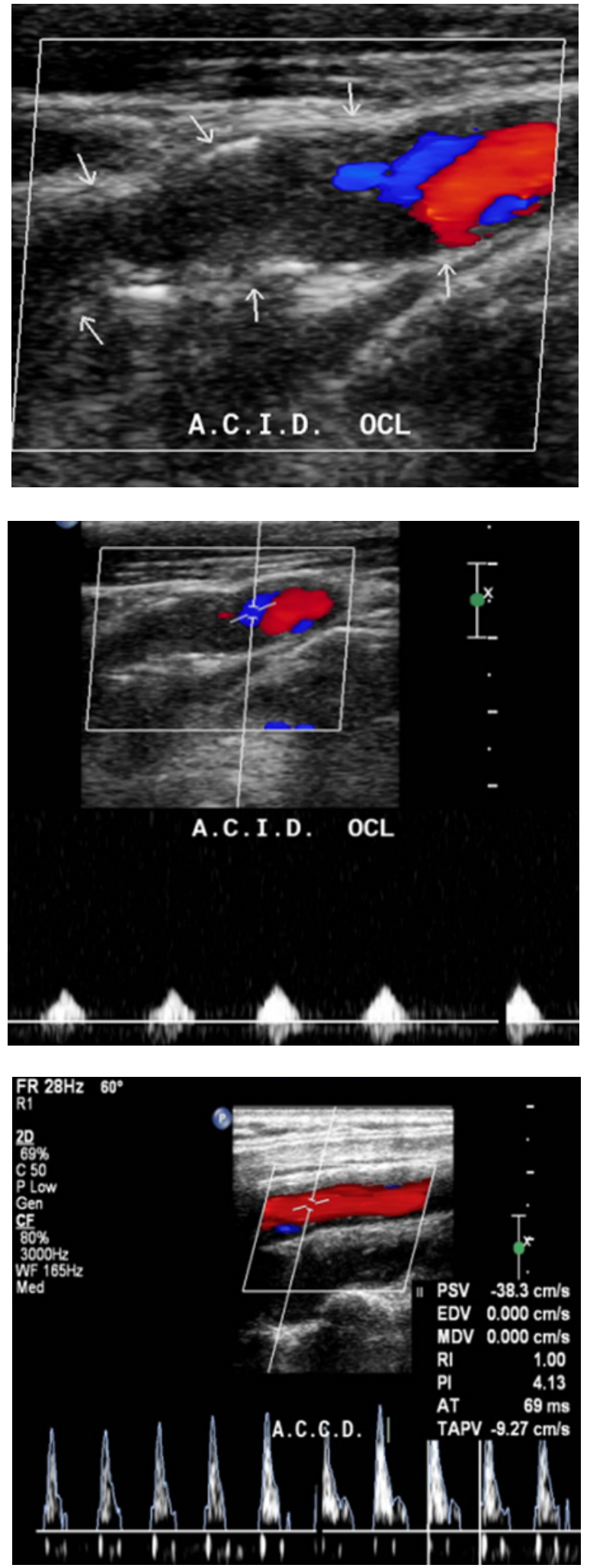

Figura 23 - Ausência de fluxo na carótida interna. Note o fluxo reverso (azul), batendo em fundo cego. Análise espectral com fluxo de alta resistência na ACC compatível com a oclusão distal. 


\section{Artigo Especial}

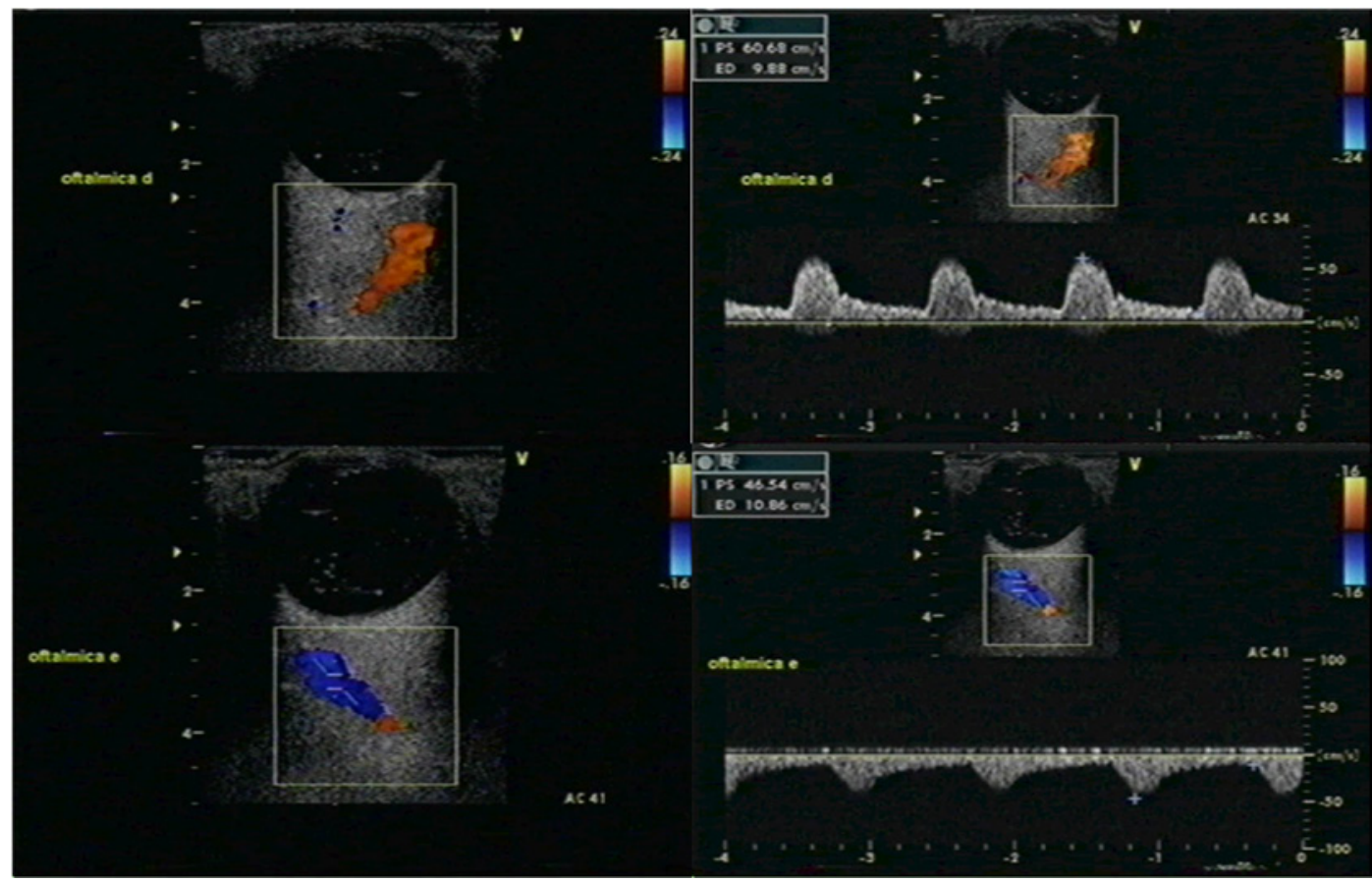

Figura 24 - Oclusão da carótida interna esquerda, com fluxo retrógrado na artéria oftálmica ipsilateral, contrasta com fluxo anterógrado na artéria oftálmica direita (contralateral).

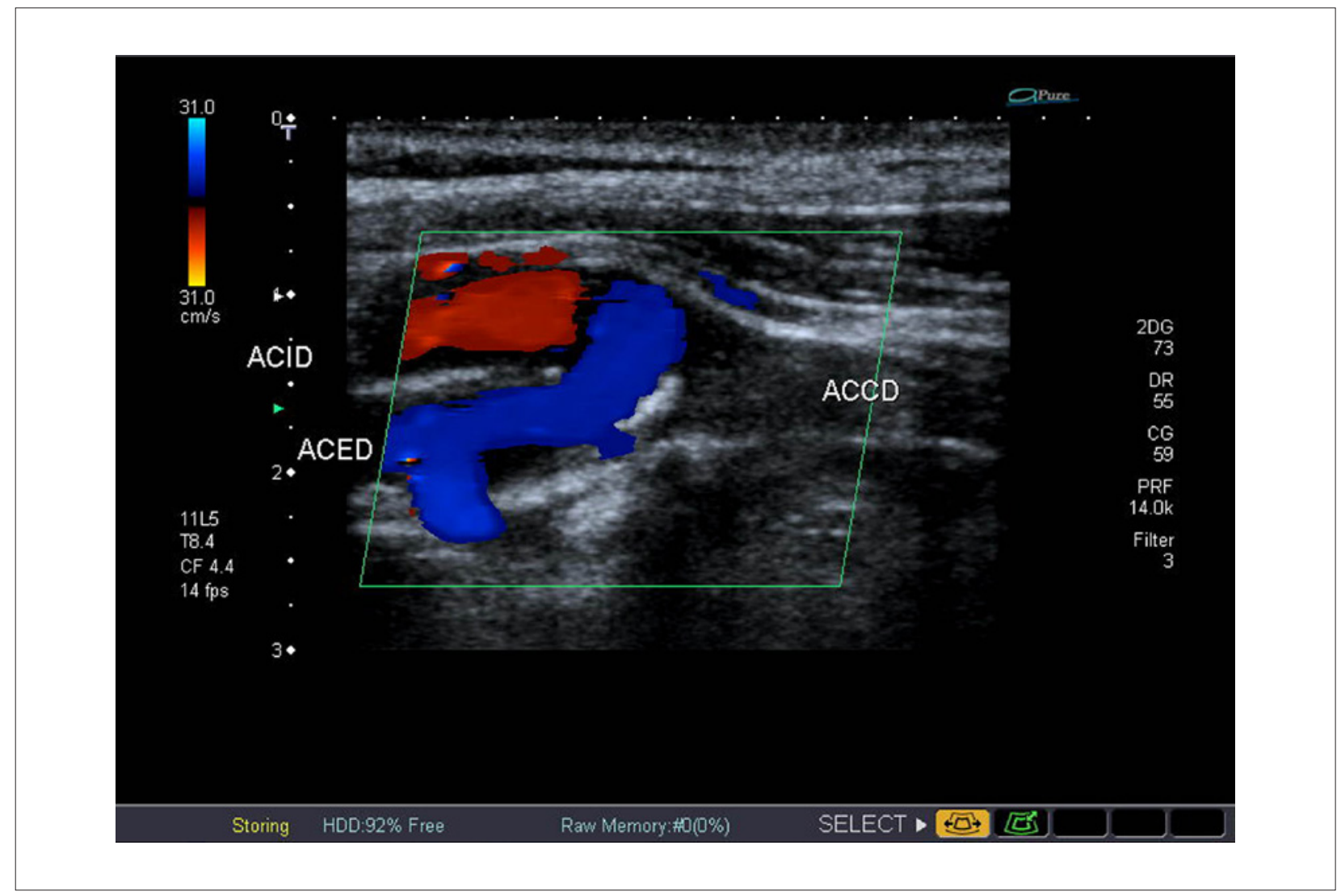

Figura 25 - Oclusão da artéria carótida comum, com artéria carótida interna pérvia, com fluxo proveniente da artéria carótida externa. 
Matos e cols. ${ }^{125}$ estudaram 21 pacientes com estenose isolada da carótida comum (sem lesões na $\mathrm{ACl}$ ipsilateral ou doença carotídea contralateral) e compararam o grau de estenose encontrado na angiografia com as medidas de velocidades registradas pelo Doppler pulsado. Eles demonstraram que a VPS $\geq 250 \mathrm{~cm} / \mathrm{s}$ obteve uma sensibilidade de $98,7 \%$ e $96,2 \%$ e uma especificidade de $95,7 \%$ e $100 \%$ para o diagnóstico de uma estenose angiográfica $>60 \%$ e $70 \%$ respectivamente. Em relação à VDF $\geq 60 \mathrm{~cm} / \mathrm{s}$ eles encontraram uma sensibilidade de $100 \%$ e $87 \%$ e uma especificidade de $98,7 \%$ e $95 \%$ para o diagnóstico de uma estenose angiográfica $>60 \%$ e $70 \%$, respectivamente. Os autores recomendam a validação de cada laboratório.

Além da orientação dos autores acima, sobre a necessidade de validação individual dos laboratórios, este grupo de trabalho reforça e recomenda a classificação da estenose tanto da $\mathrm{ACl}$ como da ACC utilizando não só as medidas de velocidades, mas também a análise da redução do lúmen pelo mapeamento em cores ou power Doppler do fluxo e pelo modo B (Figura 26).

Para avaliar a estenose da ACE, além da elevação da VPS, alguns autores consideram que a relação entre a VPS da carótida externa e da carótida comum maior do que 2,0 (duas vezes) geralmente se associa com estenose superior a $50 \%{ }^{126}$. Ascer e cols. ${ }^{127}$ encontraram associação entre VPS $<150 \mathrm{~cm} / \mathrm{s}$ com obstruções menores que $50 \%$ da ACE e VPS maiores que $250 \mathrm{~cm} / \mathrm{s}$ com obstruções maiores que $60 \%$.

\section{Tabela de valores para a graduação das estenoses}

O Quadro 7 traz uma sugestão de avaliação de velocidades na artéria carótida interna para nortear o examinador na quantificação das estenoses. Recomendamos que a priorização dos critérios seja a partir do mais bem estabelecido nos diversos estudos, a VPS.

\section{Condições que afetam as medidas de velocidade}

Algumas condições afetam as medidas da análise espectral. Elas podem estar localizadas na bifurcação carotídea, distal ou proximal a ela ou ainda na carótida contralateral. Dentre as condições proximais à bifurcação ressaltamos as valvopatias aórticas (estenose ou insuficiência), estenoses de origem aterosclerótica ou arterites com envolvimento do arco aórtico, ramos e carótida comum ${ }^{101,128,129}$ (Figura 27).

Devemos ter em mente que as alterações cardíacas geram efeitos sistêmicos, ou seja, as modificações encontradas nas ondas de fluxo das artérias carótidas estarão presentes bilateralmente, assim como acometem os demais leitos arteriais ${ }^{130}$.

Na presença de estenose aórtica importante há turbulência do fluxo, as velocidades podem estar reduzidas e, mesmo na presença de estenose carotídea significativa ao modo B, as velocidades absolutas podem não atingir os valores de velocidade preconizados para sua quantificação (Figuras 28 e 29). A presença de insuficiência aórtica importante, por sua vez, pode gerar um duplo pico sistólico chamado pulso bisferiens, ou ainda a ausência de fluxo diastólico ou fluxo diastólico reverso, em especial nas artérias carótidas comuns,

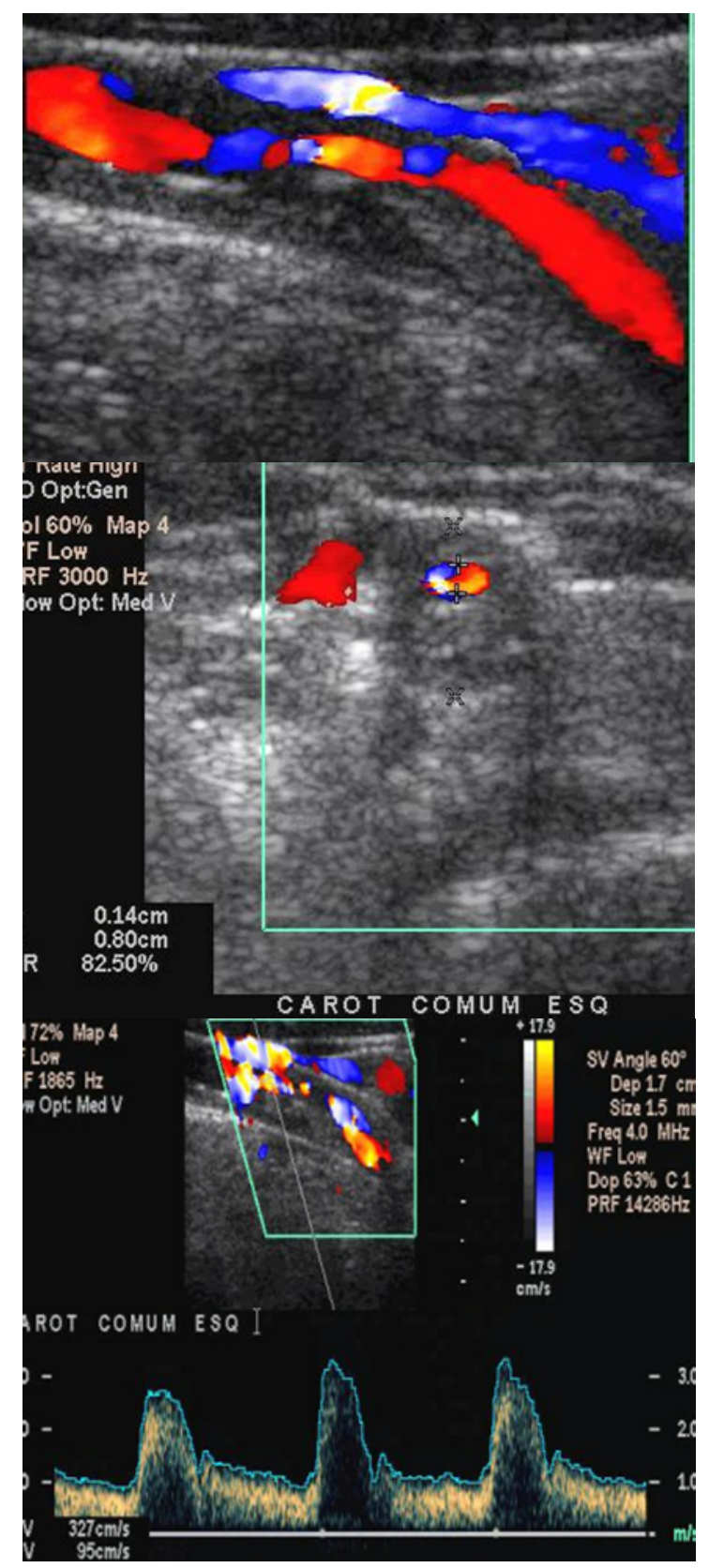

Figura 26 - Estenose da artéria carótida comum (medida anatômica e avaliação do fluxo ao Doppler).

podendo comprometer a avaliação das velocidades e relações, em especial as que envolvam a VDF3,129,130 (Figura 30).

Além das valvopatias, outras circunstâncias como a disfunção sistólica do ventrículo esquerdo de grau importante, as arritmias cardíacas, taquicardias e bradicardias podem alterar a onda fluxo no sistema arterial, incluindo as artérias carótidas, sem a presença de doença desses vasos (Figura 31). Na presença dessas condições a avaliação da VPS ou da VDF pode estar dificultada. A utilização das razões de velocidades, 


\section{Artigo Especial}

\section{Quadro 7 - Quantificação das estenoses carotídeas.}

\begin{tabular}{|c|c|c|c|c|c|}
\hline $\begin{array}{l}\text { \% Est Anat } \\
\text { Dist (Nascet) }\end{array}$ & VPS cm/s & VDF $\mathrm{cm} / \mathrm{s}$ & $\begin{array}{l}\text { VPS CI/ VPS } \\
\text { CC }\end{array}$ & $\begin{array}{l}\text { VPS Cl/ VDF } \\
\mathrm{CC}\end{array}$ & $\begin{array}{l}\text { VDF } \mathrm{Cl} / \text { VDF } \\
\mathrm{CC}\end{array}$ \\
\hline$<50 \%$ & $<140$ & $<40$ & $<2,0$ & $<8$ & $<2,6$ \\
\hline $50-59 \%$ & $140-230$ & $40-69$ & $2,0-3,1$ & $8-10$ & $2,6-5,5$ \\
\hline $60-69 \%$ & & $70-100$ & $3,2-4,0$ & $11-13$ & \\
\hline $70-79 \%$ & $>230$ & $>100$ & $>4,0$ & $14-21$ & \\
\hline $80-89 \%$ & & $>140$ & & $22-29$ & $>5,5$ \\
\hline$>90 \%$ & $>400$ & & $>5,0$ & $>30$ & \\
\hline Suboclusão & $\begin{array}{l}\text { Variável - } \\
\text { fluxo filiforme }\end{array}$ & $\begin{array}{l}\text { Variável - } \\
\text { fluxo filiforme }\end{array}$ & $\begin{array}{l}\text { Variável - } \\
\text { fluxo filiforme }\end{array}$ & $\begin{array}{l}\text { Variável - fluxo } \\
\text { filiforme }\end{array}$ & $\begin{array}{l}\text { Variável - fluxo } \\
\text { filiforme }\end{array}$ \\
\hline Oclusão & $\begin{array}{l}\text { Ausência de } \\
\text { fluxo }\end{array}$ & $\begin{array}{l}\text { Ausência de } \\
\text { fluxo }\end{array}$ & Não se aplica & Não se aplica & Não se aplica \\
\hline
\end{tabular}

As cores representam da esquerda para a direita, os critérios mais relevantes segundo a literatura.

Legenda: Est: estenose; Anat: anatômica; Dist: distal; VPS: velocidade de pico sistólico; VDF: velocidade diastólica final; CC: carótida comum; Cl: carótida interna.

assim como a avaliação ao modo B ajudam na definição diagnóstica na presença de estenose. É fundamental que haja alteração anatômica na artéria carótida, como a visualização da placa, que seja condizente com a avaliação do fluxo ${ }^{130}$.

As tortuosidades representam 25\% a 50\% dos achados de exame. Embora não haja confirmação da correlação com a presença de aterosclerose, a angulação do vaso gera aumento de velocidades independentes de estenose ou doença aterosclerótica ${ }^{131}$.

A oclusão da carótida interna na bifurcação pode transformar a onda da carótida externa em uma onda com velocidade diastólica alta (típica de artéria que irriga região com baixa resistência periférica) também chamada de "internalização" da onda de velocidade do fluxo. Na carótida interna haverá ausência de fluxo na análise espectral e ausência de sinal no modo cor, e na carótida comum encontraremos um fluxo de alta resistência compatível com a oclusão distal. Dentre as condições distais à bifurcação carotídea, a oclusão intracraniana do ramo interno gera um fluxo reverso no início da diástole na carótida interna extracraniana ${ }^{101}$.

Condição comum de superestimação da estenose carotídea é a presença de oclusão ou estenose crítica na carótida contralateral, visto que aumentos de velocidades compensatórios induzem a erros na hora de graduar a lesão estenótica. Recomenda-se a valorização dos parâmetros como medida de redução do lúmen pelo modo B e mapeamento colorido, bem como uma reavaliação após o tratamento da carótida acometida ${ }^{132}$.

\section{Avaliação das estenoses carotídeas por critérios anatômicos}

A ultrassonografia vascular (USV) é capaz de avaliar estenoses carotídeas de forma reprodutível e inócua, tanto pelo critério de velocidades, quanto pela quantificação da estenose feita pela medidas dos diâmetros residuais, preferencialmente pelo corte transverso.

Os que advogam que a quantificação seja feita por critérios anatômicos, se baseiam nas seguintes premissas ${ }^{133}$ :

- o critério de velocidades não permite discriminar faixas mais estreitas de estenoses, devido à sobreposição ("overlap") de velocidades que ocorre entre as diversas faixas (Figura 32);

- há grande variação das medidas de velocidades entre os equipamentos, provocando discrepâncias inaceitáveis no resultado;

- a correção do ângulo provoca grande variação interobservador;

- houve significativa melhora na qualidade de imagem bidimensional nos últimos anos.

Entre os participantes desse painel houve consenso de que o critério fundamental para quantificação das estenoses carotídeas é o hemodinâmico. O critério anatômico deve ser usado para caracterizar as estenoses inferiores a 50\% (sem repercussão hemodinâmica). Nesses casos deve-se informar o resultado da faixa de estenose carotídea em intervalos de $10 \%$, que foram previamente categorizadas pelo critério de velocidade. O mesmo deve ser feito em alguns casos especiais, que serão discutidos posteriormente neste tópico, 


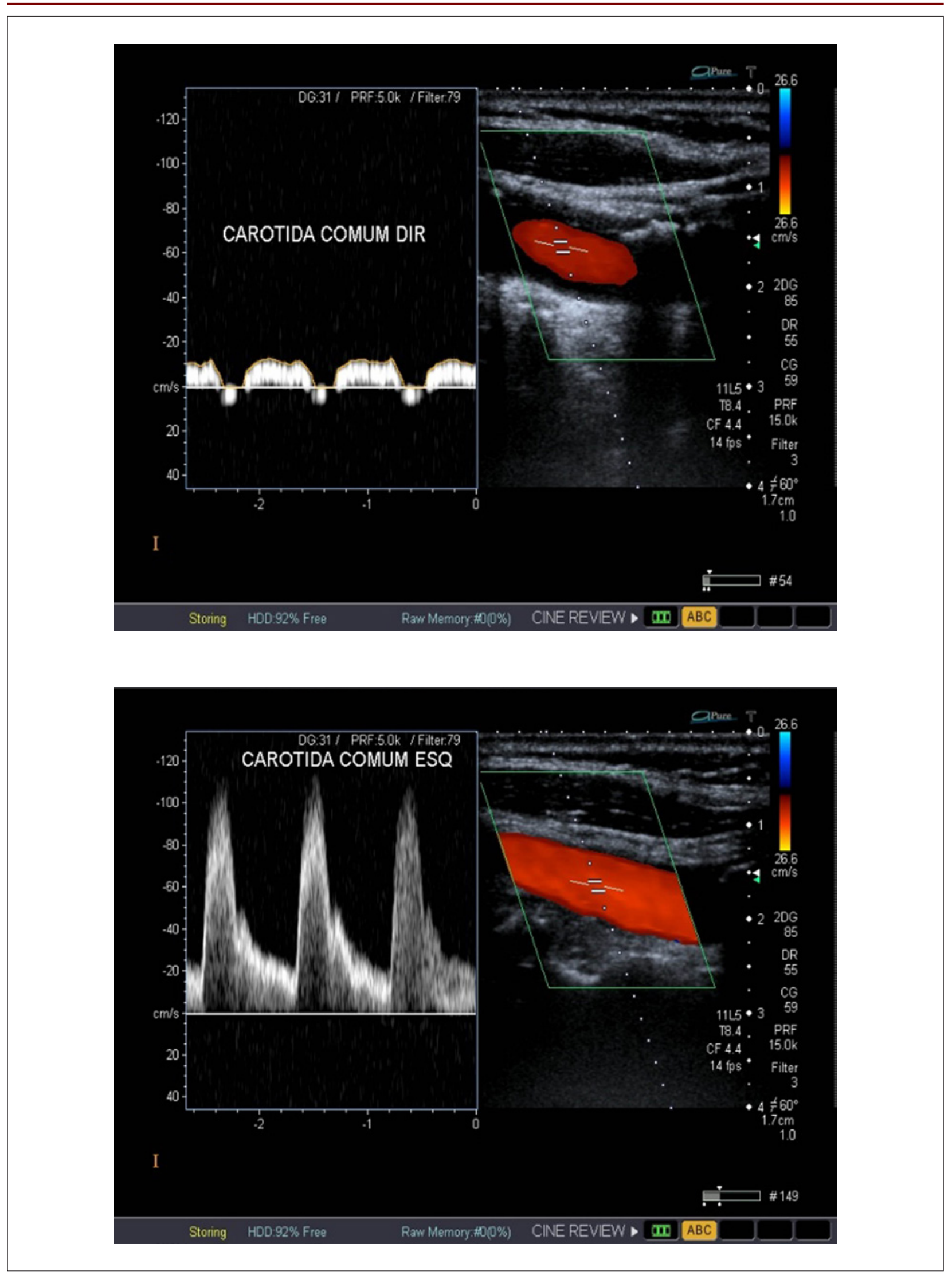

Figura 27 - Oclusão do tronco braquiocefálico - diferença de fluxo entre as carótidas comuns direita e esquerda. 


\section{Artigo Especial}

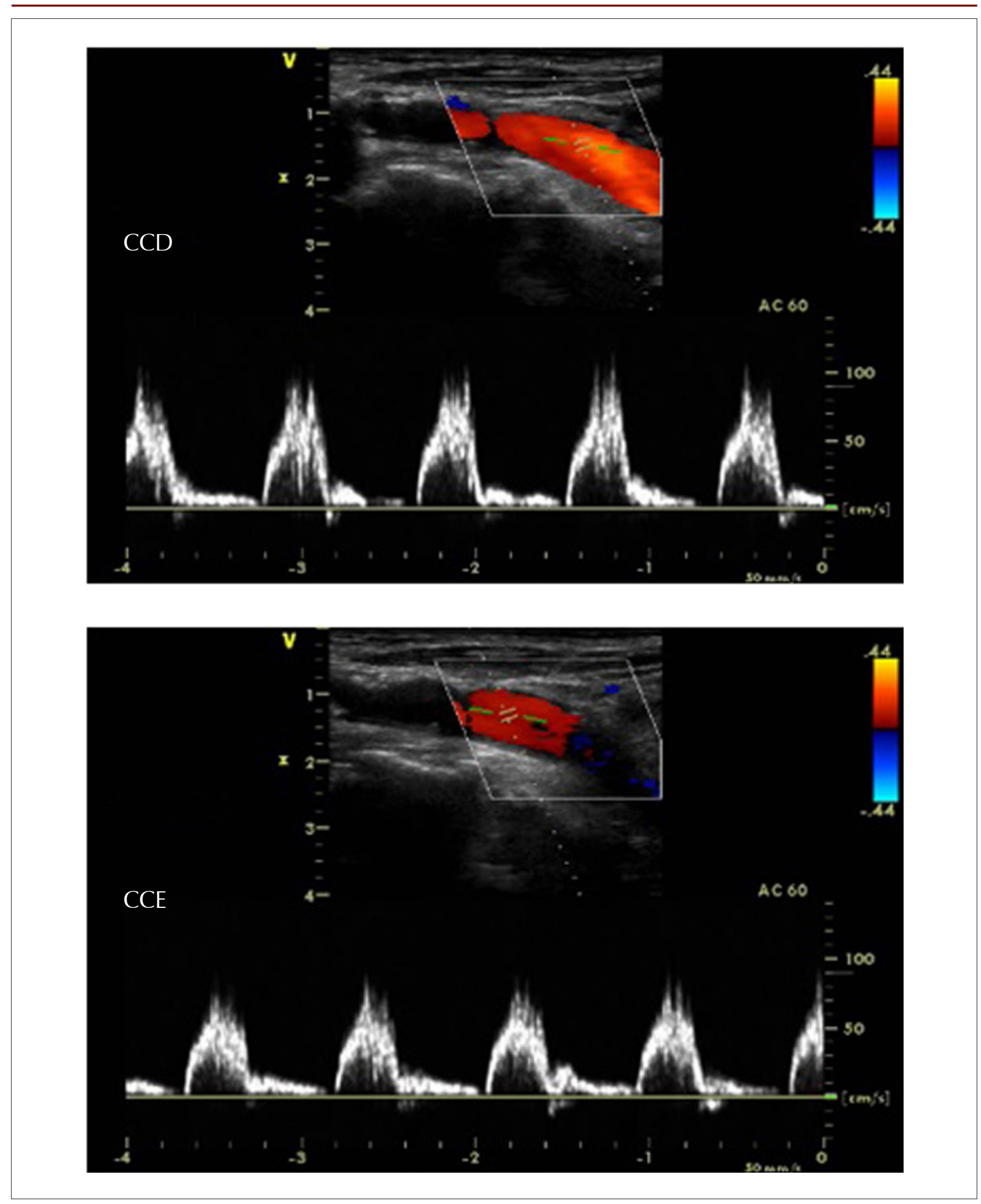

Figura 28 - Fluxo nas artérias carótidas comuns em paciente com estenose valvar aórtica importante. 


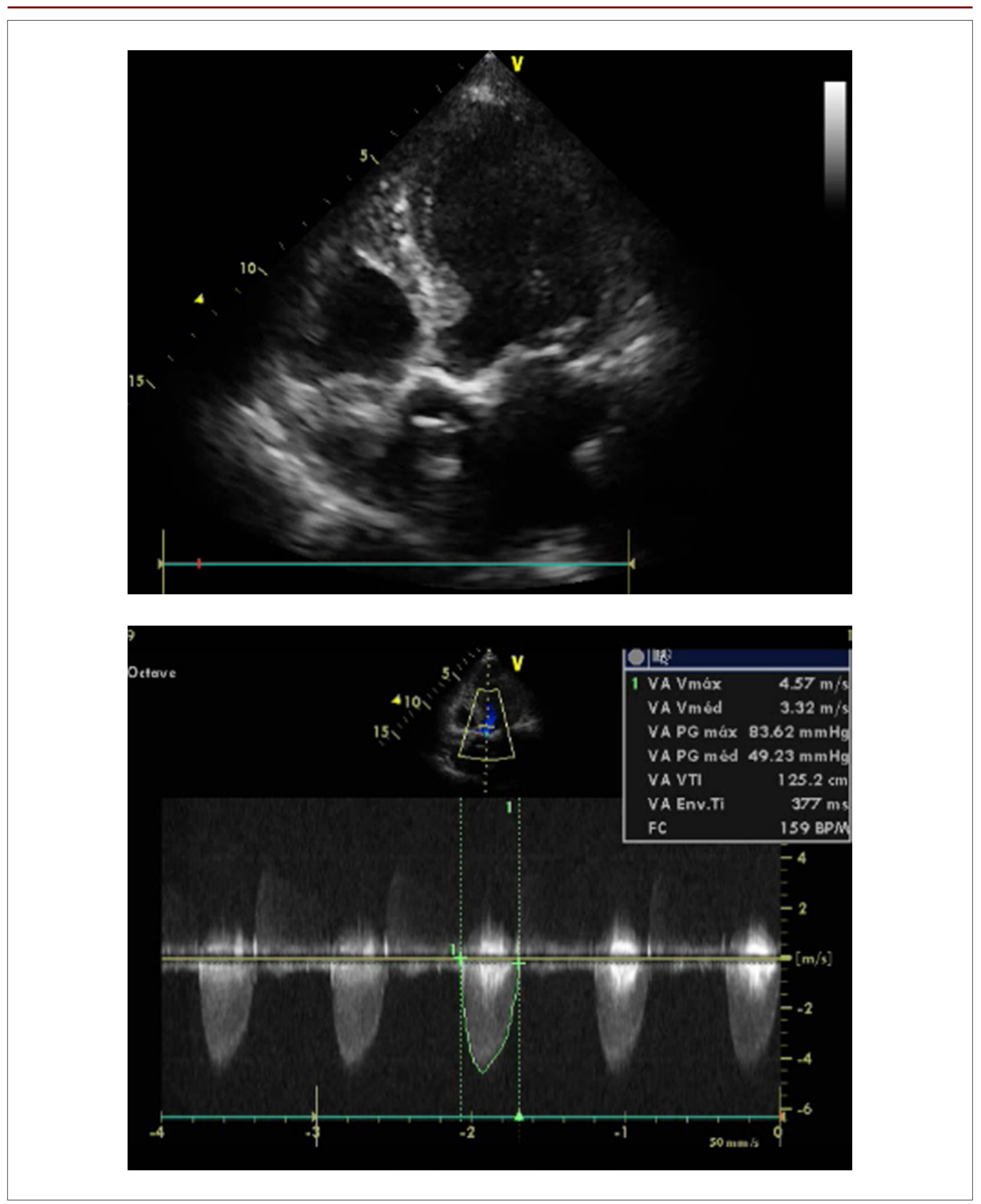

Figura 29 - EcoDopplercardiograma do mesmo paciente, demonstra o acometimento da valva aórtica e a Vmáx $=4,57 \mathrm{~m} / \mathrm{s}$. 
Freire e cols.

Recomendação para a Quantificação pelo Ultrassom da Doença Aterosclerótica

\section{Artigo Especial}

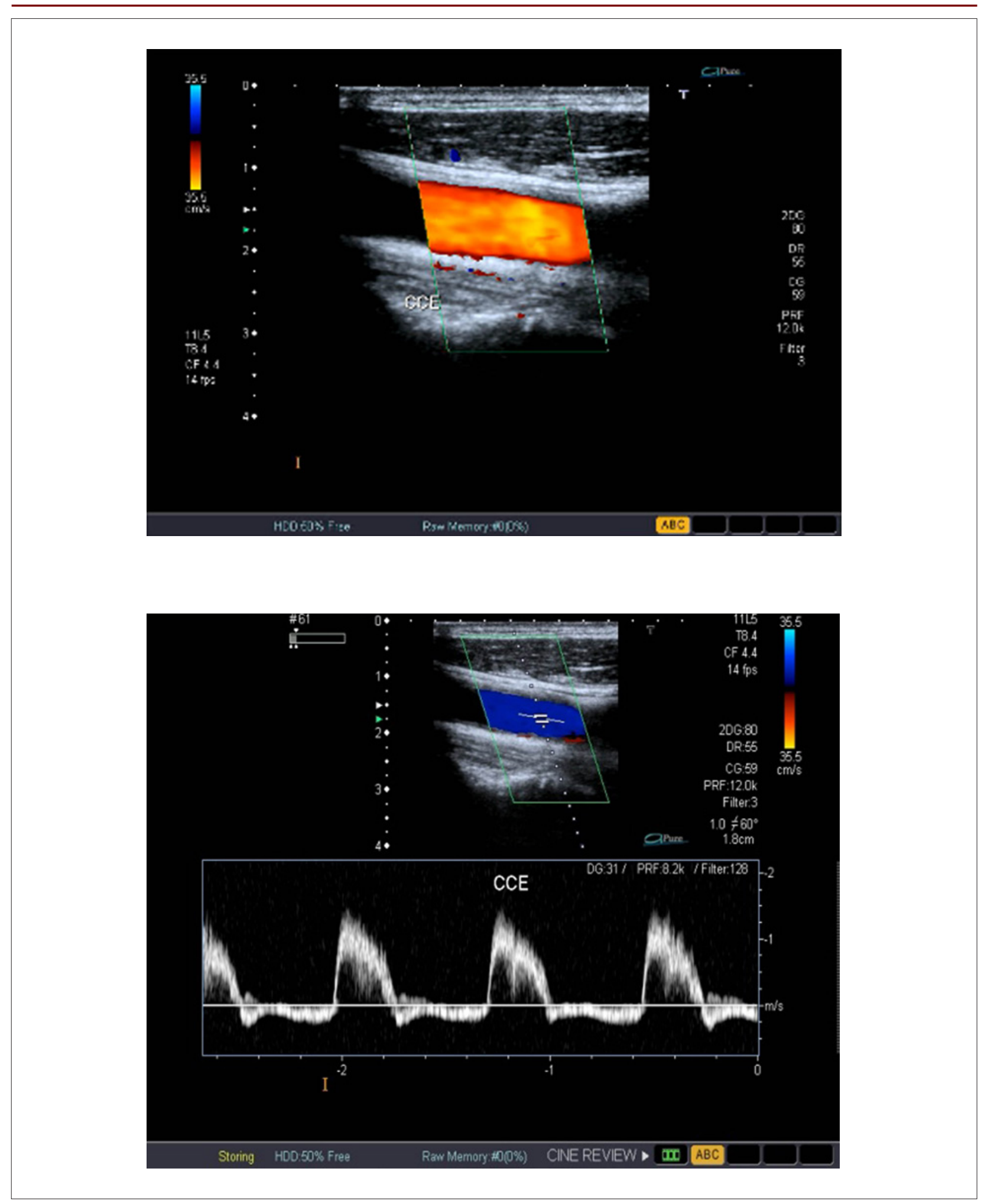

Figura 30 - Carótida comum com fluxo reverso diastólico em paciente com insuficiência aórtica importante. 


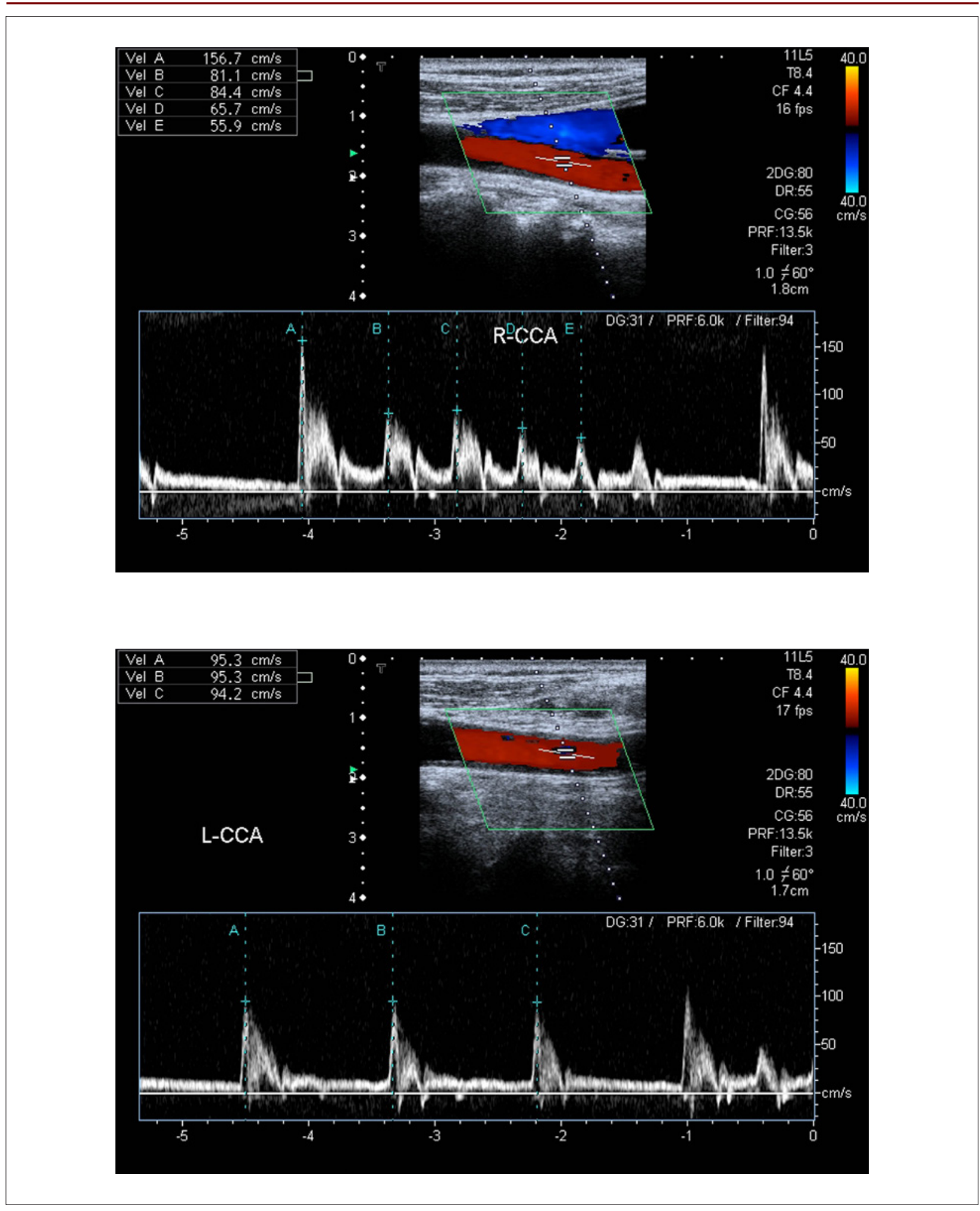

Figura 31 - Paciente com fibrilação atrial. A- Variação das velocidades; B- Períodos mais regulares, podem ser usados para avaliação das velocidades. 
onde haja distorção dos achados velocimétricos em virtude de fatores específicos.

Algumas considerações históricas devem ser abordadas para compreensão das posições desta comissão. De acordo com as correntes diretrizes, a indicação do tratamento cirúrgico das estenoses de carótidas baseiam-se na presença ou ausência de sintomas clínicos e no grau de estenose do vaso $^{84}$. Por décadas, a angiografia com contraste foi usada como padrão de referência para a quantificação das estenoses carotídeas. A arteriografia fornece um luminograma, demonstrando características como diminuição da luz, dilatação do vaso ou irregularidades e ulcerações das placas ateroscleróticas, mas não é capaz de demostrar as características das paredes arteriais ou alterações fisiológicas como velocidade e direção do fluxo sangüíneo.

Por ter abordagem através dos planos de incidência do raio $X$, a quantificação do grau de estenose é sempre feita por percentual de redução do diâmetro da luz do vaso, e nunca por redução da área. Uma redução de 50\% do diâmetro do vaso corresponde a uma redução de $75 \%$ da área do vaso (Tabela 4).

Apesar de a medida da área abordar de forma mais completa a luz residual, principalmente nos casos em que a luz é irregular (com diâmetros diferentes entre si), não recomendamos a medida da área, e sim do diâmetro residual, pois a arteriografia mede apenas o diâmetro (Figura 33).

Um dos grandes embates criados na comparação entre a USV e a arteriografia se deve ao fato de que ambos podem avaliar a luz residual e o grau de estenose carotídea, mas de formas completamente diferentes. A USV é capaz de medir de forma mais acurada, na maioria dos casos, a estenose local, pelo corte transverso, medindo os diâmetros da adventícia à adventícia e do lúmen residual. A arteriografia é capaz de medir a luz residual do vaso, não conseguindo avaliar as paredes, de forma longitudinal, medindo os diâmetros da estenose e da luz anatômica distal. Isso é reproduzido pela angiotomografia e pela angioressonância, que ganharam por isso grande confiabilidade por parte dos cirurgiões vasculares.

Os principais estudos que estabeleceram o ponto de corte em que o paciente se beneficiaria com uma abordagem terapêutica intervencionista (NASCET, ACAS e ECST) $84,133,134$ usaram a arteriografia para quantificar as estenoses nas populações estudadas; portanto, qualquer medida realizada com o ultrassom deve procurar se aproximar das medidas angiográficas utilizadas nestes estudos.

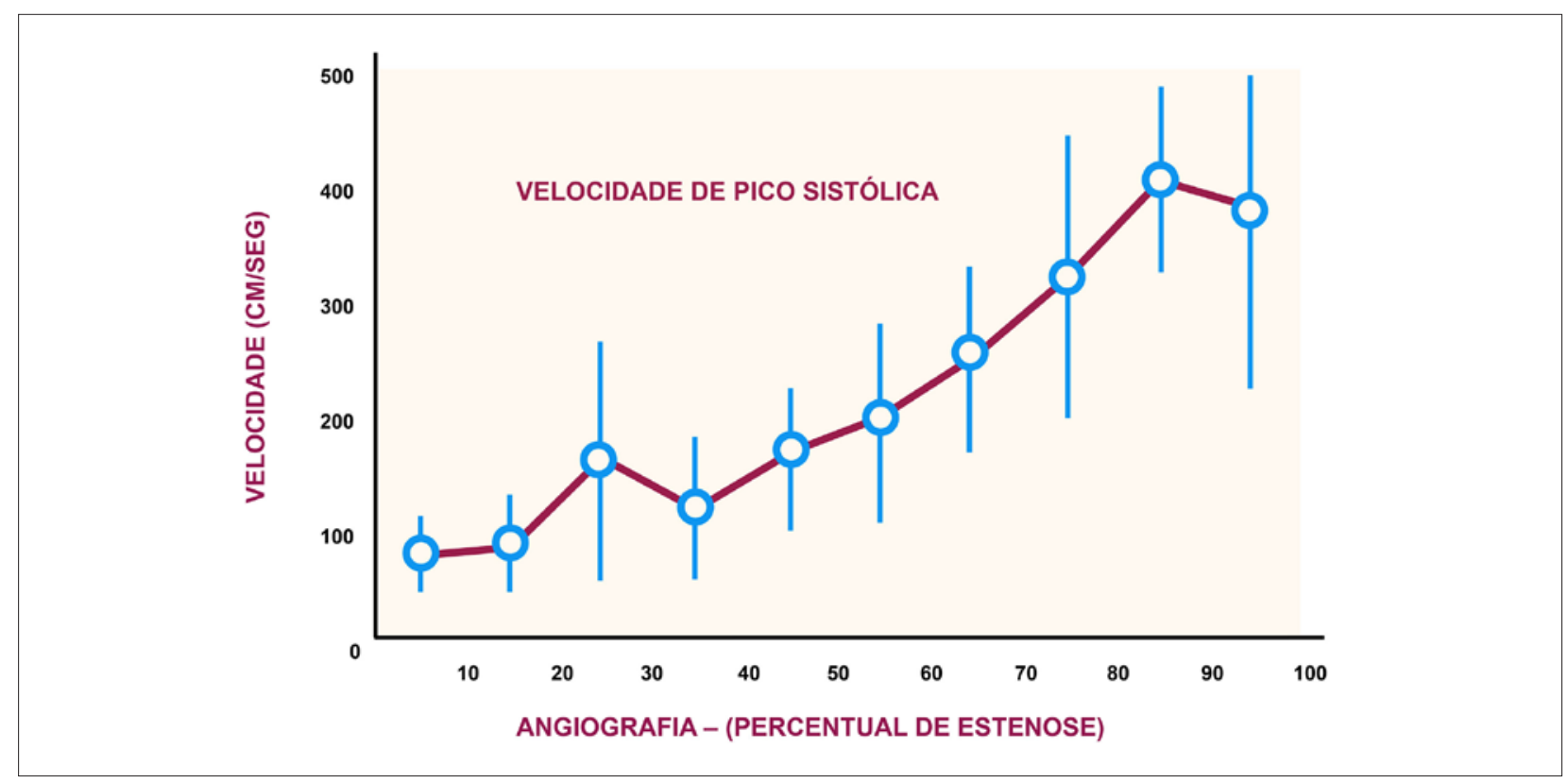

Figura 32 - Sobreposição das velocidades nas faixas adjacentes da quantificação da estenose por critérios Dopplerfluxométricos; não permitindo que faixas de estenose mais baixas (1\%-50\%) sejam usadas para definição do grau de estenose.

Tabela 4 - Correspondência entre a porcentagem das estenoses medidas por diâmetro e área

\begin{tabular}{lccccccc}
\hline Diâmetro \% & Área \% & Diâmetro \% & Área \% & Diâmetro \% & Área \% & Diâmetro \% & Área \% \\
\hline 0 & 0 & 50 & 75 & 30 & 51 & 80 & 96 \\
10 & 19 & 60 & 84 & 40 & 64 & 90 & 99 \\
20 & 36 & 70 & 91 & 50 & 75 & 100 & 100 \\
\hline
\end{tabular}



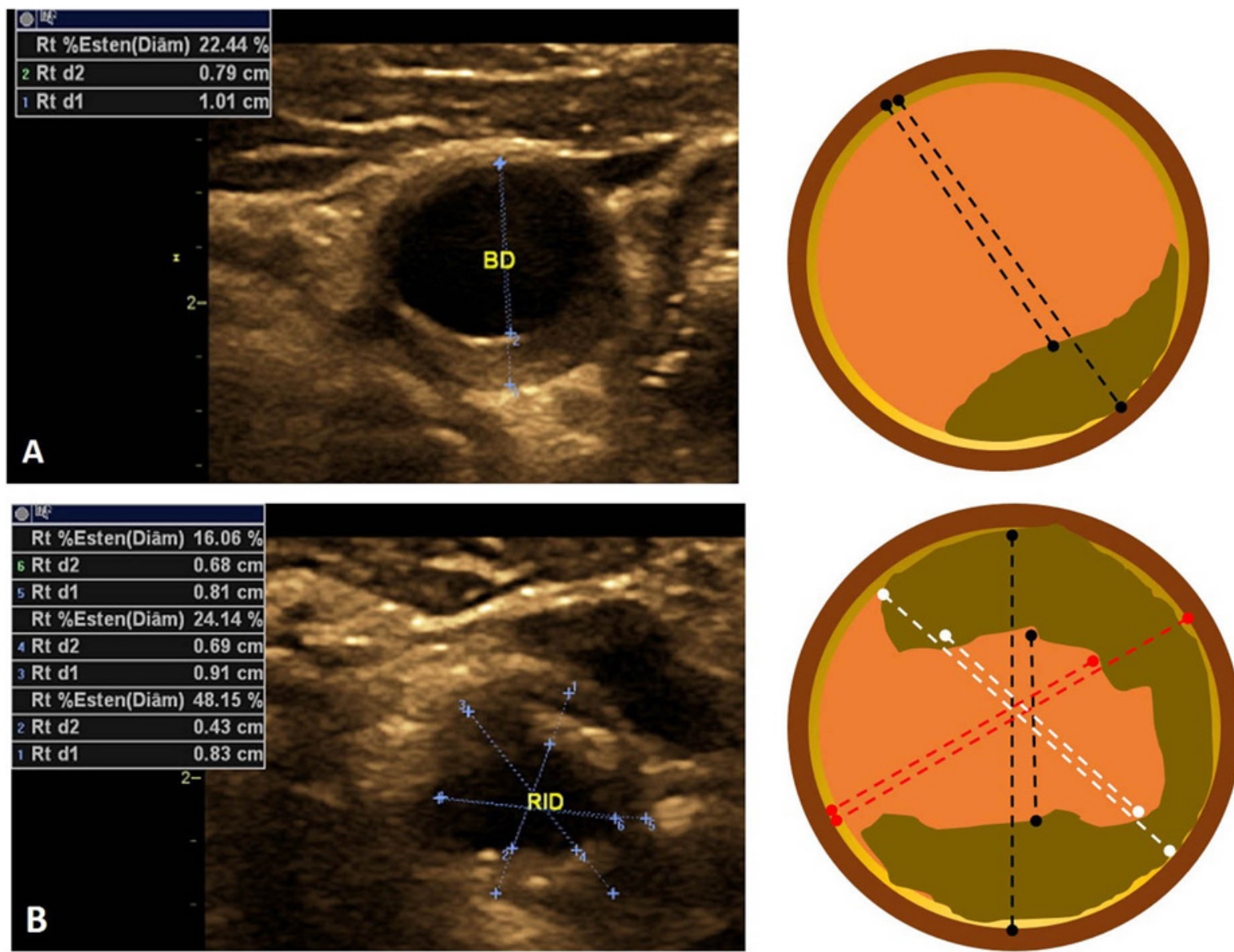

Figura 33 - Placas ateromatosas de carótidas. A- Luz regular e de fácil mensuração por haver coincidência entre as medidas nos diversos eixos; B- Luz irregular, com diferentes medidas nos diversos eixos.

Para minimizar o efeito dos lúmens residuais irregulares, com diâmetros muito diferentes, dependendo do eixo em que se corta a placa, recomendamos que a medida do diâmetro seja feita em três diferentes eixos (medida triaxial do diâmetro), representando-se a média das três medidas (Figura 34).

Para a abordagem correta dos diâmetros externos da carótida, bem como da luz residual, deve-se preferencialmente utilizar o corte transversal, pois em cortes longitudinais não temos a percepção se o nível em que o feixe de ultrassom está cortando a placa corresponde ao menor diâmetro da luz residual. Isso fica fácil de compreender quando analisamos o esquema abaixo, lembrando que o efeito dos erros da realização da medida bidimensional, realizado pelo corte longitudinal, fica minimizado quando a estenose é muito grave.

A medida do diâmetro externo do vaso deve ser feita de adventícia à adventícia. Para medida do diâmetro da luz residual utilizamos as interfaces placa/sangue e sangue/placa, tomando-se a média de três medidas, em eixos diferentes quando o orifício da luz residual excessivamente irregular. Para facilitar a identificação da interface sangue/placa, recomenda-se a utilização do B-flow ou Doppler de potência (angiodoppler).

Uma questão importante foi levantada durante a plenária: se devemos ou não incluir a íntima na medida do diâmetro da luz residual. Nos casos de estenoses menores em pacientes com a íntima muito espessada, a inclusão dessa pode gerar uma diferença de até $15 \%$ na estimativa da estenose em relação à medida na interface íntima luz. Para que não haja discrepância entre quantificações de estenoses pequenas, e sem importância clínica, foi decidido que não há necessidade de realizar medidas anatômicas em estenoses que diminuam menos de $20 \%$ do diâmetro do vaso (e assim optamos por recomendar a medida na interface sangue/parede ou sangue/placa) (Figura 35).

\section{Critério anatômico local versus critério anatômico distal}

Desde 1991, a decisão de tratar um paciente com doença carotídea sintomática tem sido largamente guiada pelos resultados dos estudos North American Syntomatic Carotid Endarterectomy Trial (NASCET) ${ }^{133}$ e pelo o European Carotid Surgery Trail (ECST) ${ }^{134}$. Ambos os estudos usaram a angiografia 


\section{Artigo Especial}

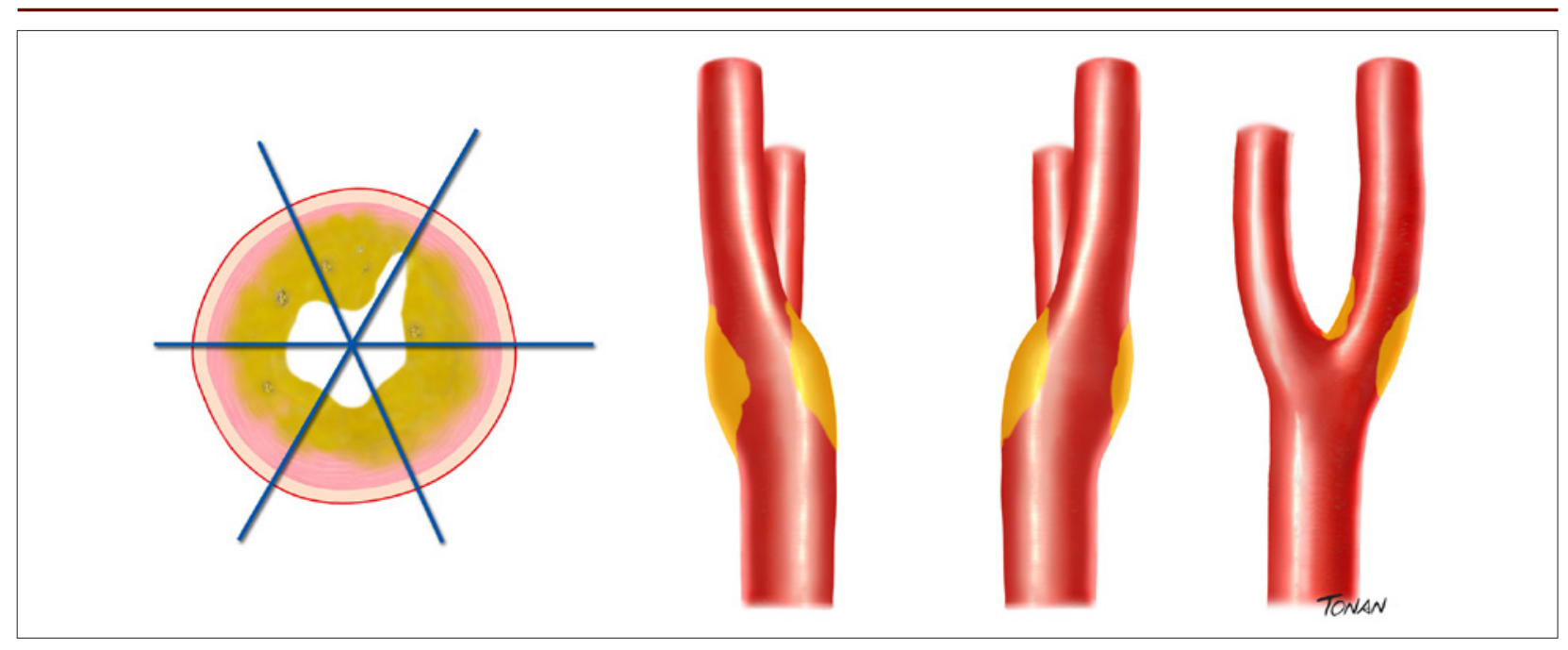

Figura 34 - Representação gráfica do corte triaxial de uma placa carotídea com lúmen irregular.

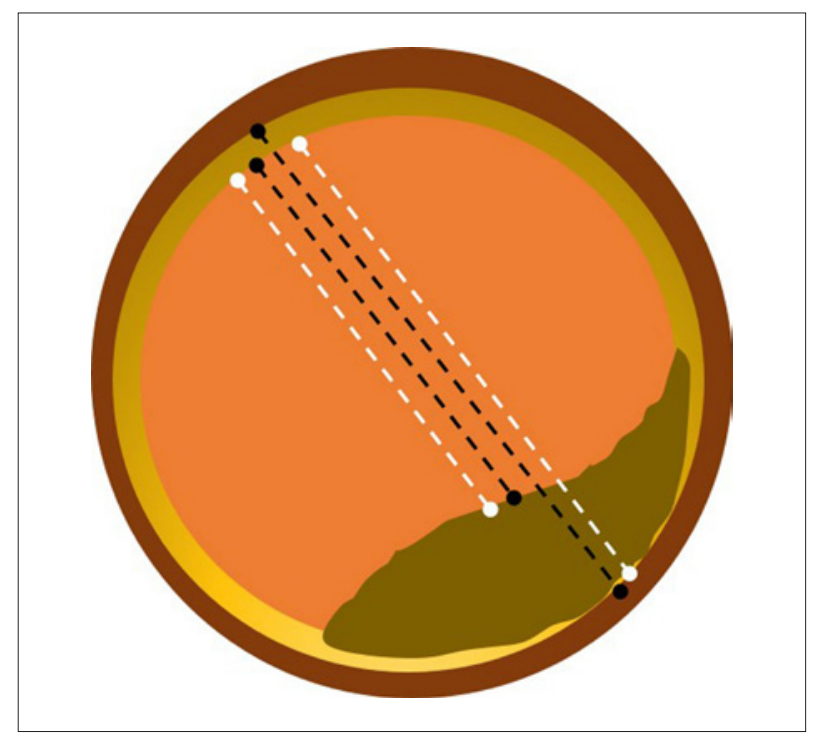

Figura 35 - Representação esquemática das possiveis diferenças de redução do diâmetro quando se inclui a intima espessada ou quando se deixa de incluí-la. Para evitar-se esse tipo de discrepância, recomendamos não medir as placas inferiores a $20 \%$ de redução do diâmetro, já que elas não apresentam significado hemodinâmico.

como modalidade de imagem para determinar o grau de estenose a partir do qual os pacientes apresentariam benefícios com a endarterectomia.

Esses estudos usaram métodos angiográficos diferentes. O estudo NASCET ${ }^{133}$ usou o critério anatômico distal, em que a medida da luz residual no local da estenose é comparada com a medida do diâmetro interno da porção distal da carótida onde o calibre se torna regular. O estudo europeu (ECST) ${ }^{134}$ utilizou o método angiográfico local para quantificação da estenose, em que o menor diâmetro da luz residual é comparado com o diâmetro do vaso no local da lesão (Figura 36A).
Essas medidas não se equivalem, exceto nos graus mais avançados de estenoses. Como as estenoses mais frequentemente estão localizadas na porção dilatada da carótida (bulbo), a estimativa da estenose pelo critério anatômico local normalmente fornece valores mais altos que o dado pelo critério anatômico distal (exemplo: uma estenose estimada em $70 \%$ pelo critério local, corresponde a uma estenose de $50 \%$ pelo critério distal). Essa diferença leva a importantes erros de quantificação das estenoses carotídeas, principalmente quando não se especifica o método que foi utilizado para realização das medidas.

Para que haja equivalência entre essas duas medidas é necessário que se realize a conversão angiográfica. Usando métodos de analise de regressão, Rothwell e cols. ${ }^{135}$ acharam que a relação entre os valores do ECST e do NASCET correspondem a ECST $\%=0,6$ NASCET $\%+40$ (Figura 36B) (Tabela 5).

Analisando-se a imagem angiográfica abaixo (Figura 37A), torna-se mais fácil entender a razão de o método angiográfico mais difundido ser o de medida distal do diâmetro (NASCET). No luminograma oferecido pela angiografia, torna-se difícil a determinação das bordas das paredes para a realização da medida anatômica local. Por esse motivo o critério anatômico local é menos confiável para a quantificação das estenoses pela arteriografia.

Em relação ao ultrassom, analisando-se a imagem acima (Figura 37B), é notório que a avaliação da estenose pelo critério anatômico local é mais fácil de ser realizada do que pelo critério anatômico distal, pois com a USV, além do luminograma fornecido pelo mapeamento em cores, temos a imagem bidimensional que nos dá a exata noção dos limites da parede externa do vaso, no local da placa. Para a realização da medida do grau de estenose pelo critério anatômico distal, como utilizada no estudo NASCET (método angiográfico mais amplamente utilizado) é necessária a medida do diâmetro em um segmento mais distal do ramo interno, localizado profundamente em uma região em que as paredes das carótidas já não se situam 

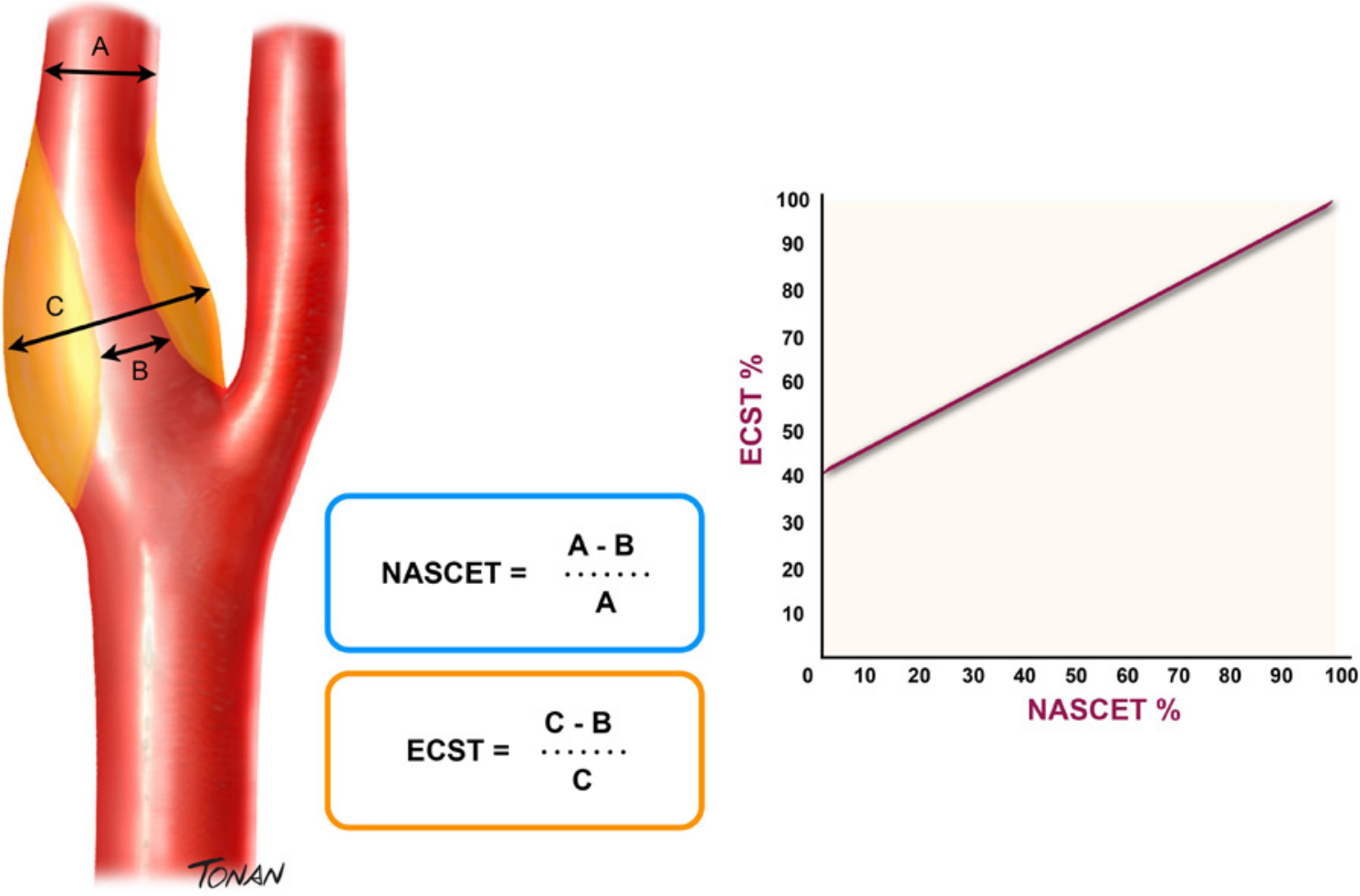

Figura 36 - A-Diagrama mostrando o cálculo da percentagem de diminuição do diâmetro pelo métodos anatômico distal (NASCET) e anatômico local (ESCT). B- Relação entre a percentagem de redução do diametro usando os métodos anatômico distal (NASCET) e anatômico local (ESCT), pela fórmula de Rothwell.

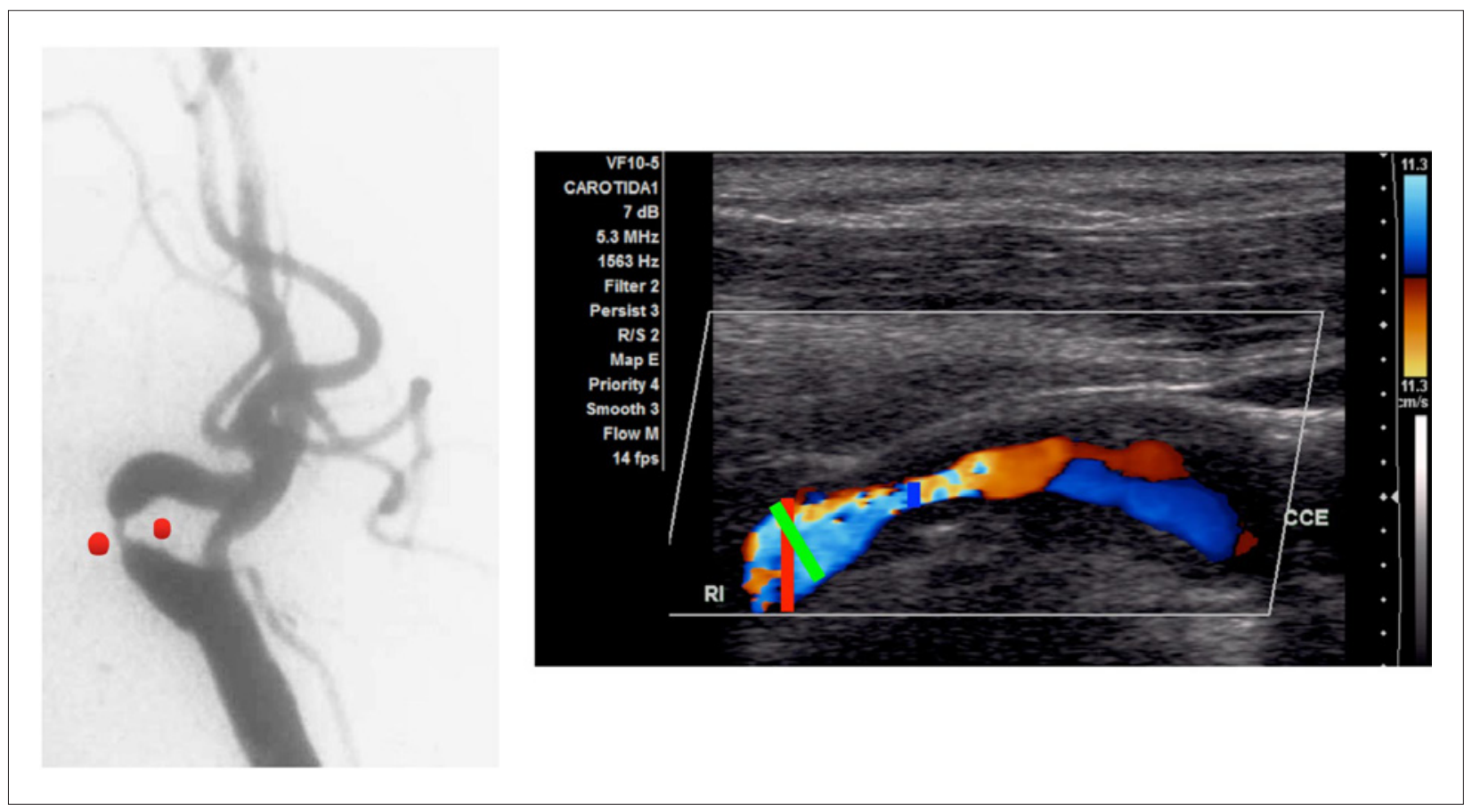

Figura 37- A-Arteriografia carotídea com estenose no ramo interno. Impossivel a determinação das margens do vaso (marca vermelha). B-Imagem ultrassonográfica mostrando a dificuldade na definição das paredes da carótida interna distal. 


\section{Artigo Especial}

perpendicularmente em relação ao feixe ultrasônico, levando a uma marcante queda da qualidade da imagem e dificultando a utilização deste método para a quantificação.

Pelos motivos expostos, recomendamos que a quantificação anatômica pela USV seja feita pelo critério anatômico local, lembrando que nas lesões acima de $80 \%$ há correlação entre as medidas realizadas por ambos os critérios anatômicos (local e distal). Nas lesões entre 50\%-80\%, para que haja correlação entre a estimativa pelo US com o resultado da arteriografia, é necessário que seja feita a conversão do valor obtido pelo US (critério anatômico local) para o valor do critério anatômico distal, através da fórmula ou do gráfico fornecidos acima. Nas lesões abaixo de 50\% recomendamos que a medida e a expressão do resultado seja fornecido pelo critério anatômico local, já que devido à dilatação peculiar da carótida, na região da dilatação do ramo interno (bulbo carótideo), o critério anatômico distal pode gerar valores negativos.

Não é infrequente que não haja correlação entre as medidas anatômicas e os critérios hemodinâmicos, mesmos com todos os cuidados descritos acima. Devemos saber quando priorizar um critério ou outro.

Os critérios anatômicos devem ser priorizados em situações de fluxo aumentado, como nas oclusões ou estenoses severas contralaterais e nos estados hiperdinâmicos (anemia, hipertireoidismo e outras), e também nas situações de baixo fluxo (baixo débito cardíaco, estenose valvar aórtica, nas lesões proximais das carótidas comuns e do tronco braquiocefálico). Nestes casos, haverá discrepância entre as relações de velocidades e as dos critérios baseados nas velocidades de pico sistólico e diastólico final.

Nas lesões muito extensas, nas placas sequenciais e nas suboclusões (situações em que pode não haver aumento das velocidades) também devemos privilegiar os critérios anatômicos. Nesses casos, o aspecto da lesão pode ser a única chave para o diagnóstico. Cuidados devem ser tomados para que os parâmetros de imagem e cor estejam perfeitamente ajustados. Esses achados devem ser confirmados pelas alterações do fluxo que ocorrerão na carótida comum (aumento da resistência, com Doppler espectral semelhante ao do ramo externo "externalizaçao do padrão de fluxo") e pelos achados obtidos ao Doppler transcraniano (amortecimento e queda da velocidade, usualmente menor que $30 \mathrm{~cm} / \mathrm{s}$ na carótida interna distal, inversão do fluxo na artéria oftálmica e/ou inversão do fluxo na artéria cerebral anterior ipisilateral, aumento do fluxo no segmento P1 da artéria cerebral posterior) ${ }^{4}$.

Atualmente, tomografias computadorizadas de alta velocidade e com multidetectores permitem a avaliação direta do diâmetro do lúmen carotídeo e dos tecidos adjacentes com altíssima resolução espacial. Bartlet e cols. ${ }^{136}$ demonstraram uma correlação linear entre a medida em milímetros do lúmen residual, ao nível da estenose da carótida, com o grau de estenose estimado pela angiografia com o método do estudo NASCET ${ }^{133}$. Os limites de 1,4 - 2,2 mm podem ser usado para avaliar uma estenose moderada (50\%-69\%) com uma sensibilidade de $75 \%$ e uma especificidade de 93,8\%. Um diâmetro da luz residual $\leq 1,3 \mathrm{~mm}$ correlaciona-se com uma estenose superior a $70 \%$ e pode ser usado como valor de corte, com sensibilidade de $88,2 \%$, especificidade de $92,4 \%$ e valor preditivo negativo de $98 \%$, sendo uma ferramenta excelente para diagnosticar ou afastar uma estenose importante. A medida direta da luz residual minimizaria potenciais erros de medida, quando se faz a relação com a luz da carótida interna distal, principalmente nos casos de colapso das paredes nas estenoses severas (Tabela 5).

Suanwela e cols. ${ }^{137}$ correlacionaram as medidas de velocidade obtidas pelo Doppler com a medida da luz residual realizada em espécimes cirúrgicas retiradas "em bloco". Mais recentemente, Yurdakul e cols. ${ }^{16}$ demonstraram utilizando a técnica B-flow, com melhor resolução temporal e espacial e menos ocorrência do fenômeno de "extravasamento" que o Color convencional e o Doppler de potência (Power Doppler), que uma luz residual menor que 1,5 $\mathrm{mm}$ apresentava performance semelhante a angiografia com subtração digital pelo método NASCET para estimar estenose do ramo interno entre 70\%-99\%, com sensibilidade de 93\%, especificidade de 94\% e acurácia de 94\% (Tabela 5).

Apesar de a resolução espacial da ultrassonografia, mesmo com a técnica de B-flow, não ser tão boa quanto a da angiotomografia, incluímos a medida da luz residual em nossa tabela de quantificação das lesões de carótida como critério complementar, como descrito (Figura 38).

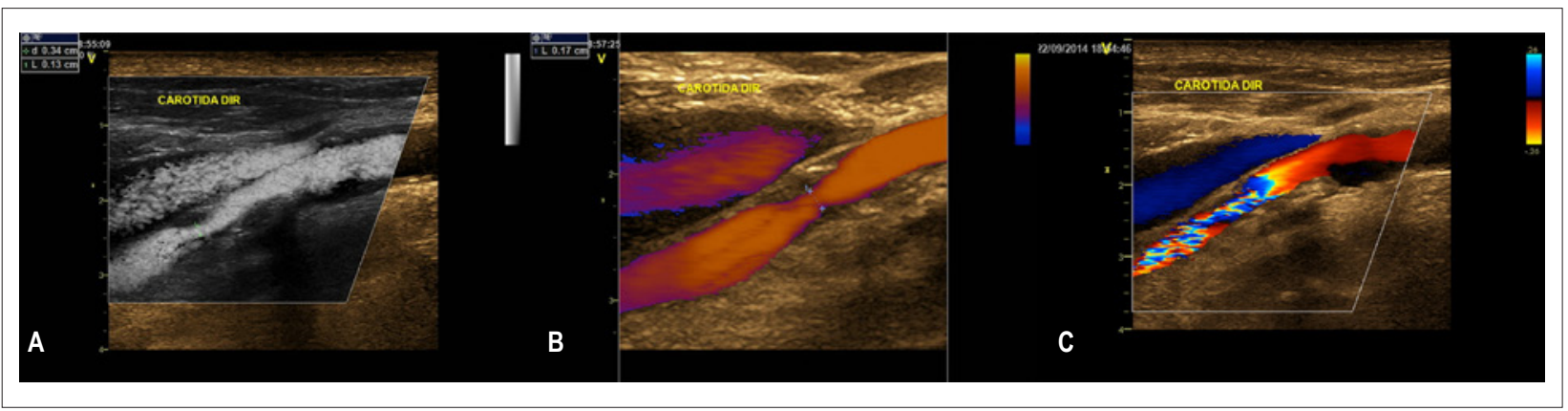

Figura 38 - Medida da luz residual $(A)$ com B-flow, $(B)$ B-flow angio e $(C)$ color convencional. Nas técnicas relacionadas com o B-flow há menor sobreposição da cor sobre a placa, sendo o método preferivel para a medida da luz residual. 
Tabela 5 - Tabela multimodalidade para quantificação das estenoses de carótidas: comparação das percentagens de diminuição do diâmetro pelos critérios anatômicos local (US), distal (arteriografia) e as correspondentes medidas da luz residual pela ultrassonografia e tomografia computadorizada. Obs.: Os cálculos da estenose anatômica local foram baseados na regressão de Rothwell

\begin{tabular}{|c|c|c|c|}
\hline $\begin{array}{l}\text { ARTERIOGRAFIA } \\
\text { (NASCET) }\end{array}$ & $\begin{array}{c}\text { \% EST - US } \\
\text { Anatômico Local } \\
\text { (ECST) }\end{array}$ & $\begin{array}{c}\text { LUMEN Residual } \\
(\mathbf{m m}) \\
\text { US- Imagem do Fluxo } \\
\text { (B- Flow) }\end{array}$ & $\begin{array}{l}\text { LUMEN Residual } \\
(\mathbf{m m}) \\
\text { Tomografia Comp }\end{array}$ \\
\hline Inferior a $\mathbf{2 0} \%$ & $<50 \%$ & \multirow{6}{*}{$>1,5$} & \multirow{4}{*}{$>2,2$} \\
\hline $20-29 \%$ & $50-55 \%$ & & \\
\hline $30-39 \%$ & $58-63 \%$ & & \\
\hline $40-49 \%$ & $64-69 \%$ & & \\
\hline $50-59 \%$ & $70-75 \%$ & & \multirow{2}{*}{$1,4-2,2$} \\
\hline $60-69 \%$ & $76-81 \%$ & & \\
\hline $70-79 \%$ & $82-87 \%$ & \multirow{3}{*}{$<1,5$} & $1,3-1,0$ \\
\hline $80-89 \%$ & $88-93 \%$ & & $<1,0$ \\
\hline $90-99 \%$ & $94-99 \%$ & & Fluxo filiforme \\
\hline Oclusão & & $\begin{array}{c}\text { Ausência de } \\
\text { preenchimento }\end{array}$ & $\begin{array}{l}\text { Ausência de } \\
\text { preenchimento }\end{array}$ \\
\hline
\end{tabular}

A escala de cores refer-se a maior experência da utilização do método pela comunidade científica.

\section{AVALIAÇÃO APÓS ENDARTERECTOMIA CAROTÍDEA E IMPLANTE DE STENT}

\section{Introdução}

O tratamento da doença aterosclerótica carotídea sintomática e assintomática é ainda uma matéria de debate multidisciplinar. O tratamento intervencionista pode ser feito através da endarterectomia carotídea ou do implante de stent carotídeo. Ambas intervenções são de indicação estabelecida na doença carotídea estenótica grave, sendo que a endarterectomia (EAC) é o procedimento de eleição em centros especializados, isto é, em centros em que o resultado cirúrgico tenha menos que $6 \%$ de AVC e mortes como complicações ${ }^{118,138}$.

O papel da USV nos pacientes que foram submetidos a tratamentos intervencionistas carotídeos é de muita importância, pois de maneira não invasiva, avalia os detalhes anatômicos e hemodinâmicos da artéria tratada. A avaliação global do paciente consiste de uma história clínica sumária, tentar obter informações como a descrição do procedimento cirúrgico a que foi submetido, medicamentos em uso, fatores de risco e, especialmente, resultados de exames diagnósticos prévios para avaliar se o procedimento solicitado se correlaciona com a história clínica do paciente e utilizar para comparação e seguimento posterior. As contraindicações a USV e as limitações do exame são semelhantes aos dos exames pré-operatórios (www.svunet.org).
Protocolo de exame:

1. Observar as características dos tecidos normais e anormais, estruturas vasculares e fluxo sanguíneo para otimizar imagens.

2. Modo B:

a. Obter imagens no corte transversal e longitudinal, utilizando janelas anterior, lateral e posterior para acessar todos os segmentos das carótidas comuns, bifurcação carotídea e carótidas interna e externa.

b. Classificar as placas e superfície das paredes dessas artérias em relação a homogeneidade/heterogeneidade e superfície regular/irregular.

3. Color Doppler:

a. Utilizar durante todo o exame e buscar pontos de aliasing ou ausência de fluxo.

b. Power Doppler/B-Flow deve ser utilizado para ajudar no diagnóstico de oclusão, estados de baixo fluxo e avaliar possibilidade de ulceração.

4. Análise espectral - realizada no plano sagital:

a. As velocidades devem ser obtidas num ângulo de $60^{\circ}$ com o cursor alinhado em paralelo as paredes do vaso, para reprodutibilidade

b. O ângulo do Doppler deve ser mantido entre $45-60^{\circ}$ sempre que possível. 
c. Ocasionalmente, por dificuldades na anatomia do paciente, um ângulo menor que $45^{\circ}$ pode ser encontrado, e isso deverá ser informado no laudo.

d. Pulsar as áreas de interesse para registrar as velocidades de pico e direção do fluxo. Documentá-las nos seguintes segmentos:

i. Carótida comum proximal, média e distal.

ii. Carótida interna proximal, média e distal.

iii. Carótida externa.

iv. Artéria subclávia - se houver sinais de roubo pela subclávia ou diferença > $20 \mathrm{mmHg}$ na pressão arterial dos membros superiores.

e. Na presença de doença, registros do Doppler espectral devem ser feitos proximal, distal e no local da lesão.

5. No local da intervenção vascular (endarterectomia ou stent), documentar:

a. Doppler espectral proximal, no local e distal ao local da intervenção.

b. Medidas dos diâmetros do vaso e extensão, morfologia e disposição das placas ateromatosas.

c. Todas as imagens adicionais necessárias a demonstrar anormalidades presentes.

\section{Endarterectomia e stent carotídeo}

O implante de stent carotídeo tem desfechos de longo prazo semelhantes ao da endarterectomia (EAC) para o tratamento da doença oclusiva carotídea sintomática. Entretanto, as taxas de AVC ou morte periprocedimento (trinta dias) são maiores do que as da EAC, como demonstrado em vários estudos e meta-análises ${ }^{139-141}$. Sugere-se, assim, que o stent carotídeo seja indicado em pacientes sintomáticos com estenose carotídea entre 70\%-99\%, quando a lesão carotídea não é passível de acesso cirúrgico (pescoço curto, lesões que se estendem ao segmento cranial ou clavicular e pacientes traqueostomizados) ou for induzida por irradiação ou dissecção ou ocorrer após EAC prévia ou pacientes com risco operatório muito elevado para EAC, isto é, grave comorbidade cardíaca e/ou pulmonar. Nos demais casos, opta-se pela indicação de intervenção com cirurgia aberta EAC ${ }^{118,141}$.

As técnicas aplicadas para a endarterectomia carotídea são:

- A implantação de "patch" (remendo) é a mais utilizada entre elas, podendo ser realizada com material de veia, principalmente de Safena Magna, ou de prótese de "PTFE" ou de pericárdio bovino, sem diferenças significativas em relação ao seguimento pós operatório.

- A sutura primária, onde é realizada a sutura direta, sem o uso do "patch", devendo ser evitada em carótidas internas com diâmetros abaixo de 4 mm, em razão do maior índice de reestenose.

- A técnica de eversão, que consiste na secção com descontinuação da carótida interna fazendo a eversão desta e a retirada da placa ateromatosa, com posterior anastomose boca a boca, sagital elíptica ou término-terminal.

Os stents possuem características próprias nas suas composições, de acordo com os seus fabricantes, sendo todos, atualmente, autoexpansíveis, e utilizados, basicamente, como amparo nas angioplastias.

\section{Complicações pós intervenção}

\section{Endarterectomia}

Os riscos e complicações potenciais após intervenção são os acidentes vasculares cerebrais com déficits neurológicos, no caso da EAC, a ruptura dos pontos de sutura com sangramentos e hematomas, ou formação de pseudoaneurisma e morte. Alterações de anatomia, tais como tortuosidades, do tipo "kinkings", "coilings" e "loopings", podem ser corrigidas durante a abordagem na EAC, mas, também, podem surgir no pós-operatório, por invaginação da parede em ponto de sutura e/ou torção do vaso, assim como mudança abrupta de calibre e espessamento parietal residual na carótida comum, que é caracterizado por visualização de duas camadas sobrepostas com pontos de sutura ecogênicos ao bidimensional, geralmente com espessura acima de 2,0 mm, que é chamado de "degrau"142.

Muito se discute sobre a necessidade do seguimento com algum método de imagem no intraoperatório da EAC; entretanto, a USV oferece muitas vantagens em relação à angiografia complementar. A USV visibiliza adequadamente as características da parede e o lúmen arterial, identifica flaps no local de clampagem da carótida comum, não necessita de contraste e não apresenta risco de embolia arterial. Os possíveis defeitos identificados no intraoperatório são: flaps, placas residuais, trombos, dissecção e estenoses e podem acontecer em $6 \%-30 \%$ dos casos, e em até $10 \%$ deles pode levar a reintervenção. A vantagem do USV é identificar defeitos técnicos não suspeitados e melhorar expertise do cirurgião. Ascher e cols ${ }^{142}$ utilizaram a ultrassonografia vascular intraoperatória com um transdutor em "taco de hockey" de 10-15 MHz, e reexploraram a carótida se encontrassem velocidades de pico sistólica (VPS) acima de $150 \mathrm{~cm} / \mathrm{s}$ associadas a alterações ao bidimensional. O ponto de corte da VPS variou entre 125 e $230 \mathrm{~cm} / \mathrm{s}$. A associação da elevação das velocidades com a presença de alterações ao bidimensional se deve à possibilidade da elevação das velocidades por espasmo arterial distal ao clamp na $\mathrm{ACl}$, na ausência de alterações estruturais ${ }^{143}$.

Assim, o seguimento pós-endarterectomia de carótida consiste em definir o status pós-operatório da funcionalidade da carótida tratada, sendo considerado como resultado adequado, ou satisfatório, quanto mais próximo for para o vaso nativo, avaliando placas residuais, paredes, anastomoses, calibres e fluxos ${ }^{142}$. O protocolo de exame deve ser o mesmo realizado para o cálculo das estenoses em artérias nativas, como atenção para os detalhes anatômicos descritos acima.

Os achados ultrassonográficos após EAC estão frequente e diretamente relacionados com a aplicação correta da técnica cirúrgica, que, quando favorável e bem aplicada, demonstra uma anatomia muito similar ao vaso nativo. As características ultrassonográficas e complicações principais após EAC são (Figura 39 e Quadro 8): 


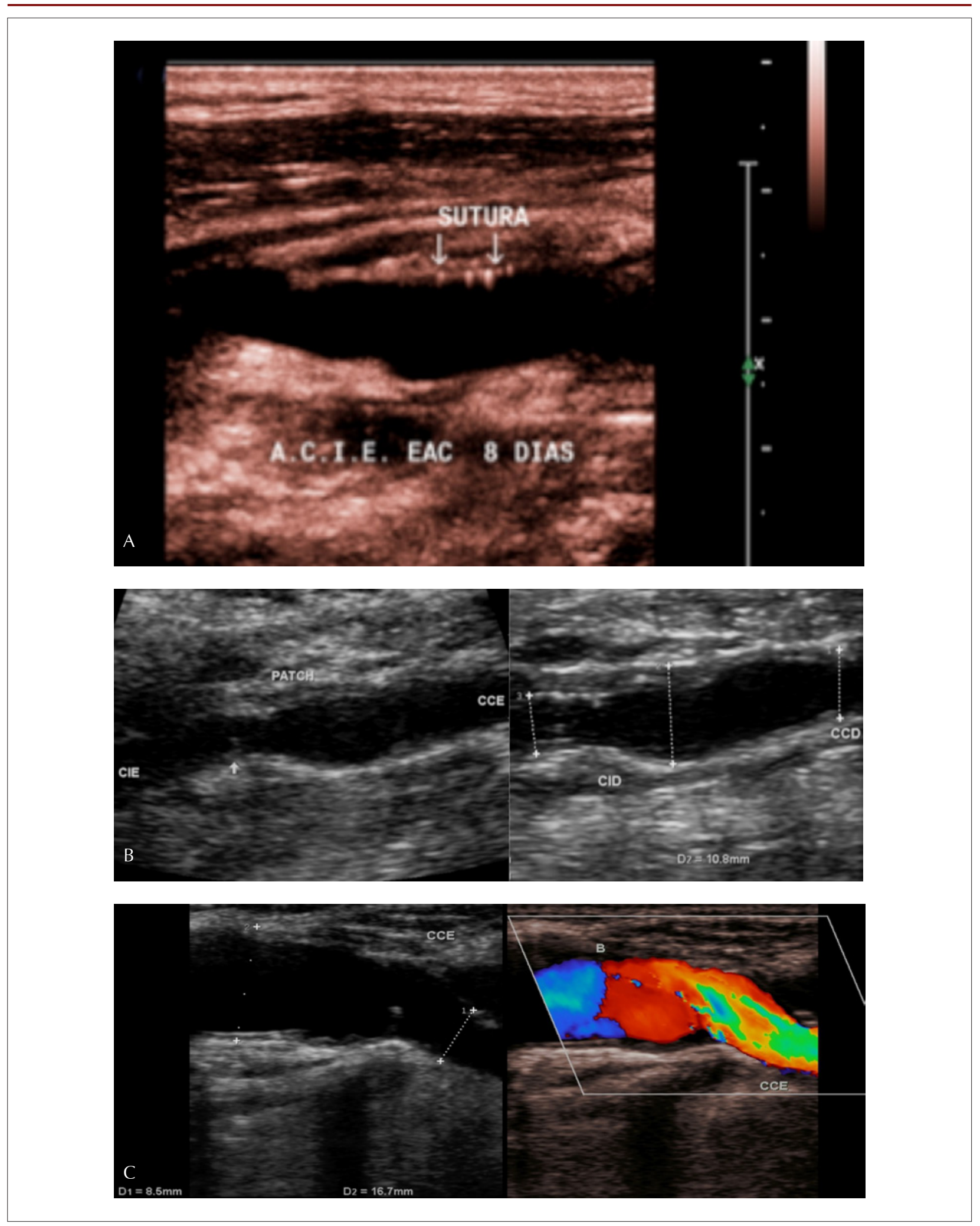

Figura 39 - Imagens pós-endarterectomia carotídea. A- Linha de sutura; B- Endarterectomia com colocação de "patch"; C- Dilatação do vaso pelo implante de "patch". 
a) a identificação de pontos de sutura como imagens puntiformes, arredondadas e hiperecogênicas bem definidas, intercaladas nos casos de utilização de "patch" e sobrepostas adjacentes nos casos de sutura primária;

b) alargamento das paredes e lúmen do vaso no segmento abordado na EAC, com diâmetro maior em relação aos segmentos proximal e/ou distal e/ou contralateral, configurando e podendo evoluir tardiamente com dilatação do tipo aneurismática. Por isso, devem-se aferir as medidas dos diâmetros no vaso nativo, nos locais das anastomoses e na região do alargamento, para que se possa acompanhar e comparar posteriormente, seja por adaptação da parede do vaso, seja por evolução da doença aterosclerótica;

c) a ocorrência de trombo no local da intervenção, que é caracterizada por imagem hipoecogênica com ou sem componente móvel, no exame realizado imediata ou em até trinta dias;

d) presença de pseudoaneurisma, que se caracteriza por ruptura de ponto de sutura com formação de hematoma envolvido por tecidos adjacentes, extracarotídeo, porém relacionado com o lúmen do vaso;

e) avaliar placas ateromatosas residuais, podendo se apresentar no local da abordagem como um degrau, sendo o ponto final da exérese incompleta da placa, seja proximal ou distal;

f) acompanhamento da evolução da doença aterosclerótica, tardia, com surgimento de novas placas ateromatosas. Nas séries atuais a reestenose ocorre em cerca de 5-10\% das EAC, e em séries recentes esa taxa é menor do que $5 \%$ nos procedimentos com patch e são diagnosticados com a vigilância do pós-operatório com USV. A descrição dos tipos de reestenose será feita juntamente com as que ocorrem após implantes de stents carotídeos ${ }^{118}$.

\section{Stent carotídeo}

Os riscos e complicações potenciais após implante de stent carotídeo são também déficits neurológicos, lesões nos vasos utilizados para a abordagem da estenose carotídea, lesão da artéria no local da estenose e nas artérias distais, mal posicionamento do stent, mal funcionamento do stent por fratura ou reestenose ou má expansão ou formação de pseudoaneurisma e morte. A USV tem papel importante no seguimento do funcionamento do stent e diagnóstico precoce de suas complicações. Apesar do material do stent ser altamente refletivo, ele não produz nenhum artefato significativo que limite sua adequada avaliação ${ }^{118,138,144,145}$ (Quadro 8).

\section{- Reestenose}

A reestenose intra-stent (RIS) é a complicação mais frequente de longo prazo e ocorre em cerca de 3\% a 5\% dos pacientes, apesar de na literatura a ocorrência variar de $1 \%$ a $30 \%{ }^{118,146}$. O mismatch de complacência entre a carótida nativa e o segmento com stent, o remodelamento arterial positivo (expansão do stent) e o aumento da rigidez do local onde se encontra o stent, na redução da elasticidade do vaso resultando em disfunção endotelial, hiperplasia neointimal e reestenose (remodelamento negativo) e alteração hemodinâmica ${ }^{145}$.
A reestenose é uma condição geralmente benigna que não requer revascularização, exceto em condições específicas, tais como quando a reestenose leva a sintomas isquêmicos recorrentes ou progride para lesão pré-oclusiva (> 80\%). Nessas condições, pode ser justificável repetir a revascularização ${ }^{118}$. A estenose recorrente durante a "cicatrização" ou adaptação do tratamento é considerada uma resposta biológica exacerbada a lesão vascular promovida pela intervenção. Dois mecanismos principais parecem contribuir para o estreitamento luminal: a hiperplasia neointimal como resposta precoce (três a 24 meses), tanto pós-EAC quanto implante de stent, e a modificação nos componentes da parede arterial levando a uma retração arterial na fase crônica da cicatrização. Este último mecanismo de reestenose é prevenido pelo arcabouço do stent. A reestenose tardia geralmente está associada a lesão aterosclerótica (após 24 meses $)^{147}$.

A reestenose recorrente após o implante do stent se dá principalmente devido à hiperplasia neointimal. Do ponto de vista morfológico, no seguimento dos stents carotídeos, seus diâmetros devem ser medidos, pelo modo B, nas extremidades proximal e distal e no meio do stent, no local onde a placa pré-intervenção estiver localizada (Figura 40) e medir a espessura máxima da neointima, isto é, da camada entre o stent e o lúmen. Em estudo prospectivo para acompanhamento da proliferação neointimal típica em Wallstents carotídeos, nota-se que ela começa a ocorrer cerca de três meses do implante, aumenta significativamente nos primeiros seis meses após implante e continua a aumentar mais lentamente durante o primeiro ano e se torna mais estável no segundo ano após o implante ${ }^{141,148}$. Assim, ocorre um remodelamento positivo da artéria com a expansão do stent e um remodelamento negativo do lúmen pela proliferação neointimal. Algumas variáveis são preditoras da RIS, como idade, sexo, tabagismo, diabetes, hipertensão, dislipidemia, doença autoimune, doença aterosclerótica em outros leitos vasculares, oclusão da carótida contralateral, implante de stent para tratamento de reestenose pós-endarterectomia carotídea e uma velocidade de pico sistólica pós-implante de stent $>120 \mathrm{~cm} / \mathrm{s}$ ao USV, indicando uma estenose residual pós-implante ${ }^{149,150}$.

\section{Hiperplasia neointimal}

Ao ultrassom, o aspecto da hiperplasia é de um espessamento proliferativo concêntrico da parede do stent ou da carótida submetida a EAC em direção ao lúmen, de aspecto ecolucente, habitualmente uniforme e com superfície lisa, podendo ser segmentar ou multisegmentar. Já a aterosclerose demonstra irregularidade luminal com textura heterogênea ${ }^{147}$.

Após EAC, a hiperplasia neointimal é diagnosticada com base no tempo de ocorrência após o procedimento, menos de dois anos, e o cálculo da estenose é realizado como para a artéria nativa. Com relação ao stents carotídeos, Lal e cols. ${ }^{151}$ classificaram através do USV, com boa correlação angiográfica, o grau de hiperplasia neointimal baseada na extensão da lesão e na sua localização em relação ao stent. Os autores também encontraram uma associação positiva entre o padrão de hiperplasia e a necessidade de reintervensão, isto é, quanto pior o padrão de hiperplasia 
Quadro 8 - Complicações pós-intervenção: endarterectomia e implante de stent

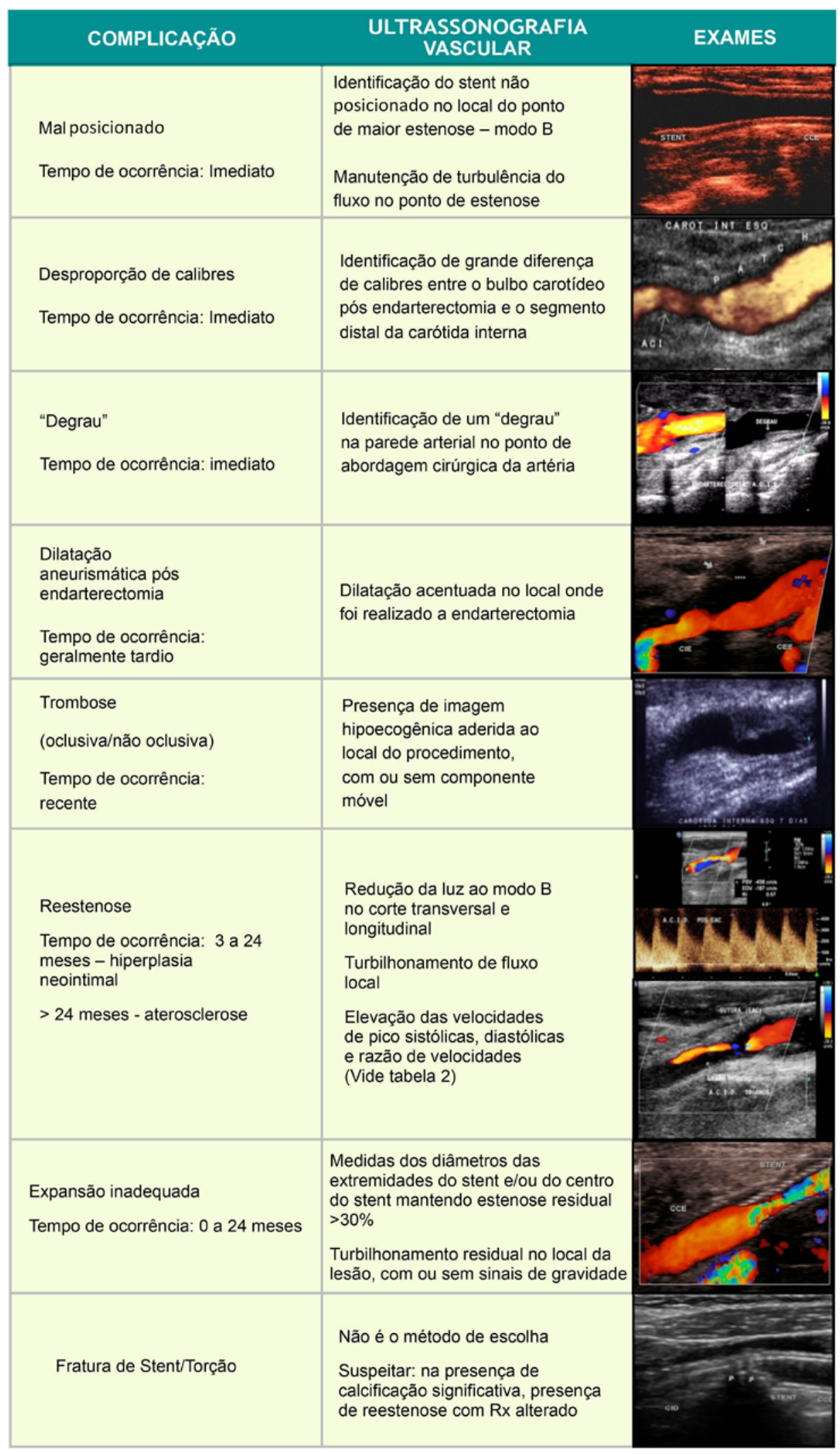




\section{Artigo Especial}

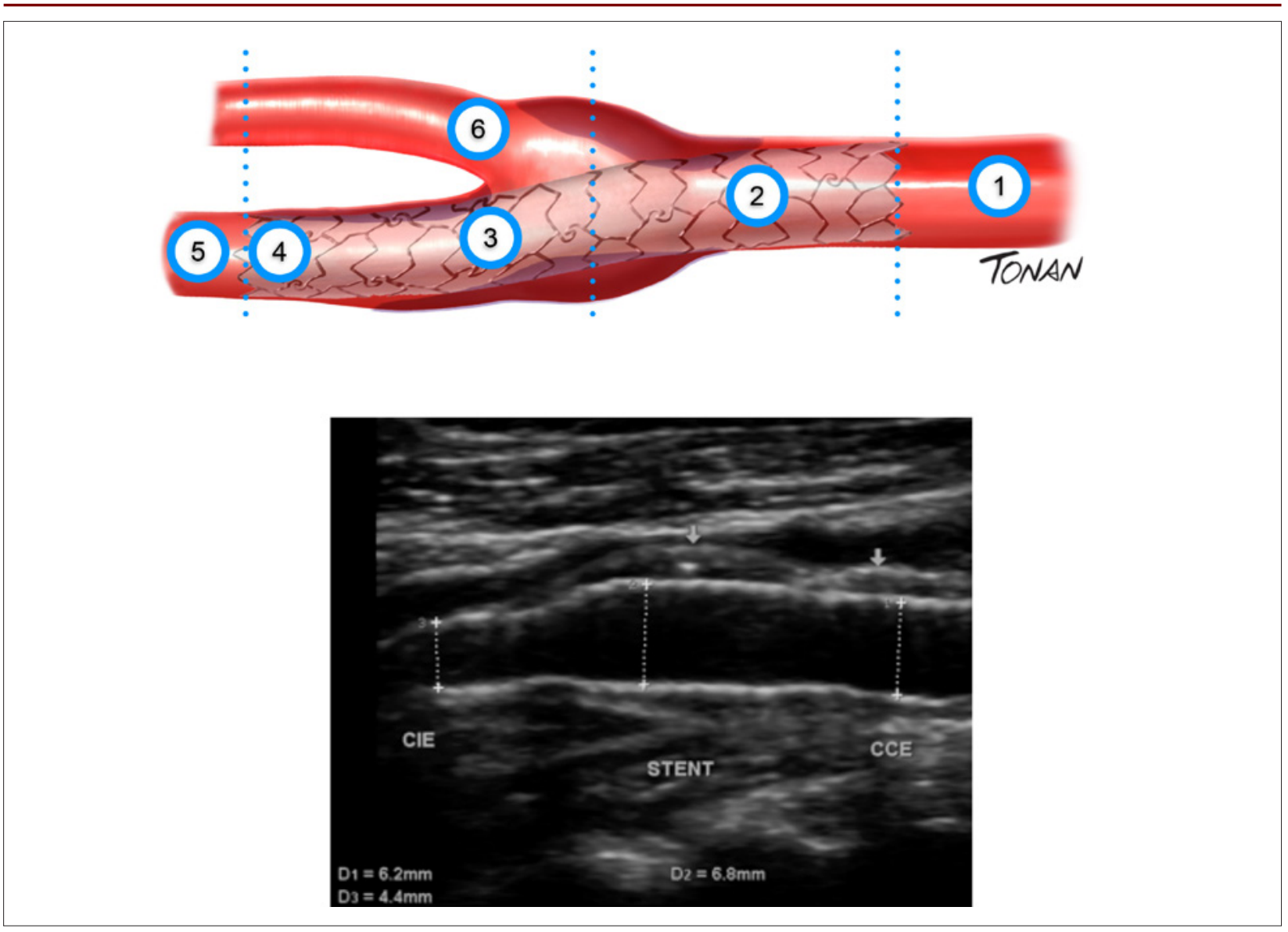

Figura 40 - Locais onde avaliar e medir o stent após o implante.

maior a chance de necessidade de reintervenção, e também parece que o padrão de RIS pode variar de acordo com as propriedades biomecânicas do stent, isto é, material, desenho geométrico e dimensão antes e depois do implante. Entretanto, estudos futuros são necessários para definir melhor essa análise. Utilizam-se as imagens no corte longitudinal padrão, com o transdutor colocado diretamente sobre a carótida tratada, para medir a extensão da lesão em relação ao stent utilizando-se o power Doppler para delinear melhor a lesão. O rastreamento no corte transversal, desde a base do pescoço até o angulo da mandíbula, obtendo imagens de toda a carótida comum e interna, é utilizado para avaliar os diâmetros intraluminais, também utilizando o power Doppler. A hiperplasia neointimal é classificada em (Figura 41):

1. Tipo I (Focal na extremidade do stent): lesões $\leq 10 \mathrm{~mm}$ de extensão na extremidade proximal ou distal do stent (apenas uma margem). Quando a lesão acometer as duas extremidades é definida como Tipo I multifocal de extremidades.

2. Tipo II (Focal intra-stent): lesões $\leq 10 \mathrm{~mm}$ de extensão apenas intra-stent, sem extensão para as extremidades; quando duas ou mais lesões $\leq 10 \mathrm{~mm}$ ocorrerem intrastent são definidas como Tipo II multifocal intra-stent.
3. Tipo III (Difusa intra-stent): lesão $>10 \mathrm{~mm}$ intra-stent sem extensão para as margens externas do stent.

4. Tipo IV (Difusa proliferativa): lesão $>10 \mathrm{~mm}$ intra-stent com extensão além das margens externas do stent.

5. Tipo V (Oclusão): ausência de fluxo e luz residual intra-stent.

\section{Dopplervelocimetria na quantificação das estenoses}

Apesar de a imagem do modo B ser geralmente muito útil na estimativa da estenose, as velocidades sistólica, diastólica e razões de velocidades são os parâmetros mais utilizados na quantificação hemodinâmica da estenose. Independentemente do mecanismo da estenose, ou seja, aterosclerótico ou por hiperplasia neointimal. A estimativa de estenose após EAC se baseia também na medida das velocidades de pico sistólicas (VPS), diastólicas (VDF) e razão de velocidades. Pouco foi publicado em relação às modificações dos pontos de corte das VPS, VDF e razão de velocidades após EAC, entretanto destaca-se o estudo de AbuRahma e cols. ${ }^{152}$ que, após avaliar duzentos casos, sugeriu os seguintes pontos de corte da Dopplervelocimetria: VPS $\geq 155 \mathrm{~cm} / \mathrm{s}$ é o ponto de corte para estenose $\geq 30 \%$ com acurácia de $98 \%$, VPS $\geq 213 \mathrm{~cm} / \mathrm{s}$ para estenose $\geq 50 \%$ com acurácia de $99 \%$ e VPS $\geq 274 \mathrm{~cm} / \mathrm{s}$ para estenose $\geq 70 \%$ com acurácia de 98\% (Tabela 6). 
Através do seguimento sistemático de séries de pacientes submetidos a implante do stent carotídeo, a maioria dos autores percebeu que ao utilizar os critérios de velocidade empregados para o diagnóstico de estenose em artéria nativa para o diagnóstico de RIS havia uma superestimação do grau de estenose, pois são estruturalmente diferentes, reduzindo assim a acurácia do USV para essa avaliação. Uma carótida sem stent parece ser mais elástica do que uma carótida com stent, mesmo quando está presente uma placa aterosclerótica estenosante. Além disso, deve-se lembrar de que a placa aterosclerótica não é removida com o implante do stent, contribuindo para a redução da complacência. Assim, vários estudos foram publicados avaliando os melhores pontos de corte utilizando de curvas ROC, para a sua definição ${ }^{144,146,153-159}$. Entretanto, na maioria das séries houve um pequeno número de pacientes que desenvolveram RIS, limitando sua análise, e também não há uma diferenciação entre os tipos de stents e sua influência nos picos de velocidade sistólica. Obviamente, os dados obtidos por um laboratório vascular irá variar dos de outros laboratórios devido a diferenças de equipamentos, habilidades técnicas do ecografista e da interpretação dos dados. Assim, cada laboratório vascular deve idealmente validar seu próprio método.
Deve-se lembrar de que as velocidades de pico são obtidas o mais próximo da lesão, usando um volume de amostra de 1-1,5 mm e um ângulo de $60^{\circ}$ ou menos e são registradas, como nas artérias sem stents, as VPS, VDF e a razão de velocidades entre a VPS do stent e VPS do segmento distal da carótida comum. Os critérios de velocidade, combinados com o padrão do color Doppler e o modo B (escala de cinzas), podem com segurança caracterizar a estenose importante intra-stent, isto é, avaliação multiparamétrica ${ }^{146}$. Na Tabela 7 está sumarizado os parâmetros apontados como de melhor acurácia para a graduação da estenose carotídea pós-implante de stent de conceituados laboratórios vasculares. Em todos os estudos, a sensibilidade e a especificidade foram maiores para a VPS seguidos da razão de velocidades sendo iguais ou acima de $90 \%$. Essa recomendação sugere a utilização dos critérios de AbuRahma para quantificação das estenoses de stent ${ }^{146}$. Assim, devido a essa elevada sensibilidade, acessibilidade, ausência de radiação ou necessidade de contraste e custo-benefício, a análise multiparamétrica através da USV deve ser o primeiro método de imagem para seguimento após EAC e o implante de stent carotídeo e em pacientes com um exame ultrassonográfico normal dispensa outros exames complementares.
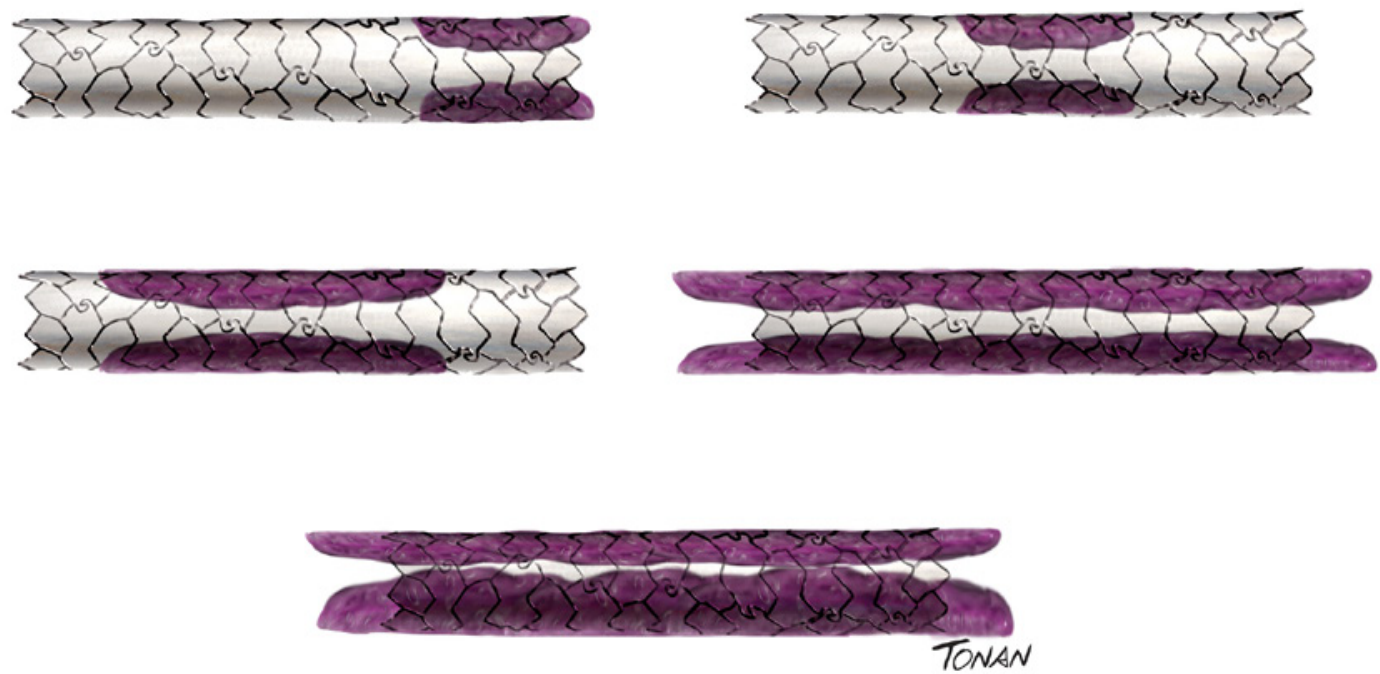

Figura 41 - Tipos de hiperplasia neointimal.

Tabela 6 - Valores velocimétricos para classificação das estenoses após endarterectomia carotídea

\begin{tabular}{lllr}
\hline$\%$ Estenose & VPS & VDF & Razão de velocidade \\
\hline$>30$ & 155 & 41 & 1,64 \\
$>50$ & 213 & 60 & 2,25 \\
$>70$ & 274 & 80 & 3,35 \\
\hline
\end{tabular}

VPS = velocidade de pico sistólica em $\mathrm{cm} / \mathrm{s} ; \mathrm{VDF}=$ velocidade diastólica final em $\mathrm{cm} / \mathrm{s}$; Razão de velocidade de pico sistólica na lesão e a velocidade de pico sistólica na carótida comum distal. 


\section{Artigo Especial}

Tabela 7 - Critérios velocimétricos para avaliação de reestenose após implante de stent carotídeo

\begin{tabular}{|c|c|c|c|c|}
\hline Autor & Estenose $<50 \%$ & Estenose $>50 \%$ & Estenose $>70 \%$ & Estenose $>80 \%$ \\
\hline Stanziale et al & $\begin{array}{l}\text { VPS }<225 \\
\text { st/cc }<2,5\end{array}$ & $\begin{array}{l}\text { VPS }>225 \\
s t / c c \geq 2,5\end{array}$ & $\begin{array}{l}\text { VPS } \geq 350 \\
s t / c c \geq 4,75\end{array}$ & \\
\hline Peterson et al & & & $\begin{array}{l}V P S>170 \\
V D F>120\end{array}$ & \\
\hline Chi et al & $\begin{array}{l}\text { VPS }<240 \\
\text { st/cc }<2,4\end{array}$ & $\begin{array}{l}\text { VPS }>240 \\
s t / c c \geq 2,45\end{array}$ & $\begin{array}{l}\text { VPS } \geq 450 \\
s t / c c \geq 4,3\end{array}$ & \\
\hline Lal et al & $<220$ & $\begin{array}{c}\text { VPS }-220-339 \\
s t / c c \geq 2,7\end{array}$ & & $\begin{array}{l}\text { VPS } \geq 340 \\
s t / c c \geq 4,15\end{array}$ \\
\hline Aburahma et al & VPS $<224$ & $\begin{array}{l}\text { VPS } \geq 224 \\
\text { VDF } \geq 88 \\
\text { st } / c c \geq 3,4\end{array}$ & & $\begin{array}{l}\text { VPS } \geq 325 \\
\text { VDF } \geq 119 \\
s t / c c \geq 4,5\end{array}$ \\
\hline Cumbie et al & $\begin{array}{l}\text { VPS }<195 \\
s t / c c<2,2\end{array}$ & $\begin{array}{l}V P S \geq 195 \\
V D F \geq 75 \\
s t / c c \geq 2,2\end{array}$ & & $\begin{array}{l}\text { VPS } \geq 205 \\
\mathrm{st} / \mathrm{cc} \geq 2,6\end{array}$ \\
\hline Chahwan et al & $\begin{array}{c}\text { VPS }<175 \\
\text { st/cc }<\end{array}$ & $\begin{array}{l}V P S \geq 155 \\
V D F \geq 44\end{array}$ & & $\begin{array}{l}V P S>365 \\
V D F>110\end{array}$ \\
\hline Zhou et al & & & $\begin{array}{l}\text { VPS } \geq 300 \\
V D F>90 \\
s t / c c \geq 4,0\end{array}$ & \\
\hline Recomendada & VPS $<220$ & $\begin{array}{l}V P S \geq 220 \\
V D F \geq 90 \\
s t / c c \geq 3,5\end{array}$ & & $\begin{array}{l}V P S \geq 325 \\
V D F \geq 120 \\
\text { st/cc } \geq 4,5\end{array}$ \\
\hline
\end{tabular}

VPS = velocidade de pico sistólica em $\mathrm{cm} / \mathrm{s} ; \mathrm{st} / \mathrm{cc}=$ razão de velocidade de pico sistólica intra-stent e carótida comum distal; $V D F=$ velocidade diastólica final em $\mathrm{cm} / \mathrm{s}$

\section{Expansão do stent}

A expansão do stent se dá do primeiro dia de sua inserção até os dois anos, porém essa expansão é mais pronunciada nos primeiros três meses, e especialmente nas extremidades. É considerado sucesso no implante do stent quando a estenose residual for menor que 30\% à angiografia após procedimento imediato ou precoce. Parece que a expansão do stent tem alguma relação com a morfologia da placa. Simplificadamente, as placas devem ser descritas como nas artérias nativas: placa ecolucente, placa ecogênica e placa calcificada com sombra acústica extensa. A expansão no meio do stent é pior (expansão incompleta) nas placas com aspecto calcificadas, maior nas placas ecolucentes e intermediário nas placas ecogênicas. Ao contrário, a expansão da parte do stent proximal e distal à placa é independente do tipo de placa. Assim, as medidas internas da carótida comum pré-stent, extremidade proximal do stent, meio do stent, extremidade distal do stent e carótida interna distal podem ser úteis no seguimento da expansão do stent (Figura 40) ${ }^{144,148,160,161}$.

A Figura 42 ilustra os aspectos evolutivos da doença carotídea após implante de stent em relação ao tempo de implante, incluido expansão incompleta, estenose residual, hiperplasia neointimal e evolução tardia da doença.

\section{Efeito do stent na carotida externa}

A carótida externa é uma importante via colateral, especialmente nos pacientes com polígono de Willis incompleto; seria importante saber a evolução das lesões nessa artéria após o procedimento.
Um dos efeitos do implante de stent para o tratamento das lesões da carótida interna é a obstrução da origem da carótida externa (CE), já que a maioria das lesões ateroscleróticas graves é localizada na bifurcação carotídea, estendendo-se ao segmento proximal da carótida interna. A placa ateromatosa é deslocada na camada mediaintimal pela angioplastia, e não comprimida, podendo causar estenose na origem da CE. Esse efeito não apresenta relação direta com o stent, que serve como um amparo. Além disso, alguns autores investigaram o impacto do implante do stent e observaram a ocorrência de uma turbulência de fluxo pelas malhas do stent na origem da CE como o mecanismo de "estenose" de sua origem, que ocorre logo após o implante, mas que tem um curso estável após um ano. Como a taxa de RIS é baixa, a importância da CE como via colateral é reduzida. Também é descrita a ocorrência de maior progressão da lesão na CE ipsilateral ao stent, mesmo sem a sobreposição do stent na origem e oclusão da CE após o implante in2,163. $^{16}$.

\section{Fratura de stent}

Fraturas em stents carotídeos são passíveis de ocorrer devido a muitos fatores. A ampla movimentação da região cervical e cabeça, com movimentos de extensão, flexão e rotação, expõe a carótida a forças de deformação axial e de compressão. Além disso, há um movimento de torção fisiológico entre as carótidas pela diferença de resistências entre elas; assim, carótidas rígidas pelo envelhecimento, tortuosas ou com placas ateroscleróticas apresentam fatores de estress adicional, pela redução dessa elasticidade. 


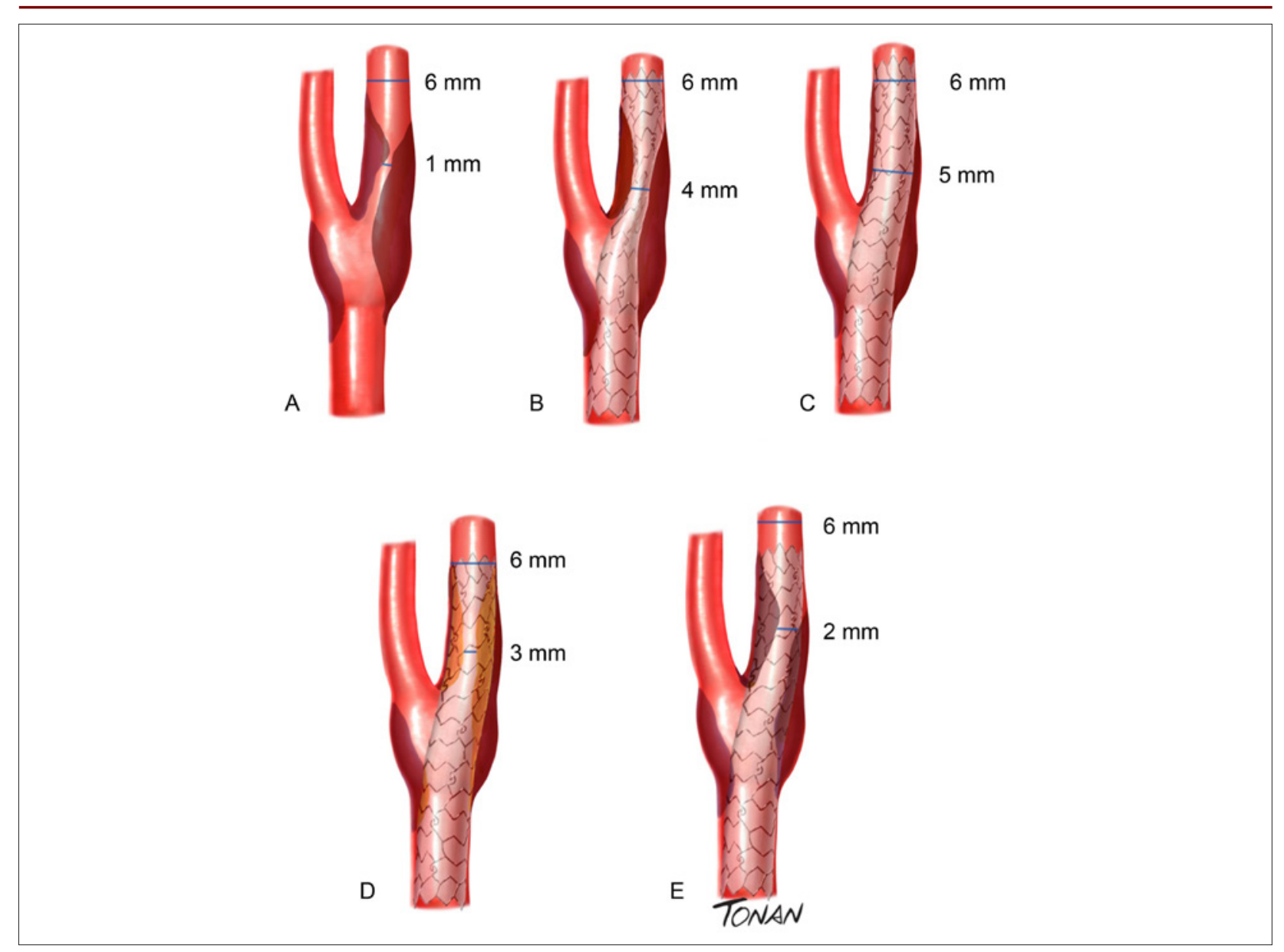

Figura 42 - Aspectos evolutivos da doença carotídea após implante de stent em relação ao tempo de implante. A-Estenose original; $B$ - Expansão incompleta; $C$ - Estenose residual; $D$ - Reestenose precoce por hiperplasia neointimal; E- Reestenose tardia por aterosclerose.

A carótida submetida ao implante de stent, além de sofrer essas forças externas de deformação, tem uma importante redução de sua elasticidade. Pesquisadores estudaram o efeito da movimentação da cabeça sobre stents carotídeos usando a angiorressonância e encontraram uma perda da capacidade natural de flexão, extensão e rotação da carótida após implante de stent. Também a flexibilidade do stent ex vivo é maior do que quando ele se encontra in vivo ${ }^{164}$. A presença de calcificação importante na carótida parece ser um forte preditor de complicações após o implante do stent ( 7,7 vezes), e devido ao aumento significativo da rigidez no local da lesão em contrapartida das extremidades do stent, que irão sofrer maior impacto de movimentos cervicais, predispondo a fraturas. Fadiga e fratura de stents originam no esforço concentrado em determinadas regiões que estão sob modos alternados de cargas externas (pressão, flexão e torção). Os defeitos microscópicos, depois de muitos ciclos de carga, produzem microfissuras que aumentam em condições favoráveis de estresse ambientais. A taxa de microfissura-alargamento depende, principalmente, do material de que é feito o stent. Uma vez que uma fenda atinge um tamanho crítico, pode haver uma fratura definitiva abrupta que rompe a continuidade estrutural do stent ${ }^{165}$.
Parece que não há diferença do número e fraturas entre os stents de célula aberta ou fechada, mas a aparência dos stents de células abertas é mais irregular, que pode simular uma fratura. Entretanto, a USV não identifica ainda, adequadamente, as fraturas de stent, porém deve ser feita uma documentação da malha desse para comparação em exames de seguimento ${ }^{166}$.

Um algoritmo proposto para a detecção da fratura de stent seria: angiografia intraoperatória com uma foto magnificada do stent para inspeção da estrutura do stent e utilização como referência futura. Pacientes com reestenose detectada ao USV e pacientes com suspeita de fratura de stent pelo Rx anteroposterior e lateral devem ser submetidos a angiografia rotacional sem contraste ${ }^{165}$.

\section{Recomendação}

Recomendamos que seja realizado o exame completo para mapeamento pré-intervenção, que forneça todas as informações necessárias para a escolha do procedimento ideal para cada caso.

Apesar de a literatura ser controversa, recomendamos que o protocolo para seguimento pós-intervenção, tanto 
para a EAC como para o stent carotídeo, seja baseado em um exame imediato ou em um exame precoce, em até trinta dias, seguido de outro no sexto mês para avaliação da técnica e detecção de estenoses residuais.

A partir desses, o seguimento deve ser determinado pelos resultados dos exames iniciais ou pelo aparecimento de sintomas neurológicos.

Para uma vigilância pós-operatória, baseada no fato de que nos dois primeiros anos são ocorrem a maior frequência de eventos vasculares e neurológicos, recomendamos que o seguimento com a USV para estenoses residuais, estenoses contralaterais e reestenoses precoces seja:

- Cada seis meses: para estenose $>50 \%$ e surgimento de sintomas neurológicos, ou outras anormalidade significativas;

- No primeiro e no segundo ano: para reestenoses e/ou estenoses contralaterais $<50 \%$ e para outras anormalidades não significativas que forem detectadas.

\section{Avaliação da Doença Ateromatosa em Artérias Vertebrais pelo Ultrassom com Doppler Colorido}

A investigação de envolvimento aterosclerótico das artérias vertebrais extracranianas através da ultrassonografia com Doppler colorido é indissociável do estudo das carótidas e essencial para o diagnóstico e tratamento das lesões severas, bem como para avaliação criteriosa dos riscos da abordagem cirúrgica carotídea. Aproximadamente 25\% dos acidentes isquêmicos encefálicos envolvem a circulação posterior e a doença ateromatosa corresponde a $20 \%$ dos $\operatorname{casos}^{167}$.

\section{Anatomia do sistema vertebrobasilar}

As artérias vertebrais (direita e esquerda) originam-se (Vzero) nas respectivas subclávias predominantemente posterior à emergência dos ramos tireocervicais e dividem-se em quatro segmentos: três extracranianos e um intracraniano ${ }^{168,169}$ (Figuras 43 e 44):

V1 (origem): desde origem até entrada no forame do processo transverso da sexta vertebra cervical (C6); pode ser tortuoso e representa o local de maior incidência de doença aterosclerótica.

V2 (segmento interapofisário): desde processo transverso de $\mathrm{C} 6$ até $\mathrm{C} 2$.

V3 ( segmento cefálico): desde saida de vertebral no atlas até entrada no canal espinhal.

V4 (segmento intracraniano): desde perfuração da dura máter (forame magno) até artéria basilar. Ressalte-se o ramo cerebelar posterior inferior (ACPI), antes da fusão com vertebral contralateral para formação da basilar.

Obs.: Podem ocorrer variações anatômicas de origem da vertebral ou do nível de entrada do vaso no forame do processo transverso. Em 5\% dos casos a vertebral esquerda pode se originar diretamente do arco aórtico. Outras variações mais raras incluem sua origem a partir da carótida comum ou carótida externa ${ }^{168}$, dupla origem ou fenestração da artéria, estas últimas extremamente raras ${ }^{170}$.

\section{Avaliação ultrassonográfica de vertebrais}

Com os recursos técnicos atualmente disponíveis consegue-se estudar a artéria vertebral em toda a sua extensão, incluindo o segmento intracraniano e a artéria basilar proximal. Recomendamos incluir na rotina de avaliação o estudo da origem do vaso (sede mais frequente das estenoses) e os demais segmentos extracranianos.

\section{Metodologia do exame de rotina}

A posição do paciente é a mesma adotada para o estudo das carótidas. A profundidade do campo de imagem pode variar com a anatomia do pescoço. A escala de cores deve ser reduzida, aumentando-se a sensibilidade de detecção do fluxo em cores.

Recomenda-se iniciar o exame pelo segmento interapofisário da vertebral (V2) por ser esse o de mais fácil identificação e inconfundível com outros vasos cervicais. A partir da imagem do segmento médio da carótida comum no plano longitudinal, faz-se um movimento em báscula posteriormente (até que as sombras acústicas dos processos transversos das vertebrais se tornem visiveis na tela). Nesse ponto, com auxílio do Doppler colorido e de pequenos movimentos de angulação, procura-se identificar a artéria (acompanhada de sua veia) e passa-se a registrar as curvas espectrais, sempre lembrando de adequar a escala e o ângulo de ataque do vaso. Para identificação da origem da artéria recomenda-se seguir a partir desse ponto em direção à sua origem. Nos casos de anatomia desfavorável outros transdutores podem ser usados (o setorial pediátrico, microconvexo ou abdominal convexo, por exemplo; todos com frequência na faixa de 5-8 MHz). Nesses casos, apesar da queda da qualidade da imagem bidimensional, a menor área de contato (setorial pediátrico e microconvexo) e um expressivo aumento da sensibilidade do Doppler colorido facilitarão sobremaneira a tarefa. O segmento V3 da vertebral é o único segmento palpável e situa-se abaixo do processo mastoide do osso temporal (marco anatômico para o estudo). Nessa região, observa-se a saída do vaso do forame transverso e seu curso em torno do processo mastoide (também chamada de "alça do atlas" em razão da relação anatômica com esse corpo vertebral). A análise desse segmento é especialmente necessária nas situações em que há suspeita de sintomas de insuficiência vertebrobasilar por compressão extrínseca de estruturas anatômicas como osteofitos, bandas e discos vertebrais (fig. 43F). Nesses casos um estudo dinâmico com rotação do pescoço deve ser executado. Apesar de não fazer parte da rotina, o segmento intracraniano pode ser estudado através da janela transforaminal e com sonda setorial cardíaca de adulto (frequencia de $2 \mathrm{MHz}$, obrigatoriamente).

\section{Parâmetros normais}

Diâmetro: varia de 2-4 mm. Assimetria de calibre entre as vertebrais é frequente ( $73 \%$ dos casos), sendo a esquerda mais calibrosa em 50\% dos $\operatorname{casos}^{167,169}$.

Doppler pulsátil: o padrão normal consiste em curvas espectrais de ondas de fluxo laminar, anterógrado, de baixa resistencia, com velocidade de pico sistólica (VPS) entre $20-60 \mathrm{~cm} / \mathrm{s}$ no segmento V2 e podendo variar de $30-100 \mathrm{~cm} / \mathrm{s}$ na origem da vertebral. Em razão da frequente 

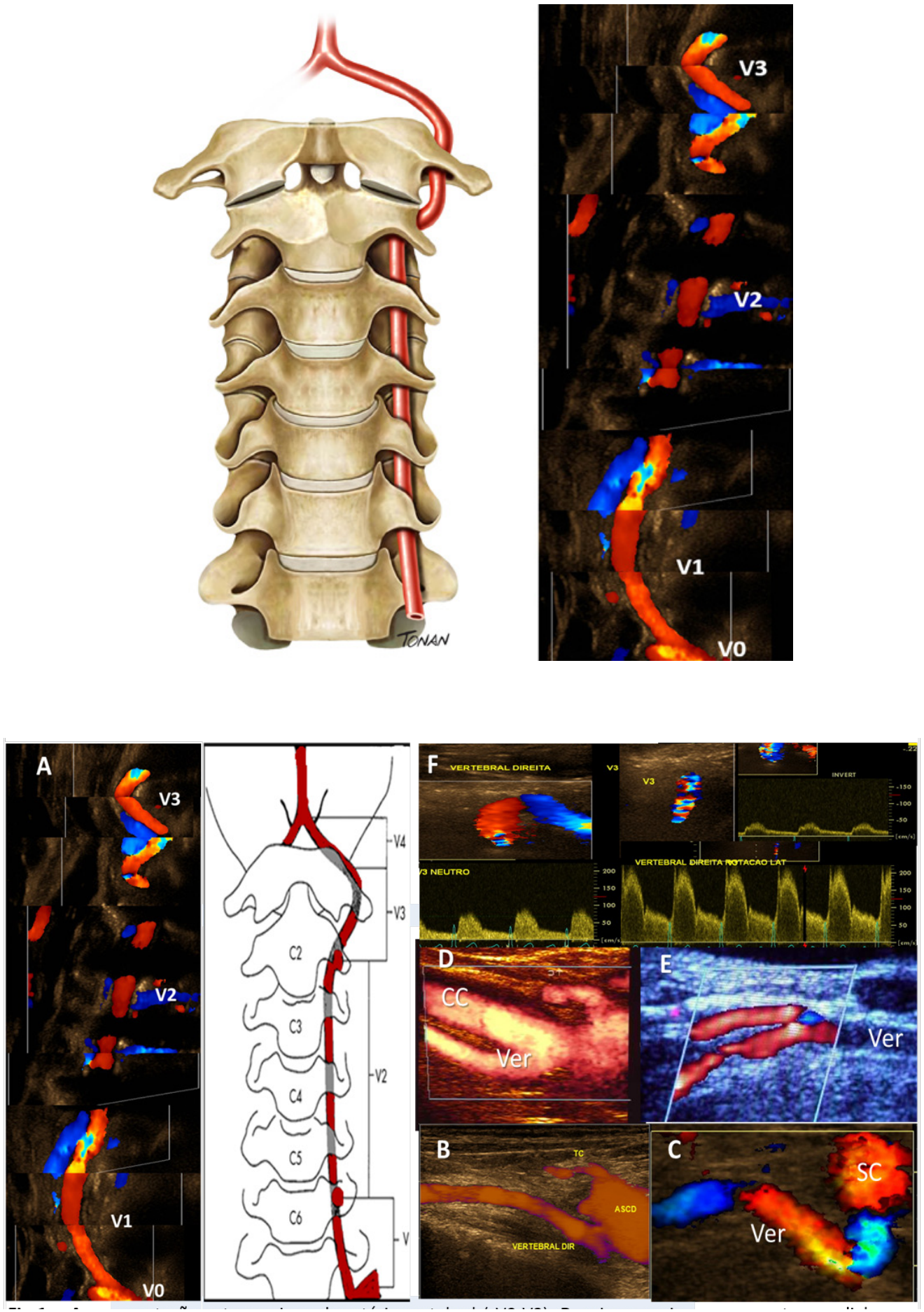

Figura 43 - A- Segmentação extracraniana da artéria vertebral (VO-V3); B- Origem mais comum posteromedial e sua relação anatômica com o ramo tireocervical; C- Origem inferior; D-Origem a partir da carótida comum; E- Fenestração da artéria vertebral; $F$ - Segmento cefálico em posição neutra e após a rotação do pescoço com compressão extrínseca gerando estenose dinâmica. 


\section{Artigo Especial}

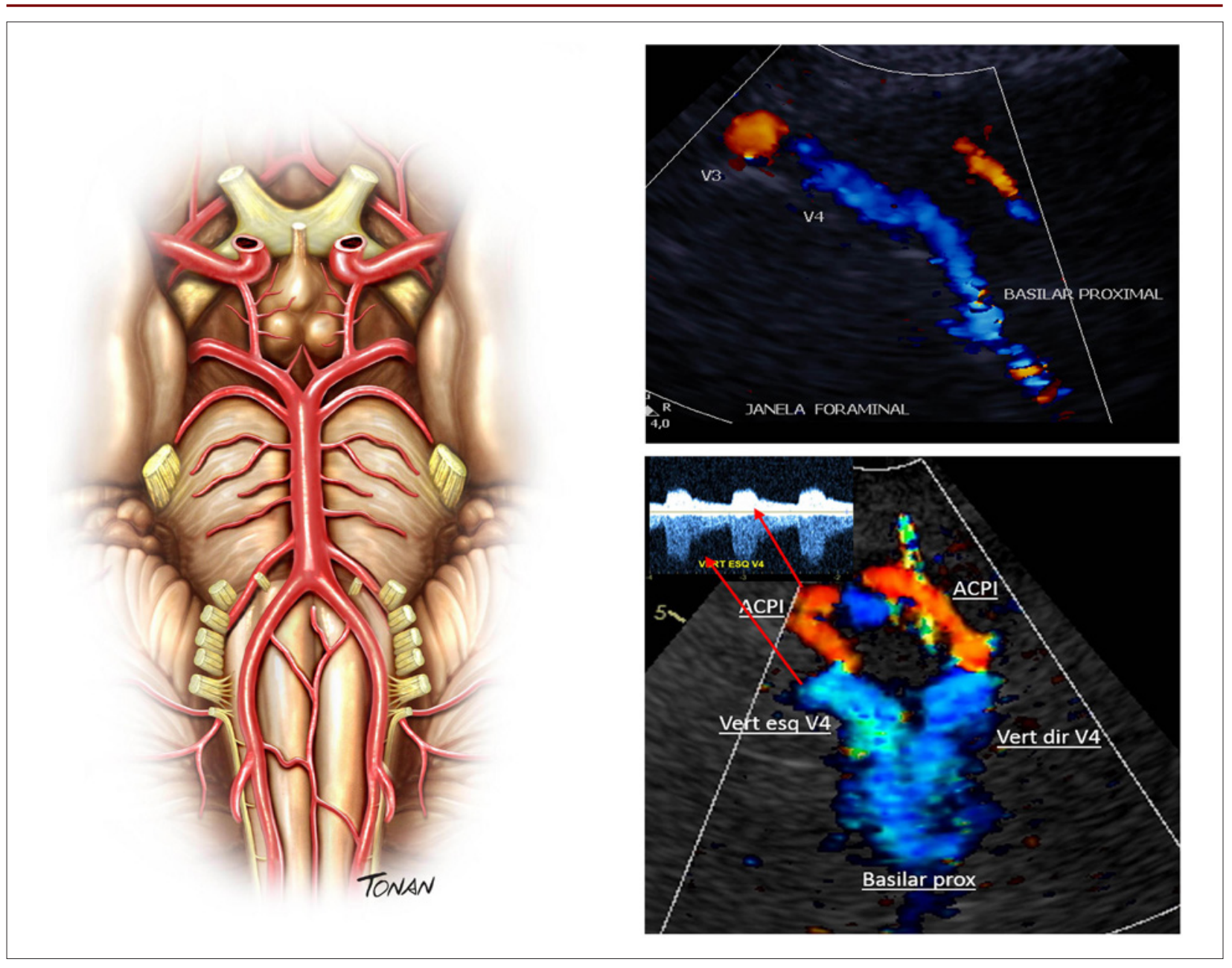

Figura 44 - Segmento vertebrobasilar intracraniano com origem da artéria cerebelar posterior inferior (ACPI).

assimetria de diâmetro, há considerável diferença de Vmáx e índice de resistência (IR) entre vertebrais normais de um mesmo indivíduo ${ }^{168}$.

Obs.: Idosos com artérias intracranianas mais rígidas por arteriosclerose podem apresentar IR mais elevado, e isso não indica necessariamente obstrução distal ${ }^{171}$.

A hipoplasia de vertebral é uma variante anatômica com relatos muito discordantes de prevalência na literatura, variando de $1,9 \%-26,5 \%$ na população geral ${ }^{172}$. Tal variação se justifica em parte pela diversidade de critérios e métodos utilizados. Geralmente é definida como diâmetro do vaso igual ou inferior a 2,0 mm (ou assimetria de calibre entre as vertebrais com relação $>1: 1,7)$. Velocidades de fluxo sanguineo reduzidas e curvas espectrais com padrão de resistência elevada são critérios funcionais para a sua definição ${ }^{169}$. A hipoplasia dificulta a identificação do vaso. Sempre que isso ocorrer deve-se pesquisar sua presença em todos os segmentos possíveis e avaliar a vertebral contralateral, que costuma ser calibrosa (Figura 45). Uma vertebral hipoplásica impossibilita o diagnóstico de lesão obstrutiva distal baseada em padrão de curva espectral da onda de fluxo e tal hipótese deve ser avaliada com outro método de imagem, incluindo-se o Doppler transcraniano.

Obs.: Mais recentemente tem-se correlacionado a presença de hipoplasia da vertebral a maior prevalência de AVE isquêmico em território posterior ${ }^{173,174}$. Essa hipótese, contudo, necessita de maior validação por estudos.

\section{Quantificação da estenose}

\section{Estenose proximal (V0-V1)}

O diagnóstico baseia-se na identificação de turbilhonamento ao color Doppler e aumento de velocidades de fluxo no local da lesão (que nem sempre é visualizada). Em vertebrais com curso tortuoso pode haver um aumento fisiológico das velocidades. Uma curva espectral amortecida à vazante corrobora a presença de estenose significativa proximal. Em casos com imagem bidimensional de boa qualidade pode-se identificar a redução luminal do vaso e medir, com auxílio do powerangio, o lúmen residual pelo critério anatômico distal (Figura 46). 
Recomendamos a utilização da tabela 8, adaptada do estudo de Yang Hua e cols. ${ }^{175}$, com valores de corte para a definição dos graus de estenose proximal da artéria vertebral. A velocidade de pico sistólica (VPS) na origem do vaso é o parâmetro de maior especificidade (> 90\%) para quantificação de estenose vertebral proximal, quando comparada aos demais critérios espectrais como índice de velocidade máxima (IVV) e velocidade diastólica final (VDF).

\section{Estenose vertebral nos demais segmentos (V2-V4)}

Quando o local da estenose é identificado ao ultrassom, sua avaliação deve se basear em análise multiparamétrica

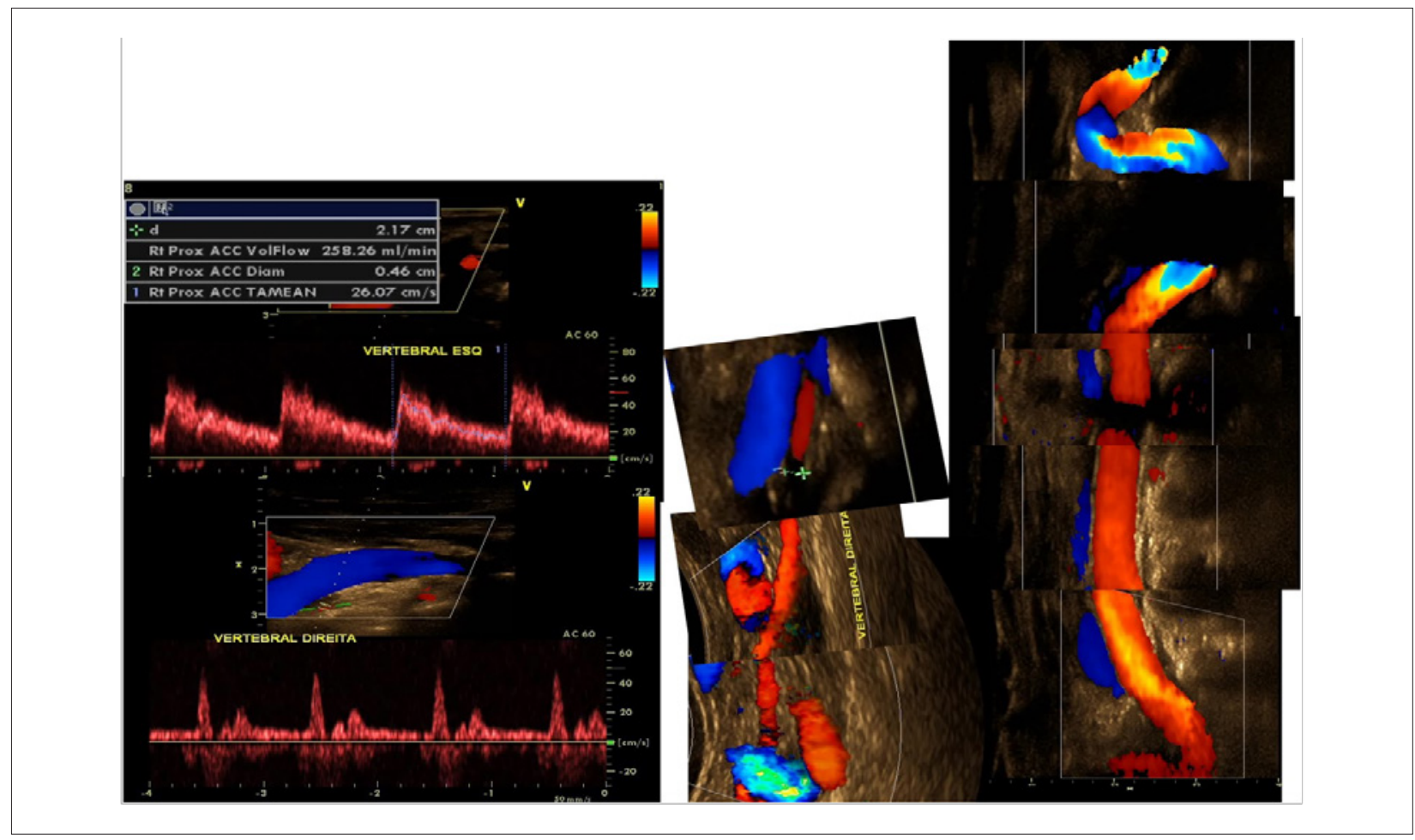

Figura 45 - Hipoplasia da artéria vertebral direita com fluxos comparativos (alta resistência à direita).

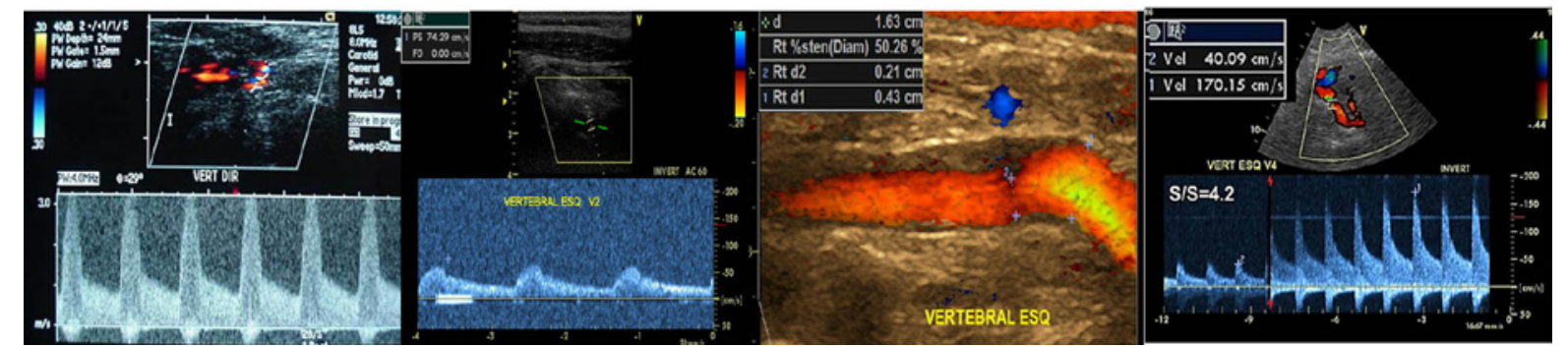

Figura 46 - Parâmetros diagnósticos de estenose da artéria vertebral: A- Velocidades sistodiastólicas no ponto da estenose; B-Amortecimento pós-estenótico do fluxo; $C$ - Medida bidimensional pelo critério anatômico distal; $D$ - Índices de velocidade.

Tabela 8 - Valores de corte para velocidades nas estenoses proximais da artéria vertebral (adaptada de Yang Hua e cols. ${ }^{175}$ )

\begin{tabular}{lccc}
\hline Estenose & $<50 \%$ & $50-69 \%$ & $70-99 \%$ \\
\hline VPS & $\geq 85 \mathrm{~cm} / \mathrm{s}$ & $\geq 140 \mathrm{~cm} / \mathrm{s}$ & $\geq 210 \mathrm{~cm} / \mathrm{s}$ \\
IVV & $\geq 1.3$ & $\geq 2.1$ & $\geq 4$ \\
VDF & $\geq 27 \mathrm{~cm} / \mathrm{s}$ & $\geq 35 \mathrm{~cm} / \mathrm{s}$ & $\geq 55 \mathrm{~cm} / \mathrm{s}$ \\
\hline
\end{tabular}

*IVV= Índice de vel máxima no ponto da estenose e o segmento V2. 


\section{Artigo Especial}

como turbulência ao color Doppler, aumento localizado das velocidades de fluxo, aumento dos índices de velocidade e amortecimento do fluxo distal, uma vez que não existem tabelas de quantificação das estenoses para esses segmentos.

Nos casos de segmentos não visualizáveis ao exame convencional (segmento V4 intracraniano), os achados são indiretos e correlacionam-se com o nível da estenose e emergência do ramo cerebelar posterior inferior (ACPI). Nas estenoses pré-emergência do ramo cerebelar posterior inferior (pré-ACPI) as curvas espectrais apresentam velocidades reduzidas e padrão de resistência elevada registradas nos segmentos V1-V2. Estenose após emergência do ramo cerebelar posterior inferior (pós-ACPI) não causa alteração de fluxo, pois há desvio para o cerebelo. Nesses casos, o estudo com DTC torna-se indispensável para o diagnóstico.

\section{Oclusão de vertebral}

Os achados variam de acordo com o nível da oclusão. A Figura 47 mostra as possíveis curvas espectrais de acordo com o nível da oclusão. Não raro, uma vertebral ocluída em sua origem pode reabitar em seu segmento distal através de circuitos anastomóticos bem definidos ${ }^{169,176-178}$. Essa possibilidade deve ser pesquisada através do estudo dos segmentos extracranianos distais.

\section{Síndrome do roubo pela subclávia}

Estenose hemodinâmicamente significativa ou oclusão do tronco braquiocefálico ou de segmento proximal da artéria subclávia (direita ou esquerda) provoca efeito de "roubo" de fluxo da vertebral contralateral (caso a vertebral ipsilateral tenha calibre normal e ausência de doença ateromatosa significativa associada) para suprir a subclávia acometida ${ }^{167-169,179}$. Nesse caso, a morfologia da curva espectral e direção da onda de fluxo em vertebral do mesmo lado da subclávia comprometida, em repouso ou após manobra de provocação de hiperemia reativa (compressão do membro superior ipsilateral com manguito de pressão insuflado), permite avaliar o efeito de "roubo". Ao contrário das estenoses vertebrais distais em que o primeiro componente afetado é o componente diastólico, no "roubo" a primeira alteração ocorre durante a fase sistólica, com breve desaceleração do fluxo sistólico (quase imperceptível para examinadores menos experientes). A Figura 48 apresenta a classificação dos diferentes tipos de morfologia das curvas espectrais encontradas nas artérias vertebrais. Em geral, o tipo de roubo correlaciona-se com graus maiores de estenose da subclávia.

\section{Considerações finais}

A pesquisa de estenose na origem da artéria vertebral, a avaliação direta e indireta de estenoses distais ou do efeito

\section{Oclusão proximal}

Pode haver reabitação distal ( V2-V3) através de colaterais como ramos tireocervicais, rede anastomótica de Bosniak ou rede de Mirabile.

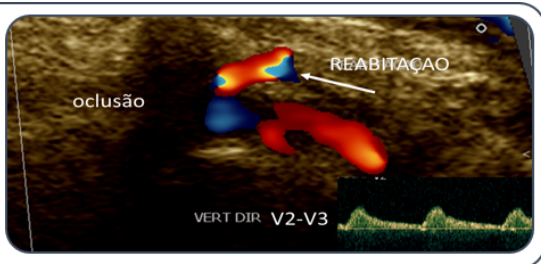

\section{Oclusão distal pré artéria cerebelar inferior ( $\mathrm{ACPI}$ )}

Fluxo de baixa amplitude, alta resistência e sem componente diastólico.

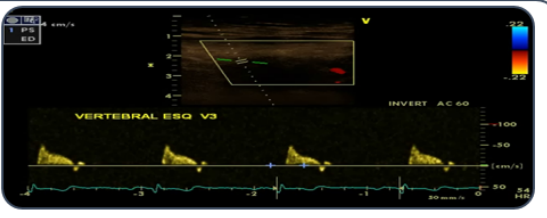

\section{Oclusão de vertebral ( V4) após a (ACPI)}

Fluxo com padrão normal transferindo-se para a PICA que irriga o cerebelo.

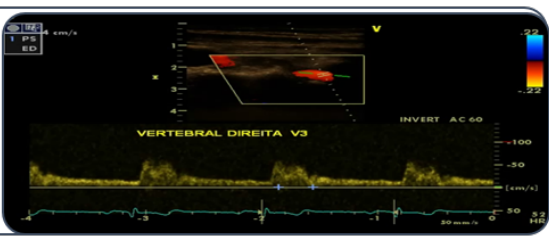

\section{Oclusão de basilar}

curvas espectrais de oclusão distal em ambas as artérias vertebrais.

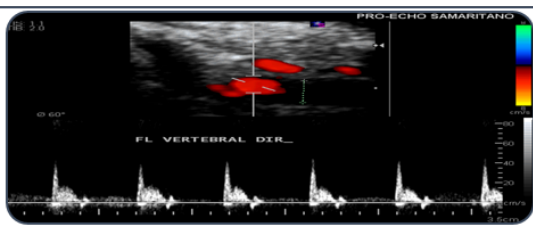

Figura 47 - Curvas espectrais de acordo com o nivel de oclusão da artéria vertebral. 
Roubo Tipo 1 - Latente

Desaceleração sistólica

Manobra de hiperemia reativa pode

potencializar o fenômeno.

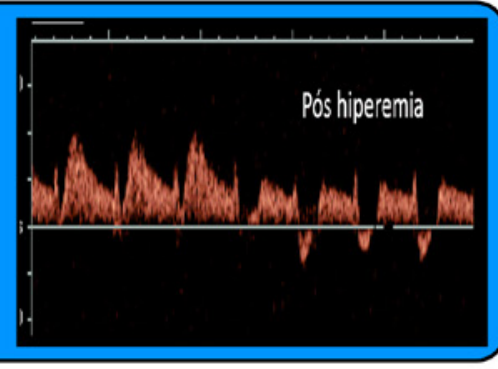

Roubo Tipo 2 - Intermitente ou parcial

Inversão sistólica do fluxo.

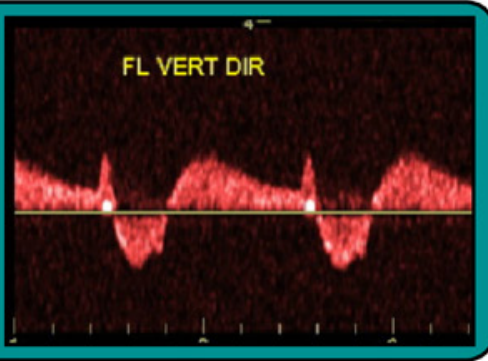

\section{Roubo Tipo 3 - Completo}

Inversão sisto diastólica do fluxo.

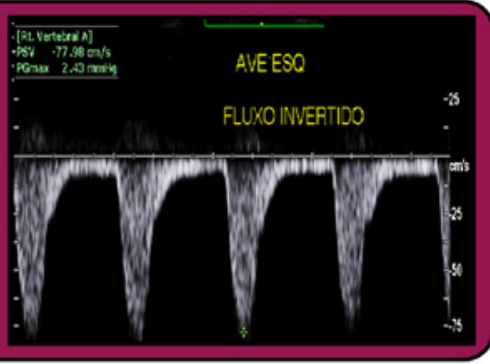

Figura 48 - Classificação dos tipos de roubo de acordo com o padrão de curva espectral.

hemodinâmico de estenoses ou oclusões em outros sítios são partes integrantes do estudo dos troncos supra-aórticos, não devendo ser negligenciadas pelo examinador. As informações obtidas podem ser relevantes e de grande importância prognóstica. Acidentes vasculares no território posterior apresentam impacto socioeconomico semelhante àquele envolvendo o território carotídeo. Com técnicas endovasculares atualmente disponíveis podemos modificar a história natural desses pacientes.

\section{Conclusão Geral}

Essas recomendações foram realizadas por um grupo de especialistas com grande experiência na área de ecografia vascular que visou reunir e analisar, criteriosamente, as evidências científicas que suportam a qualificação e quantificação da doença aterosclerótica no sistema carotideovertebral extracraniano. Ainda são muitas as lacunas de conhecimento sobre o assunto; entretanto, a despeito disso, temos critérios de ampla utilização e revalidados, que são de muito interesse e aplicabilidade por todos que atuam nessa área do conhecimento. Também, essa recomendação reafirma conceitos estabelecidos ao longo da história desse exame complementar.

Com a crescente inovação na área tecnológica de aparelhos de ultrassom, a revisão de critérios e adoção de novos parâmetros que venham a surgir vão ser uma busca constante dos comitês de especialistas para tentar, cada vez com menor invasividade e custo, típico da ferramenta do ultrassom, melhorar a acurácia diagnóstica e prognóstica.

\section{Grupos de Trabalho}

Grupo 1 - Introdução e recomendações técnicas

Participantes: Cláudia Maria Vilas Freire; Salomon Israel do Amaral; Orlando Veloso.

Grupo 2 - Espessura mediointimal e placas carotídeas

Participantes: Simone Nascimento dos Santos; Ana Cristina Lopes Albricker. 
Grupo 3 - Avaliação morfológica das placas carotídeas

Participantes: Salomon Israel do Amaral; Carmen Lucia Lascasas Porto; Márcio Vinícius Lins Barros.

\section{Grupo 4 - Quantificação das estenoses carotídeas}

Participantes: Ana Cláudia Gomes Pereira Petisco; Fanilda Souto Barros; Salomon Israel do Amaral; Márcio Vinícius Lins Barros.

Grupo 5 - Avaliação após intervenção (stent e endarterectomia)

Participantes: Cláudia Maria Vilas Freire; José Aldo Ribeiro Teodoro.

\section{Grupo 6 - Avaliação das artérias vertebrais}

Participantes: Monica Luiza de Alcantara; Orlando Veloso; Armando Luiz Cantisano.

Ilustrações médicas: Rodrigo Tonan.

\section{Contribuição dos autores}

Concepção e desenho da pesquisa: Freire CMF; Alcantara ML, Santos SN, Amaral SI, Veloso O, Porto CLL, Barros MVL, Albricker ACL, Petisco ACGP, Barros FS, Teodoro JAR, Cantisano AL, Moreira JC, Rabischoffsky A; Obtenção de dados: Freire CMF, Alcantara ML, Santos SN; Amaral SI, Veloso O, Porto CLL, Barros MVL, Albricker ACL, Petisco
ACGP, Barros FS, Teodoro JAR, Cantisano AL, Moreira JC, Rabischoffsky A; Análise e interpretação dos dados: Freire CMF, Alcantara ML, Santos SN, Amaral SI, Veloso O, Porto CLL, Barros MVL, Albricker ACL, Petisco ACGP, Barros FS, Teodoro JAR, Cantisano AL, Moreira JC, Rabischoffsky A; Redação do manuscrito: Freire CMF; Alcantara ML, Santos $\mathrm{SN}$, Amaral SI, Veloso O, Porto CLL, Barros MVL, Albricker ACL, Petisco ACGP, Barros FS, Teodoro JAR, Cantisano AL, Moreira JC, Rabischoffsky A; Revisão crítica do manuscrito quanto ao conteúdo intelectual importante: Freire CMF, Alcantara ML, Santos SN, Amaral SI, , Veloso O, Porto CLL, Barros MVL, Albricker ACL, Petisco ACGP, Barros FS, Teodoro JAR, Cantisano AL, Moreira JC, Rabischoffsky A; Coordenação do grupo: Freire CMF, Alcantara ML, Santos SN.

\section{Potencial Conflito de Interesses}

Declaramos não haver conflito de interesses pertinentes.

\section{Fontes de Financiamento}

O presente estudo não teve fontes de financiamento externas.

\section{Vinculação Acadêmica}

Não há vinculação deste estudo a programas de pós-graduação.

\section{Referências}

1. Grant EG, Benson CB, Moneta GL, Alexandrow AV, Baker JD, Bluth El et al. Carotid artery stenosis: gray-scale and Doppler US diagnosis--Society of Radiologists in Ultrasound Consensus Conference. Radiology. 2003; 229(2):340-6.

2. AbuRahma AF, Srivastava M, Stone PA, Mousa AY, Jain A, Dean LS et al. Critical appraisal of the Carotid Duplex Consensus criteria in the diagnosis of carotid artery stenosis. J Vasc Surg. 2011; 53(1):53-9; discussion 9-60.

3. Oates $\mathrm{CP}$, Naylor AR, Hartshorne T, Charles SM, Fail T, Humphries K et al. Joint recommendations for reporting carotid ultrasound investigations in the United Kingdom. Eur J Vasc Endovasc Surg. 2009; 37(3):251-61.

4. Serena J, Irimia P, Calleja S, Blanoc M, Vivancos J, Ayo-Martins O et al. [Ultrasound measurement of carotid stenosis: recommendations from the Spanish Society of Neurosonology]. Neurologia. 2013; 28(7):435-42.

5. Langlois YR, Roederer E Jr, Strandness DJ. Ultrasonic evaluation of carotid bifurcation. Echocardiography. 1987;4(2):141-59.

6. Roederer GL, Langlois YR, Jager K. A simple spectral parameter for accurate classification of severe carotid artery disease. Bruit.1984;8:174.

7. Mattos MA, Hodgson KJ, Faught WE, Mansour A, Barkmeier LD, Ramsey $\mathrm{DE}$, et al. Carotid endarterectomy without angiography: is color-flow duplex scanning sufficient? Surgery. 1994;116(4):776-82.; discussion 82-3.

8. Dawson DL, Zierler RE, Strandness DE Jr, Clowes AW, Kohler TR. The role of duplex scanning and arteriography before carotid endarterectomy: a prospective study. J Vasc Surg. 1993;18(4):673-80.; discussion 80-3.

9. Ainsworth CD, Blake CC, Tamayo A, Beletsky V, Fenster A, Spence JD. 3D ultrasound measurement of change in carotid plaque volume: a tool for rapid evaluation of new therapies. Stroke. 2005;36(9):1904-9.
10. Naqvi TZ, Lee MS. Carotid Intima-Media Thickness and Plaque in Cardiovascular Risk Assessment. JACC Cardiovasc Imaging. 2014; 7(10):1025-38

11. Ward B, Baker AC, Humphrey VF. Nonlinear propagation applied to the improvement of resolution in diagnostic medical ultrasound. J Acoustic Soc Am.1997;101(1):143-54.

12. Christopher T. Finite amplitude distortion-based inhomogeneous pulse echo ultrasonic imaging. IEEE Trans Ultrason Ferroelectr Freq Control.1997;44(1):125-39.

13. Coleridge-Smith P, Labropoulos N, Partsch H, Myers K, Nicolaides A, Cavezzi A. Duplex ultrasound investigation of the veins in chronic venous disease of the lower limbs--UIP consensus document. Part I. Basic principles. Eur J Vasc Endovasc Surg. 2006;31(1):83-92.

14. Zwiebel WJ, Fruechte D. Basics of abdominal and pelvic duplex: instrumentation, anatomy, and vascular Doppler signatures. Semin Ultrasound CTMR.1992;13(1):3-21.

15. Gerhard-Herman M, Gardin JM, Jaff M, Roman M, Naqvi TZ, Mohler E, et al. Guidelines for noninvasive vascular laboratory testing: a report from the American Society of Echocardiography and the Society of Vascular Medicine and Biology. J Am Soc Echocardiogr.2006;19(8):955-72.

16. Yurdakul M, Tola M, Cumhur T. B-flow imaging for assessment of $70 \%$ to $99 \%$ internal carotid artery stenosis based on residual lumen diameter. J Ultrasound Med.2006;25(2):211-5.

17. Pinto CAV. Contraste por microbolhas em ultrassonografia no diagnostico diferencial entre oclusão e pseudoclusão da carótida interna: correlação co a angiotomografia [Tese]. São Paulo: Faculdade de Medicina. Universidade de São Paulo;2010. 
18. Ten Kate GL, van den Oord SC, Sijbrands EJ, van der Lugt A, de Jong N, Bosch $\mathrm{JG}$, et al.Current status and future developments of contrast-enhanced ultrasound of carotid atherosclerosis. J Vasc Surg. 2013;57(2):539-46.

19. Yusuf S, Zhao F, Mehta SR, Chrolavicius S, Tognoni G, Fox KK. Effects of clopidogrel in addition to aspirin in patients with acute coronary syndromes without ST-segment elevation. N Engl J Med. 2001;345(7):494-502.

20. Brundtland $\mathrm{GH}$. From the World Health Organization. Reducing risks to health, promoting healthy life. JAMA. 2002;288(16):1974.

21. Gaziano TA, Bitton A, Anand S, Abrahams-Gessel S, Murphy A. Growing epidemic of coronary heart disease in low- and middle-income countries. Curr Probl Cardiol.2010; 35(2):72-115.

22. Wilson PW, D'Agostino RB, Levy D, Belanger AM, Silbershatz H, Kannel WB. Prediction of coronary heart disease using risk factor categories. Circulation. 1998:97(18):1837-47.

23. Sociedade Brasileira de Cardiologia, Xavier HT, Izar MC, Faria Neto JR, Assad MH, Rocha VZ, Sposito AC, et al. [V Brazilian Guidelines on Dyslipidemias and Prevention of Atherosclerosis]. Arq Bras Cardiol.2013;101(4 Suppl 1):1-20.

24. Grundy SM, Pasternak R, Greenland P, Smith SJr, Fuster V. AHA/ACC scientific statement: Assessment of cardiovascular risk by use of multiple-risk-factor assessment equations: a statement for healthcare professionals from the American Heart Association and the American College of Cardiology. J Am Coll Cardiol .1999;34(4):1348-59.

25. Assmann G, Cullen P, Schulte H. Simple scoring scheme for calculating the risk of acute coronary events based on the 10-year follow-up of the prospective cardiovascular Munster (PROCAM) study. Circulation. 2002; 105(3): 310-5.

26. Brindle P, Beswick A, Fahey T, Ebrahim S. Accuracy and impact of risk assessment in the primary prevention of cardiovascular disease: a systematic review. Heart. 2006;92(12):1752-9.

27. Woodward M, Brindle P, Tunstall-Pedoe H, SIGN group on estimation. Adding social deprivation and family history to cardiovascular risk assessment: the ASSIGN score from the Scottish Heart Health Extended Cohort (SHHEC). Heart. 2007;93(2):172-6.

28. Ford ES, Giles WH, Mokdad AH. The distribution of 10-Year risk for coronary heart disease among US adults: findings from the National Health and Nutrition Examination Survey III. J Am Coll Cardiol. 2004;43(10):1791-6.

29. Jacobson TA, Griffiths GG, Varas C, Gause D, Sung JC, Ballantyne CM. Impact of evidence-based "clinical judgment" on the number of American adults requiring lipid-lowering therapy based on updated NHANES III data. National Health and Nutrition Examination Survey. Arch Intern Med.2000;160(9):1361-9.

30. Sposito AC, Caramelli B, Fonseca FA, Bertolami MC, Afiune Neto A, Souza $A D$, et al. [IV Brazilian Guideline for Dyslipidemia and Atherosclerosis prevention: Department of Atherosclerosis of Brazilian Society of Cardiology]. Arq Bras Cardiol.2007;88(Suppl 1):2-19.

31. Touboul PJ, Hennerici MG, Meairs S, Adams H, Amarenco F, Bornstein $\mathrm{N}$, et al. Mannheim carotid intima-media thickness and plaque consensus (2004-2006-2011). An update on behalf of the advisory board of the $3 \mathrm{rd}$, 4th and 5th watching the risk symposia, at the 13th, 15th and 20th European Stroke Conferences, Mannheim, Germany, 2004, Brussels, Belgium, 2006, and Hamburg, Germany, 2011. Cerebrovasc Dis. 2012; 34(4):290-6.

32. Stein JH, Korcarz CE, Hurst RT, Lonn E, Kendall CB, Mohler ER. Use of carotid ultrasound to identify subclinical vascular disease and evaluate cardiovascular disease risk: a consensus statement from the American Society of Echocardiography Carotid Intima-Media Thickness Task Force. Endorsed by the Society for Vascular Medicine. J Am Soc Echocardiogr.2008;21(2):93-111.

33. Salonen JT, Salonen R. Ultrasonographically assessed carotid morphology and the risk of coronary heart disease. Arterioscler Thromb.1991;11(5):1245-9.
34. Chambless LE, Heiss G, Folsom AR, Rosamond W, Szlo M, Sharrett AR, et al.Association of coronary heart disease incidence with carotid arterial wal thickness and major risk factors: the Atherosclerosis Risk in Communities (ARIC) Study, 1987-1993. Am J Epidemiol.1997;146(6):483-94.

35. Lorenz MW, von Kegler S, Steinmetz H, Markus HS, Sitzer M. Carotid intima-media thickening indicates a higher vascular risk across a wide age range: prospective data from the Carotid Atherosclerosis Progression Study (CAPS). Stroke. 2006;37(1):87-92.

36. van der Meer IM, Bots ML, Hofman A, del Sol AI, van der Kuip DA Witteman JC. Predictive value of noninvasive measures of atherosclerosis for incident myocardial infarction: the Rotterdam Study. Circulation. 2004;109(9):1089-94.

37. Yeboah J, McClelland RL, Polonsky TS, Burke GL, Sibley CT, O'Leary $\mathrm{D}$, et al. Comparison of novel risk markers for improvement in cardiovascular risk assessment in intermediate-risk individuals. JAMA.2012;308(8):788-95

38. Polak JF, Pencina MJ, Pencina KM, O'Donnell CJ, Wolf PA, D'Agostino RB Carotid-wall intima-media thickness and cardiovascular events. N Engl J Med. 2011;365(3):213-21.

39. Johnsen $\mathrm{SH}$, Mathiesen EB, Joakimsen O, Stensland E, Welsgaard T, Lochen $\mathrm{ML}$, et al. Carotid atherosclerosis is a stronger predictor of myocardial infarction in women than in men: a 6-year follow-up study of 6226 persons: the Tromso Study. Stroke. 2007;38(11):2873-80.

40. Polak JF, Pencina MJ, O'Leary DH, D'Agostino RB. Common carotid artery intima-media thickness progression as a predictor of stroke in multi-ethnic study of atherosclerosis. Stroke. 2011;42(11):3017-21.

41. Howard G, Sharrett AR, Heiss G, Evans GW, Chambless LE, Riley WA. Carotid artery intimal-medial thickness distribution in general populations as evaluated by B-mode ultrasound. ARIC Investigators. Stroke. 24(9):1297-304.

42. Santos IS, Bittencourt MS, Oliveira IR, Souza AG, Meireles DP, Rundek T, et al. Carotid intima-media thickness value distributions in The Brazilian Longitudinal Study of Adult Health (ELSA-Brasil). Atherosclerosis. 2014;237(1):227-35.

43. Nambi V, Chambless L, Folsom AR, Mosley T, Boerwinkle E, Ballantyne CM. Carotid intima-media thickness and presence or absence of plaque improves prediction of coronary heart disease risk: the ARIC (Atherosclerosis Risk In Communities) study. J Am Coll Cardiol. 2010;55(15):1600-7.

44. Den Ruijter HM, Peters SA, Anderson TJ, Britton AR, Dekker JM, Eijker-Mans MJ, et al. Common carotid intima-media thickness measurements in cardiovascular risk prediction: a meta-analysis. JAMA. 2012; 308(8):796-803

45. Anderson TJ, Charbonneau F, Title LM, Buithieu J, Rose MS, Conradson $\mathrm{H}$, et al. Microvascular function predicts cardiovascular events in primary prevention: long-term results from the Firefighters and Their Endothelium (FATE) study. Circulation. 2011;123(2):163-9.

46. Lorenz MW, Schaefer C, Steinmetz H, Sitzer M. Is carotid intima media thickness useful for individual prediction of cardiovascular risk? Ten-year results from the Carotid Atherosclerosis Progression Study (CAPS). Eur Heart). 2010;31(16):2041-8.

47. Goff DC Jr, Lloyd-Jones DM, Bennett G, Coady S, D'Agostino RB Gibbons R, et al. 2013 ACC/AHA guideline on the assessment of cardiovascular risk: a report of the American College of Cardiology/ American Heart Association Task Force on Practice Guidelines. Circulation. 2014;129(25 Suppl 2):S49-73.

48. Simao AF, Precoma DB, Andrade JP, Correa FH, Saraiva JF, Oliveira GM, et al.[l Brazilian Guidelines for Cardiovascular Prevention].Arq Bras Cardiol.2013;101(6Suppl2):1-63.

49. Inaba Y, Chen JA, Bergmann SR. Carotid plaque, compared with carotid intima-media thickness, more accurately predicts coronary artery disease events: a meta-analysis. Atherosclerosis. 2012;220(1):128-33. 
50. Touboul PJ, Labreuche J, Vicaut E, Amarenco P, Investigators G. Carotid intima-media thickness, plaques, and Framingham risk score as independent determinants of stroke risk. Stroke. 2005;36(8):1741-5.

51. Rosvall M, Janzon L, Berglund G, Engstrom G, Hedblad B. Incident coronary events and case fatality in relation to common carotid intima-media thickness. J Intern Med.2005;257(5):430-7.

52. Cournot M, Taraszkiewicz D, Cambou JP, Galinier M, Boccalon H, Hanaire-Broutin $\mathrm{H}$, et al. Additional prognostic value of physical examination, exercise testing, and arterial ultrasonography for coronary risk assessment in primary prevention. Am Heart J. 2009;158(5):845-51.

53. Plichart M, Celermajer DS, Zureik M, Helmer C, Jouven X, Ritchie K, et al. Carotid intima-media thickness in plaque-free site, carotid plaques and coronary heart disease risk prediction in older adults. The Three-City Study. Atherosclerosis. 2011;219(2):917-24.

54. Cao JJ, Arnold AM, Manolio TA, Polak JF, Psaty BM, Hirsch CH, et al. Association of carotid artery intima-media thickness, plaques, and C-reactive protein with future cardiovascular disease and all-cause mortality: the Cardiovascular Health Study. Circulation. 2007;116(1):32-8.

55. Polak JF, Szklo M, Kronmal RA, Burke GL, Shea S, Zavodni AE, et al. The value of carotid artery plaque and intima-media thickness for incident cardiovascular disease: the multi-ethnic study of atherosclerosis. J Am Heart Assoc. 2013;2(2):e000087.

56. Lorenz MW, Polak JF, Kavousi M, Mathiesen EB, Volzke H, Tuomainer TP, et al.Carotid intima-media thickness progression to predict cardiovascular events in the general population (the PROG-IMT collaborative project): a meta-analysis of individual participant data. Lancet.2012;379(9831):2053-62.

57. Xie W, Wu Y, Wang W, Zhao D, Liang L, Wang M, et al. A longitudinal study of carotid plaque and risk of ischemic cardiovascular disease in the Chinese population. J Am Soc Echocardiogr. 2011;24(7):729-37.

58. Santos RD, Gagliardi AC, Xavier HT, Casella Filho A, Araujo DB, Cesena FX, et al. [First Brazilian Guidelines for Familial Hypercholesterolemia]. Arq Bras Cardiol. 2012;99(2 Suppl 2):1-28.

59. Folsom AR, Kronmal RA, Detrano RC, O'Leary DH, Bild DE, Bluemke DA, et al. Coronary artery calcification compared with carotid intima-media thickness in the prediction of cardiovascular disease incidence: the Multi-Ethnic Study of Atherosclerosis (MESA). Arch Int Med. 2008;168(12):1333-9.

60. Freire CM, Ribeiro AL, Barbosa FB, Nogueira Al, de Almeida MC, Barbosa $\mathrm{MM}$, et al. Comparison between automated and manual measurements of carotid intima-media thickness in clinical practice. Vasc Health Risk Manag. 2009;5:811-7

61. Doyon A, Kracht D, Bayazit AK, Deveci M, Duzova A, Kramar RT, et al. Carotid artery intima-media thickness and distensibility in children and adolescents: reference values and role of body dimensions. Hypertension. 2013;62(3):550-6.

62. Bohm B, Hartmann K, Buck M, Oberhoffer R. Sex differences of carotid intima-media thickness in healthy children and adolescents. Atherosclerosis 2009;206(2):458-63.

63. Hayward RA, Krumholz HM, Zulman DM, Timbie JW, Vijan S. Optimizing statin treatment for primary prevention of coronary artery disease. Ann Intern Med. 2010;152(2):69-77.

64. Collins GS, Altman DG. An independent external validation and evaluation of QRISK cardiovascular risk prediction: a prospective open cohort study. BMJ. 2009;339:b2584.

65. Widder B, Paulat K, Hackspacher J, Hamann H, Hutschenreiter S, Kreutzer C, etal. Morphological characterization of carotid artery stenoses by ultrasound duplex scanning. Ultrasound Med Biol. 1990;16(4):349-54.

66. Davies MJ, Richardson PD, Woolf N, Katz DR, Mann J. Risk of thrombosis in human atherosclerotic plaques: role of extracellular lipid, macrophage, and smooth muscle cell content. Br Heart J. 1993;69(5):377-81.
67. Libby P. Molecular bases of the acute coronary syndromes. Circulation. 1995;91(11):2844-50.

68. Wain RA, Lyon RT, Veith FJ, Berdejo GL, Yuan JG, Suggs WD, et al. Accuracy of duplex ultrasound in evaluating carotid artery anatomy before endarterectomy. J Vasc Surg.1988;27(2):235-42.; discussion 42-4.

69. Landry A, Spence JD, Fenster A. Measurement of carotid plaque volume by 3-dimensional ultrasound. Stroke. 2004;35(4):864-9.

70. de Bray JM, Baud JM, Dauzat M. Consensus concerning the morphology and the risk of carotid plaques. Cerebrovasc Dis. 1997;7:289-96.

71. Reilly LM, Lusby RJ, Hughes L, Ferrell LD, Stoney RJ, Ehrenfeld WK. Carotid plaque histology using real-time ultrasonography: clinical and therapeutic implications. Am J Surg.1983;146(2):188-93.

72. Geroulakos G, Ramaswani G, Nicolaides A, James K, Labropoulos, N, Belcaro G, et al.. Characterization of symptomatic and asymptomatic carotid plaques using high-resolution real-time ultrasonography. Br J Surg. 1993;80(10):1274-7.

73. el-Barghouty N, Geroulakos G, Nicolaides A, Androulakis A, Bahal V. Computer-assisted carotid plaque characterisation. Eur J Vasc Endovasc Surg. 1995;9(4):389-93.

74. Muraki M, Mikami T, Yoshimoto T, Fujimoto S, Tokuda K, Kaneko S, et al. New criteria for the sonographic diagnosis of a plaque ulcer in the extracranial carotid artery. AJR Am J Roentgenol. 2012;198(5):1161-6.

75. Johnson JM, Kennelly MM, Decesare D, Morgan S, Sparrow A. Natural history of asymptomatic carotid plaque. Arch Surg.1985;120(9):1010-2.

76. Langsfeld M, Gray-Weale AC, Lusby RJ. The role of plaque morphology and diameter reduction in the development of new symptoms in asymptomatic carotid arteries. J Vasc Surg. 1989;9(4):548-57.

77. Polak JF, Shemanski L, O'Leary DH, Lefkowitz D, Price TR, Savage PJ, et al. Hypoechoic plaque at US of the carotid artery: an independent risk factor for incident stroke in adults aged 65 years or older. Cardiovascular Health Study. Radiology .1998;208(3):649-54.

78. Mathiesen EB, Bonaa KH, Joakimsen O. Echolucent plaques are associated with high risk of ischemic cerebrovascular events in carotid stenosis: the Tromso Study. Circulation .2001;103(17):2171-5.

79. Momjian-Mayor I, Kuzmanovic I, Momjian S, Bonvin C, Albanese S, Bichsel D, et al. Accuracy of a novel risk index combining degree of stenosis of the carotid artery and plaque surface echogenicity. Stroke.2012; 43(5):1260-5

80. Nicolaides AN, Kakkos SK, Griffin M, Sabetai M, Dhanjil S, Thomas DJ, et al. Effect of image normalization on carotid plaque classification and the risk of ipsilateral hemispheric ischemic events: results from the asymptomatic carotid stenosis and risk of stroke study. Vascular. 2005;13(4):211-21.

81. Cronenwett JL, Johnston KW. Rutherford's vascular surgery. $8^{\text {th }}$ ed. Philadelphia: Elsevier Saunders; 2014.

82. North American Symptomatic Carotid Endarterectomy Trial C. Beneficial effect of carotid endarterectomy in symptomatic patients with high-grade carotid stenosis. N Engl J Med. 1991;325(7)445-53.

83. MRC European Carotid Surgery Trial: interim results for symptomatic patients with severe (70-99\%) or with mild (0-29\%) carotid stenosis. European Carotid Surgery Trialists' Collaborative Group. Lancet. 1991; 337(8752):1235-43.

84. Endarterectomy for asymptomatic carotid artery stenosis. Executive Committee for the Asymptomatic Carotid Atherosclerosis Study. JAMA.1995:273(18):1421-8.

85. Faries PL, Chaer RA, Patel S, Lin SC, De Rubertis B, Kent KC. Current management of extracranial carotid artery disease. Vasc Endovasc Surg. 2006;40(3):165-75

86. Brott TG, Hobson RW 2nd, Howard G. Stenting versus endarterectomy for treatment of carotid-artery stenosis. N Engl J Med. 2010;363(1):11-23. 
87. Hankey GJ, Warlow CP, Sellar RJ. Cerebral angiographic risk in mild cerebrovascular disease. Stroke. 1990; 21(2):209-22.

88. Wardlaw JM, Chappell FM, Best JJ, Wartolowska K, Berry E; NHS Research and Development Health Technology Assessment Carotid Stenosis Imaging Group. Non-invasive imaging compared with intra-arterial angiography in the diagnosis of symptomatic carotid stenosis: a meta-analysis. Lancet. 2006;367(9521):1503-12.

89. Beach KW, Bergelin RO, Leotta DF, Primozich JF, Sevareid PM, Stutzman ET, et al. Standardized ultrasound evaluation of carotid stenosis for clinical trials: University of Washington Ultrasound Reading Center. Cardiovasc Ultrasound. 2010;8:39.

90. Ricotta JJ, Aburahma A, Ascher E, Eskandari M, Faries P, Lal BK, et al. Updated Society for Vascular Surgery guidelines for management of extracranial carotid disease. J Vasc Surg. 2011;54(3):e1-31

91. Pontes SM, Barros FS, Roelke LH, Almeida MAT, Sandri JL, Jacques C $M$, et al.. Mapeamento ecográfico da bifurcação das artérias carótidas extracranianas para planejamento cirúrgico: diferenças baseadas no gênero do paciente. J Vasc Bras. 2011;10(3):222-8.

92. Huston J 3rd, James EM, Brown RD Jr, Lefsrud RD, Ilstrup DM, Robertson $\mathrm{EF}$, et al. Redefined duplex ultrasonographic criteria for diagnosis of carotid artery stenosis. Mayo Clin Proc. 2000;75(11):1133-40.

93. Strandness DE. Duplex scanning in vascular disorders. New York:Lippincott Williams \& Wilkins; 2002.

94. AbuRahma AF, Robinson PA, Strickler DL, Alberts S, Young L. Proposed new duplex classification for threshold stenoses used in various symptomatic and asymptomatic carotid endarterectomy trials. Ann Vasc Surg. 1998;12(4):349-58.

95. von Reutern GM, Goertler MW, Bornstein NM, del Sette M, Evans DH, Hetzel A, et al. Grading carotid stenosis using ultrasonic methods. Stroke. 2012;43(3):916-21.

96. Arous EJ, Baril DT, Robinson WP, Aiello FA, Hevelone ND, Arous EJ, et al. Institutional differences in carotid artery duplex diagnostic criteria result in significant variability in classification of carotid artery stenoses and likely lead to disparities in care. Circ Cardiovasc Qual Outcomes. 2014; 7(3):423-9.

97. Bryant CE, Pugh N. D. Coleman DP, Morris RJ, Williams PT, Humphries $\mathrm{KN}$. Comparison of Doppler ultrasound velocity parameters in the determination of internal carotid stenosis. Ultrasound. 2013.21:124-31.

98. Scissons RP, Altenburg L, Hampton J, Hasenauer J, Jones L,Greg M, et al. Quantification of Doppler velocity measurements: Doppler cursor alignment parallel to wall versus parallel to flow stream. J Vasc Tech. 1998;22(1):17-21.

99. Tola M, Yurdakul M. Effect of Doppler angle in diagnosis of internal carotid artery stenosis. J Ultrasound Med.2006;25(9):1187-92.

100. Moneta G. Doença Carotídea Aterosclerótica. Rio de Janeiro: Editora Di Livros; 2011.

101. Wood MM, Romine LE, Lee YK, Richman KM, O'Boyle MK, Paz DA, et al. Spectral Doppler signature waveforms in ultrasonography: a review of normal and abnormal waveforms. Ultrasound Q. 2010;26(2):83-99.

102. Jmor S, El-Atrozy T, Griffin M, Tegos T, Dhanjil S, Nicolaides A. Grading internal carotid artery stenosis using B-mode ultrasound (in vivo study). Eur J Vasc Endovasc Surg.1999; 18(4):315-22.

103. Tahmasebpour HR, Buckley AR, Cooperberg PL, Fix CH. Sonographic examination of the carotid arteries. Radiographics. 2005;25(6):1561-75.

104. Petisco ACG, Saleh MH, Jesus CA, Metzger PB, Dourado MS. Doppler ecografia das artérias carótidas: critérios de velocidade validados pela arteriografia. Arq Bras Cardiol: Imagem Cardiovasc. 2015;28(1):17-21

105. Braun RM, Bertino RE, Milbrandt J, Bray M, Society of Radiologists in Ultrasound Consensus Criteria to a Single Institution Clinical P. Ultrasound imaging of carotid artery stenosis: application of the Society of Radiologists in Ultrasound Consensus Criteria to a Single Institution Clinical Practice. Ultrasound Q.2008;24(3):161-6.

106. Sabeti S, Schillinger M, Mlekusch W, Wellfort A, Haumer M, Nachtmann T, et al. Quantification of internal carotid artery stenosis with duplex US: comparative analysis of different flow velocity criteria. Radiology .2004;231(2):431-9.

107. Hood DB, Mattos MA, Mansour A, Ramsey DE, Hodgson KJ, Barkmeier LD, et al. Prospective evaluation of new duplex criteria to identify $70 \%$ interna carotid artery stenosis. J Vasc Surg.1996;23(2):254-61; discussion 61-2.

108. Faught WE, Mattos MA, van Bemmelen PS, et al. Color-flow duplex scanning of carotid arteries: new velocity criteria based on receiver operator characteristic analysis for threshold stenoses used in the symptomatic and asymptomatic carotid trials. Journal of vascular surgery 1994; 19(5): 818-27; discussion 27-8.

109. Shaalan WE, Wahlgren CM, Desai T, Piano G, Skelly C, Bassiouny HS Reappraisal of velocity criteria for carotid bulb/internal carotid artery stenosis utilizing high-resolution B-mode ultrasound validated with computed tomography angiography. J Vasc Surg.2008;48(1):104-12; discussion 12-3.

110. Jahromi AS, Cina CS, Liu Y, Clase CM. Sensitivity and specificity of color duplex ultrasound measurement in the estimation of internal carotid artery stenosis: a systematic review and meta-analysis. J Vasc Surg.2005;41(6):962-72.

111. Moneta GL, Edwards JM, Papanicolaou G, Hatsukami T, Taylor LM Jr, Strandness DE Jr, et al. Screening for asymptomatic internal carotid artery stenosis: duplex criteria for discriminating $60 \%$ to $99 \%$ stenosis. J Vasc Surg.1995;21(6):989-94.

112. Moneta GL, Edwards JM, Chitwood RW, Taylor L, Lee RW, Cummings CA et al. Correlation of North American Symptomatic Carotid Endarterectomy Trial (NASCET) angiographic definition of 70\% to $99 \%$ internal carotid artery stenosis with duplex scanning. J Vasc Surg.1993; 17(1):152-7; discussion 7-9.

113. Grant EG, Duerinckx AJ, El Saden SM, Melany ML, Hathout GT, Zimmerman PT et al. Ability to use duplex US to quantify internal carotid arteria stenoses: fact or fiction? Radiology.2000; 214(1): 247-52.

114. Filis KA, Arko FR, Johnson BL, Pipinos I, Harris EJ, Olcott C et al. Duplex ultrasound criteria for defining the severity of carotid stenosis. Ann Vasc Surg.2002; 16(4):413-21.

115. Nicolaides AN, Shifrin EG, Bradbury A, Dhanjil S, Griffin M, Belcaro G, et al. Angiographic and duplex grading of internal carotid stenosis: can we overcome the confusion? J Endovasc Surg.1996;3(2):158-65.

116. Chua HC, Sitoh YY, EarnestA, Venketasubramanian N. Detection of internal carotid artery stenosis with duplex velocity criteria using receiver operating characteristic analysis. Ann Acad Med Singapore. 2007;36(4):247-52.

117. Bluth El, Stavros AT, Marich KW, Wetzner SM, Aufrichtig D, Baker JD. Carotid duplex sonography: a multicenter recommendation for standardized imaging and Doppler criteria. Radiographics. 1988;8(3):487-506.

118. Brott TG, Halperin JL, Abbara S, Bacharach JM, Barr JD, Bush RL, et al. 2011 ASA/ACCF/AHA/AANN/AANS/ACR/ASNR/CNS/SAIP/SCAI/SIR/ SNIS/SVM/SVS guideline on the management of patients with extracranial carotid and vertebral artery disease: executive summary: a report of the American College of Cardiology Foundation/American Heart Association Task Force on Practice Guidelines, and the American Stroke Association, American Association of Neuroscience Nurses, American Association of Neurological Surgeons, American College of Radiology, American Society of Neuroradiology, Congress of Neurological Surgeons, Society of Atherosclerosis Imaging and Prevention, Society for Cardiovascular Angiography and Interventions, Society of Interventional Radiology, Society of NeuroInterventional Surgery, Society for Vascular Medicine, and Society for Vascular Surgery. Vasc Med.2011;16(1):35-77.

119. Yadav JS. Functional occlusions of the carotid artery (string signs): to treat or not to treat? JACC Cardiovasc Intervent. 2010;3(3):305-6 
120. Thanvi B, Robinson T. Complete occlusion of extracranial internal carotid artery: clinical features, pathophysiology, diagnosis and management. Postgrad Med J.2007;83(976):95-9.

121. Yamamoto T, Mori K, Yasuhara T, Tei M, Yokoi N, Kinoshita S, et al. Ophthalmic artery blood flow in patients with internal carotid artery occlusion. Br J Ophthalmol.2004;88(4):505-8.

122. Moneta GL, Esmode N, Rumwell E, Primozich JF. Moneta GL, Mitchell EL, et al. Extracranial carotid and vertebral arteries. In: Zierler RE, (editor) Strandness's duplex scanning in vascular disorders. 4th ed. Philadelphia: Lippincott Williams and Wilkins; 2010. p.87.

123. Clair DG, Greenberg RK. Diagnosis and treatment of proximal carotid lesions. Semin Vasc Surg.2000; 13(2):103-8.

124. Slovut DP, Romero JM, Hannon KM, Dick J, Jaff MR. Detection of common carotid artery stenosis using duplex ultrasonography: a validation study with computed tomographic angiography. J Vasc Med.2010;51(1):65-70.

125. Matos JM, Barshes NR, McCoy S, Pisimisis G, Felkai D, Kougias P, et al. Validating common carotid stenosis by duplex ultrasound with carotid angiogram or computed tomography scan. J Vasc Surg.2014;59(2):435-9.

126. Paivansalo MG, Siniluoto TM, Tikkakoski TA, Myllyla V, Suramo IJ. Duplex US of the external carotid artery. Acta Radiol.1996; 37:41.

127. Ascer E, Gennaro M, Pollina RM, Salles-Cunha S, Lorenson E, Yorkovich WR et al. The natural history of the external carotid artery after carotid endarterectomy: implications for management. J Vasc Surg.1996; 23(4):582-5

128. Beach KW, Leotta DF, Zierler RE. Carotid Doppler velocity measurements and anatomic stenosis: correlation is futile. Vasc Endovasc Surg.2012;46(6):466-74.

129. Morimoto N, Morimoto K, Morimoto $\mathrm{Y}$, Sakamoto $\mathrm{T}$, Matsumori M, Okada K, et al. Reverse diastolic flow in the common carotid artery in severe aortic regurgitation, causing brain ischemia. J Thorac Cardiovasc Surg.2008;135(5):1176-7.

130. Bendick PJ. Cardiac effects on peripheral vascular wave forms. J Vasc Ultrasound.2011;25(4):237-43.

131. Togay-Isikay C, Kim J, Betterman K, Andrews C, Meads D, Tesh P, et al. Carotid artery tortuosity, kinking, coiling: stroke risk factor, marker, or curiosity? Acta Neurol Belg. 2005;105(2):68-72.

132. Preiss JE, Itum DS, Reeves JG, Dewaryc Y, Rajani R, Veeraswamy R, et al. Carotid duplex criteria for patients with contralateral occlusion. J Surg Res.2015;193(1):28-32.

133. Ferguson GG, Eliasziw M, Barr HW, Clagett GP, Barnes RW, Wallace MC, et al. The North American Symptomatic Carotid Endarterectomy Trial: surgical results in 1415 patients. Stroke.1999;30(9):1751-8.

134. Randomised trial of endarterectomy for recently symptomatic carotid stenosis: final results of the MRC European Carotid Surgery Trial (ECST). Lancet. 1998;351(9113):1379-87.

135. Rothwell PM, Gibson RJ, Slattery J, Sellar RJ, Warlow CP. Equivalence of measurements of carotid stenosis. A comparison of three methods on 1001 angiograms. European Carotid Surgery Trialists' Collaborative Group. Stroke. 1994;25(12):2435-9.

136. Bartlett ES, Walters TD, Symons SP, Fox AJ. Quantification of carotid stenosis on CT angiography. AJNR Am J Neuroradiol. 2006;27(1):13-9.

137. Suwanwela N, Can U, Furie KL, Southern JF, Macdonald NR, Ogilvy CS, et al. Carotid Doppler ultrasound criteria for internal carotid artery stenosis based on residual lumen diameter calculated from en bloc carotid endarterectomy specimens. Stroke. 1996;27(11):1965-9.

138. Lanza G, Setacci C, Cremonesi A, Ricci S, Inzitari D, de Donato G, et al. Carotid Artery Stenting: Second Consensus Document of the ICCS/ ISO-SPREAD Joint Committee. Cerebrovasc Dis. 2014;38(2):77-93.

139. McPhee JT, Hill JS, Ciocca RG, Messina LM, Eslami MH. Carotid endarterectomy was performed with lower stroke and death rates than carotid artery stenting in the United States in 2003 and 2004. J Vasc Surg. 2007; 46(6):1112-8.

140. Meier P, Knapp G, Tamhane U, Chaturvedi S, Gurm HS. Short term and intermediate term comparison of endarterectomy versus stenting for carotid artery stenosis: systematic review and meta-analysis of randomised controlled clinical trials. BMJ. 2010;340:c467.

141. Yoshida S, Bensley RP, Glaser JD, Nabzdyk CS, Hamdan AW, Wyers MC, et al. The current national criteria for carotid artery stenting overestimate its efficacy in patients who are symptomatic and at high risk. J Vasc Surg. 2013;58(1):120-7.

142. Ascher E, Markevich N, Kallakuri S, Schutzer RW, Hingorani AP. Intraoperative carotid artery duplex scanning in a modern series of 650 consecutive primary endarterectomy procedures. J Vasc Surg.2004;39(2):416-20.

143. Ricco JB, Forbes TL. Trans-atlantic debate: the role of completion imaging following carotid artery endarterectomy. Eur J Vasc Endovasc Surg. 2013;45(5):423

144. Morales MM, Anacleto A, Buchdid MA, Simeoni PR, Ledesma S, Cêntala S, et al. Morphological and hemodynamic patterns of carotid stenosis treated by endarterectomy with patch closure versus stenting: a duplex ultrasound study. Clinics (Sao Paulo). 2010;65(12):1315-23.

145. Barros P, Felgueiras H, Pinheiro D, Guerra M, Gama V, Veloso M. Restenosis after carotid artery stenting using a specific designed ultrasonographic protocol. J Stroke Cerebrovasc Dis. 2014;23(6):1416-20.

145. AbuRahma AF, Abu-Halimah S, Bensenhaver J, Dean LS, Keiffer T, Emmett $M$, et al. Optimal carotid duplex velocity criteria for defining the severity of carotid in-stent restenosis. J Vasc Surg. 2008;48(3):589-94.

147. Bekelis K, Moses Z, Missios S, Desai A, Labropoulos N. Indications for treatment of recurrent carotid stenosis. Br J Surg .2013;100(4):440-7.

148. Willfort-Ehringer A, Ahmadi R, Gruber D, Gschwandtner ME, Haumer A, Haumer $M$, et al. .Arterial remodeling and hemodynamics in carotid stents: a prospective duplex ultrasound study over 2 years. J Vasc Surg. 2004;39(4):728-34.

149. Wasser K, Schnaudigel S, Wohlfahrt J, Psychogios MN, Schramm P, Knauth $\mathrm{M}$, et al. Cinical impact and predictors of carotid artery in-stent restenosis. J Neurol.2012;259(9):1896-902.

150. Setacci C, de Donato G, Setacci F, Pieraccini M, Cappelli A, Trovato R, et al. In-stent restenosis after carotid angioplasty and stenting: a challenge for the vascular surgeon. Eur J Vasc Endovasc Surg. $2005 ; 29(6): 601-7$

151. Lal BK, Kaperonis EA, Cuadra S, Kapadia I, Hobson RW 2nd. Patterns of in-stent restenosis after carotid artery stenting: classification and implications for long-term outcome. J Vasc Surg. 2007;46(5):833-40.

152. AbuRahma AF, Stone P, Deem S, Dean LS, Keiffer T, Deem E. Proposed duplex velocity criteria for carotid restenosis following carotid endarterectomy with patch closure. J Vasc Surg 2009; 50(2): 286-91, 91 e1-2; discussion 91.

153. Stanziale SF, Wholey MH, Boules TN, Selzer F, Makaroun MS. Determining in-stent stenosis of carotid arteries by duplex ultrasound criteria. J Endovasc Ther 2005 ; $12(3)$ : 346-53.

154. Cumbie T, Rosero EB, Valentine RJ, Modrall JG, Clagett GP, Timaran CH. Utility and accuracy of duplex ultrasonography in evaluating in-stent restenosis after carotid stenting. Am J Surg 2008; 196(5): 623-8.

155. Peterson BG, Longo GM, Kibbe MR, et al. Duplex ultrasound remains a reliable test even after carotid stenting. Ann Vasc Surg 2005; 19(6): 793-7.

156. Lal BK, Hobson RW, 2nd, Tofighi B, Kapadia I, Cuadra S, Jamil Z. Duplex ultrasound velocity criteria for the stented carotid artery. Journal of vascular surgery $2008 ; 47(1)$ : 63-73.

157. Chi YW, White CJ, Woods TC, Goldman CK. Ultrasound velocity criteria for carotid in-stent restenosis. Catheter Cardiovasc Interv. 2007; 69(3):349-54. 
158. Nederkoorn PJ, Brown MM. Optimal cut-off criteria for duplex ultrasound for the diagnosis of restenosis in stented carotid arteries: review and protocol for a diagnostic study. BMC Neurol. 2009;9:36.

159. Zhou W, Felkai DD, Evans M, McCoy SA, Lin PH, Kouglas P, etal. Ultrasound criteria for severe in-stent restenosis following carotid artery stenting. J Vasc Surg. 2008;47(1):74-80.

160. Nicolaides AN. Asymptomatic carotid stenosis and risk of stroke. Identification of a high risk group (ACSRS). A natural history study. Int Angiol. $1995 ; 14(1): 21-3$

161. Wasser K, Karch A, Groschel S, Witzenhausen J, Groschei K, Bahr M, et al. Plaque morphology detected with Duplex ultrasound before carotid angioplasty and stenting (CAS) is not a predictor of carotid artery in-stent restenosis, a case control study. BMC Neurol. 2013;13:163.

162. Willfort-Ehringer A, Ahmadi R, Gruber D, Gschwandtner ME, Haumer A, Heinz $\mathrm{G}$, et al. Effect of carotid artery stenting on the external carotid artery. J Vasc Surg. 2003;38(5):1039-44.

163. de Borst GJ, Vos JA, Reichman B, Hellings WE, de Vries JP, Suttorp MJ, et al. The fate of the external carotid artery after carotid artery stenting. A follow-up study with duplex ultrasonography. Eur J Vasc Endovasc Surg. 2007;33(6):657-63.

164. Vos JA, Vos AW, Linsen MA, Marcus JT, Overtoom IT, van den Berg, et al. Impact of head movements on morphology and flow in the internal carotid artery after carotid angioplasty and stenting versus endarterectomy. J Vasc Surg. 2005;41(3):469-75.

165. Sfyroeras GS, Koutsiaris A, Karathanos C, Giannakopoulos A, Giannoukas AD. Clinical relevance and treatment of carotid stent fractures. J Vasc Surg.2010;51(5):1280-5.

166. Boehm G, Gschwendtner M, Schillinger M. Carotid stent fracture: diagnosis and management. Catheter Cardiovasc Interv. 2009;74(2):273-7.

167. Cloud GC, Markus HS. Diagnosis and management of vertebral artery stenosis. QJM. 2003;96(1):27-54.

168. Buckenham TM, Wright IA. Ultrasound of the extracranial vertebral artery. Br J Radiol. 2004;77(913):15-20.
169. Vicenzini E, Ricciardi MC, Sirimarco G, Di Piero V, Lenzi GL. Extracranial and intracranial sonographic findings in vertebral artery diseases. J Ultrasound Med. 2010;29(12):1811-23.

170. Lemke AJ, Benndorf G, Liebig T, Felix R. Anomalous origin of the right vertebral artery: review of the literature and case report of right vertebral artery origin distal to the left subclavian artery. AJNR Am J Neuroradiol. 1999;20(7):1318-21

171. Hallerstam S, Rosfors S. Blood flow and flow resistance in the vertebral arteries of patients with and without carotid atherosclerosis. Clin Physio Funct Imaging. 2004;24(2):96-102.

172. Thierfelder KM, Baumann AB, Sommer WH, Armbruster M, Opherk C, Janssen $\mathrm{H}$, et al. Vertebral artery hypoplasia: frequency and effect on cerebellar blood flow characteristics. Stroke. 2014;45(5):1363-8.

173. Chuang YM, Chan L, Wu HM, Lee SP, Chu YT. The clinical relevance of vertebral artery hypoplasia. Acta Neurol Taiwan. 2012;21(1):1-7.

174. Wityk RJ, Chang HM, Rosengart A, Han WC, Dewitt LD, Pessin MS, et al. Proximal extracranial vertebral artery disease in the New England Medical Center Posterior Circulation Registry. Arch Neurol.1998;55(4):470-8. .

175. Hua Y, Meng XF, Jia LY. Color Doppler imaging evaluation of proximal vertebral artery stenosis. AJR Am J Roentgenol. 2009;193(5):1434-8.

176. Bosniak MA. Cervical arterial pathways associated with brachiocephalic occlusive disease. Am J Roentgenol Radium Ther Nucl Med.1964;91:1232-44.

177. Nagahata M, Kondo R, Mouri W, Sato A, Ito M, Sato S, et al. Bilateral carotid and vertebral rete mirabile presenting with subarachnoid hemorrhage caused by the rupture of spinal artery aneurysm. Tohoku J Exper Med. 2013;230(4):205-9.

178. Saito K, Kimura K, Nagatsuka K, Nagano K, Minematsu K, Ueno S, et al. Vertebral artery occlusion in duplex color-coded ultrasonography. Stroke. 2004;35(5):1068-72

179. Kliewer MA, Hertzberg BS, Kim DH, Bowie JD, Courneya DL, Carroll BA. Vertebral artery Doppler waveform changes indicating subclavian stea physiology. AJR Am J Roentgenol.2000; 174(3): 815-9. 